\title{
The Thinking Body; \\ A study of the architectural ramifications of Maurice Merleau-Ponty's rendering of the human body's capacities
}

\author{
by \\ Karan August \\ A thesis \\ submitted to the \\ Victoria University of Wellington \\ in fulfilment of the requirements for the degree of \\ Masters of Architecture \\ in Architecture
}

Victoria University of Wellington

27 October 2008 


\title{
Authorization to Submit Thesis
}

\author{
Author: Karan August
}

Thesis Title: "The Thinking Body; A study of the architectural ramifications of Maurice Merleau-Ponty's rendering of the human body's capacities"

Degree Name: Masters of Architecture

Discipline: Architecture

School: School of Architecture, Victoria University of Wellington

Supervisor: Dr. Jan Smitheram

Supervisor: Dr. Peter Wood

Year: 2008

Availability Statement:I hereby consent to the above thesis being consulted, borrowed, copied or reproduced in accordance with the provisions of the Library Regulations from time to time made by the Academic Board.

\section{Signature}

Date 
Deposit Statements: I agree to Victoria University of Wellington having the non-exclusive right to archive digitally and make publicly accessible this thesis. Creator/Contributor(s) I am the sole creator of this work as a whole and can archive digitally and make accessible the work. I own the intellectual property rights inherent in the work as a whole. I have explicitly acknowledged in the work any significant contribution made to the work by others and the sources that I have used. Third Party Content I declare that if this work is archived digitally and made accessible, it will not be in breach of any agreement with a third party that has or is entitled to publish this work. Verification I am supplying the digital file that is a direct equivalent of the work which is described and referred to in this declaration. Preservation and Distribution I agree to Victoria University of Wellington having the right to keep this work in any file format and copy the thesis and transfer it to any file format for the purposes of preservation and distribution.

\section{Signature}

Karan August 
For my Parents

Carolyn and Jürgen Kasprik 


\section{Abstract}

Phenomenology offers a conceptual framework that connects and strengthens the architect's intuitive understanding of the human experience of space with the theorist's more critical approach. Phenomenology is an ideal vehicle for architectural theorists to avoid the friction between first-hand or subjective experience and generalised or abstracted accounts of experience.

In this thesis I extract an account of the human experience of space that is implicit in the Philosopher Maurice Merleau-Ponty's work. ${ }^{i}$ I consider how this understanding has been employed in architectural scholarship and practice. In particular, I argue that the human body renders the richness of space through deliberate engagement with the indeterminate and independent possibilities of the world. In other words, as the body intentionally engages with the world, it synthesises objects that create determinate spatial situations. I account for Merleau-Ponty's depiction of the body's non-rule governed, non-reflective, normative directiveness towards spaces and elements, and label it the thinking body. ${ }^{\mathrm{ii}}$ Furthermore I examine how the philosophical theory of Merleau-Ponty is represented in the explicitly theoretical works of Juhani Pallasmaa. In turn I then consider how the thinking body is physically and conceptually realised in the buildings of Carlo Scarpa.

Finally I find that Juhani Pallasmaa's description of the phenomenological experience of space is incompatible with Merleau-Ponty's. The strategic importance of these different accounts emerges when projecting their implications for designed space. Pallasmaa's account points towards an architecture that prioritises sensory experiences synthesised by the mind. ${ }^{\mathrm{iii}}$ The design focus of Merleau-Ponty's philosophy leads to spatial practices

\footnotetext{
${ }^{\mathrm{i}}$ This thesis benefits from my study of philosophy at the University of California at Berkeley, where my understanding of Merleau-Ponty has been inspired and clarified by Professor Hebert Dreyfus.

${ }^{\text {ii } M e r l e a u-P o n t y, ~ M . ~(1962) . ~ P h e n o m e n o l o g y ~ o f ~ P e r c e p t i o n . ~ R o u t l e d g e, ~ T a y l o r ~ a n d ~ F r a n c i s ~}$ Group, New York, NY. [110, 138]

iii Alberto Pérez-Gómez, S. P., editor (2004). Chora: Intervals in the Philosophy of Architecture. McGill-Queens Press. [158] Pallasmaa, J. (1996). The Eyes of the Skin. Academy
} 
in line with Carlo Scarpa, that are sympathetic to the causal qualities of an intentional bodily engagement with spatial situations. In accord with Merleau-Ponty I argue that human body is our medium for the world and as such creates the spatial situation we engage with from a formless manifold of possibilities.

\section{Karan August}

October 2008 


\section{Acknowledgments}

I owe an immense debt to the magnanimity of individuals who afforded this research to develop. I am profoundly grateful to my adviser Jan Smitheram; for her expertise, generous guidance and encouragement without which I could not have completed this thesis. Similarly, I would like to thank my adviser Peter Wood for his perceptive and thoughtful feedback which refined my findings and who provided a strong role model for my work.

The approach to knowledge of Professors Hans Sluga and Hubert Dreyfus has shaped my relationship to scholarship. I am endlessly in awe of their ability to contemplate the richness of life. The enthusiasm and sharpness of Hubert Dreyfus has inspired me everyday while working on this research.

Many thanks also go to Nigel Guy and Sandra France whose advice is always worth following, the endlessly helpful and enthusiastic Victoria University Architecture Library staff, the skillful people at the Workshop, whose endeavours at the beginning of my research stayed with me, even as my time priorities shifted from making to writing, to Meredith Percival and Angela Yanko who provided a refuge for my swimming and kindly followed the endless breakthroughs in my analysis, Daniele Abreu e Lima, Warwick McLeod and the community of tutors at the Victoria University Architecture School, who took interest in my research and raised interesting questions.

I am also incredibly fortunate to have the friendships of Nikki Burrows, Yael Barbibay and Réné Lerch, who shared with me the pleasure of uncovering ideas. I am grateful for our regular meetings where concepts were fine tuned and moments of clarity hovered in the air. And to my parents Carolyn and Jürgen Kasprik, for never giving up and teaching me the possibility of a lifelong child-like wonder. To my brother Michael for being authentic.

Finally, special acknowledgement needs to be made to Karl Baker. Who not only read every draft and debated every idea, but with who my partnership is a continuous joy and treasure. 


\section{Contents}

0.1 Preface ................... vii

1 Introduction 1

1.1 The problem $\ldots \ldots \ldots \ldots \ldots \ldots \ldots$

1.1.1 Accounting for the lack . . . . . . . . . 2

1.1.2 Merleau-Ponty to the rescue . . . . . . . . 6

1.1.3 Investigating architectural theorists who have walked down this path . . . . . . . . . . . 11

1.2 Aim . . . . . . . . . . . . . . . . . 12

1.3 Scope ....................... 12

1.4 A profile of the thesis . . . . . . . . . . . . . . 13

2 The Form 15

2.1 Phenomena $\ldots \ldots \ldots \ldots \ldots \ldots \ldots$

2.2 Embodiment . . . . . . . . . . . . . . 18

2.2 .1 Innate structures $\ldots \ldots \ldots \ldots$

2.2.2 Basic general skills . . . . . . . . . . . . . . 21

2.2 .3 Cultural skills . . . . . . . . . . . . . . . 22

2.3 Skill Acquisition . . . . . . . . . . . . . . . 25 
2.4 Conclusion . . . . . . . . . . . . . . . . . . . . . . . . . 29

3 The Function 31

3.1 Intentionality $\ldots \ldots \ldots \ldots \ldots \ldots \ldots \ldots \ldots$

3.1.1 Origin and development of the term . . . . . . . . 34

3.1.2 Distinguishing the two modes . . . . . . . . . 35

3.2 The Thinking Body . . . . . . . . . . . . . . 38

3.3 Conclusion . . . . . . . . . . . . . . . . . . . . . . 49

4 Architectural Theory $\quad 51$

4.1 Implicit View $\ldots \ldots \ldots \ldots \ldots \ldots \ldots \ldots$

4.1.1 Muddled; the two modes of intentionality . . . . . 54

4.1.2 The matter of the sub-conscious $\ldots \ldots \ldots$

4.2 A collection . . . . . . . . . . . . . . 61

4.3 Conclusion . . . . . . . . . . . . . . 63

5 Built Architecture $\quad 64$

5.1 Why not? . . . . . . . . . . . . . . . 65

5.2 Architectural volumes . . . . . . . . . . . . . . 68

5.2 .1 Corridor . . . . . . . . . . . . . . 72

5.2.2 Interior room: windows and light $\ldots \ldots \ldots$. . 77

5.2 .3 Entrance . . . . . . . . . . . . . . 83

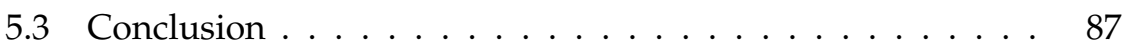

6 Conclusion $\quad 89$ 


\section{List of Figures}

2.1 Working hand drawing . . . . . . . . . . . . 17

2.2 Paolo Mascagni, Anatomiae universae icones (Images of Universal Anatomy), (1755-1815) . . . . . . . . . . . . . . . 19

2.3 Paul Cézanne, Man Smoking a Pipe, 1895-1900 . . . . . . . . . 22

From $[$ Depaulis, 2003, 64] . . . . . . . . . . . . . . . . . . 22

2.4 Jacques Tati's film Play Time . . . . . . . . . . . . . . . . . . 24

From [Lagrange, 1967, 2020-2040 sec] . . . . . . . . . . . . . . 24

2.5 then at one point $i$ did not need to translate the notes; they went directly to my hands, Francesca Woodman, Providence, Rhode Island, 1976 . . . . . . . . . . . . . . . . . . . 29

From $[$ Leach, 2006, 187] . . . . . . . . . . . . . . . . . . . . . . . . . . . 29

3.1 Working hand drawing $\ldots \ldots \ldots \ldots \ldots \ldots$

3.2 J. Boyd Hildebrant, Model of an Helium Atom . . . . . . . . . 43

From $[\mathrm{tfe}, 2008,-] \ldots \ldots \ldots \ldots$

3.3 Working hand drawing . . . . . . . . . . . . . . 47

Working hand drawings $\ldots \ldots \ldots \ldots$. . . . . . . . . 47

4.1 Steven Spielberg, Minority Report, 2002 . . . . . . . . . . . . 53

From [Dick, 2002, 2720sec.] . . . . . . . . . . . . . . . . . . . . 53 
4.2 Gustav Klimt, Pine Forest (Forest of Firs I) (1902) . . . . . . . 56

From $[$ Payne, 2000, 140-141] . . . . . . . . . . . . . . . . 56

4.3 Vittore Grubicy De Dragon, Winter (Inverno), 1898 . . . . . 58

From $[$ Greene, 2007,82$] \ldots \ldots \ldots$

4.4 Gustav Klimt, Beech Forest (1903) . . . . . . . . . . . . . . 61

From [Payne, 2000, 148-149] . . . . . . . . . . . . . . . . . . . 61

5.1 Steven Holl, Drawing Shadows, Oxnard, Ca 1986 . . . . . . 67

From [Pallasmaa et al., 2006, 67] . . . . . . . . . . . . . . . 67

5.2 Tadao Ando, Galleria Akka, Osaka Japan 1988 . . . . . . . . 68

From $[w i k, a,-] \ldots \ldots \ldots \ldots$

5.3 Friedensreich Hundertwasser, Maishima Sludge Centre, Osaka 1996-2003 . . . . . . . . . . . . . . . . . . 69

From [Fürst and Taschen, 2007, 277] $\ldots \ldots \ldots$

5.4 Friedensreich Hundertwasser, The houses are hanging underneath the meadows, 1971 . . . . . . . . . . . . . . 69

From $[$ Hundertwasser, 1973, 49] . . . . . . . . . . . . . . . . . 69

5.5 Carlo Scarpa, Castelvecchio Museum, Verona, $1964 \ldots$. . . . 72

From $[$ Crippa, 1986, 300] . . . . . . . . . . . . . . . . 72

5.6 Carlo Scarpa, Hand drawing, Castelvecchio Museum, Verona, $1964 \ldots \ldots \ldots \ldots \ldots \ldots \ldots$

From $[C$ Crippa, 1986, 300] . . . . . . . . . . . . . . . . 73

5.7 Marcel Duchamp, Nude descending a Straircase II, 1911-12 . . 74

From $[$ Bowness, 1972, 122] . . . . . . . . . . . . . . . . . 74

5.8 Carlo Scarpa, Bridge handrail details, Castelvecchio Museum, Verona, $1964 \ldots \ldots$. . . . . . . . . . . . . . 75 
From $[w i k, b,-] \ldots \ldots \ldots \ldots$

5.9 Carlo Scarpa, "The High Gallery", Museo Canovian, Possagno, $1957 \ldots \ldots \ldots \ldots \ldots \ldots$. . . . . . . . . . . . . .

From [Judith Carmel-Arthur, 2002, 31] . . . . . . . . . . . . . . 77

5.10 Carlo Scarpa, "The High Gallery”, Museo Canovian, Possagno, $1957 \ldots \ldots \ldots \ldots \ldots$. . . . . . . . . . . . . . .

From [Judith Carmel-Arthur, 2002, 34] . . . . . . . . . . . . . . 78

5.11 Carlo Scarpa, "The High Gallery”, Museo Canovian, Possagno, $1957 \ldots \ldots \ldots \ldots \ldots$. . . . . . . . . . . . . . .

From $[$ Crippa, 1986, 148] $\ldots \ldots \ldots \ldots \ldots$

5.12 Working hand drawing. . . . . . . . . . . . . . . 81

5.13 Carlo Scarpa, View of entrance bridge seen from above, Fondazione Querini Stampalia, Venice, 1961-1963 . . . . . . . . . . 83

From $[$ Albertini, 1988, 43] $\ldots \ldots \ldots \ldots$

5.14 Carlo Scarpa, View of entrance bridge seen from calle, Fondazione Querini Stampalia, Venice, 1961-1963 . . . . . . . . . . 84

From $[$ Schultz, 2007, 97] $\ldots \ldots \ldots \ldots \ldots \ldots$

5.15 Carlo Scarpa, Bridge handrail details, Fondazione Querini Stampalia, Venice, 1961-1963 . . . . . . . . . . . . . . . 85

From $[$ Murphy, 1993, 21] . . . . . . . . . . . . . . . . . . . . . . 85

5.16 Carlo Scarpa, Bridge handrail details, Fondazione Querini Stampalia, Venice, 1961-1963 . . . . . . . . . . . . . . . . 86

From $[$ Murphy, 1993, 22] . . . . . . . . . . . . . . . . . . . . 86 


\subsection{Preface}

Down the rabbit hole; where a reading of Gaston Bachelard took me.

It was a reading of Bachelard in the cold of late autumn that changed my life. I had just enrolled in undertaking a masters thesis at Victoria University of Wellington's rather contemporary Architecture School. Pleased with my new vocation, and confident in my theory, I imagined my world within a few months accompanied by chapters of writing and endless praise. In the front room of my nineteenth century workers' cottage (a bay of four windows, erected in U-shaped and reaching vertically from my knees past my up-stretched arms) welcomed my reading chair. I tucked myself up in layers of woolen blankets, scarves and cap. The borer-eaten floor boards, still strong, permitted icy breezes through the joints which had shifted with the soil over the century. I began to read Bachelard's The Poetics of Space, annotating feverishly as I progressed. ${ }^{\text {iv }}$ I shifted in my chair and poured more tea. But it was not the concepts of Bachelard's theory that affected me, so much as the events surrounding the reading.

To go back; I am not naturally endowed with the knack of reading. Teachers tested and questioned me but what seems now to fall under the wide umbrella of dyslexia, was never diagnosed as such. When 'reading' I draw upon my associations of shapes with sounds or meanings-usually only the essential meanings of words. Wee words like 'it', 'to' or 'is' are indistinguishable, but the shapes of the sentences stimulates the contextualising whole. The meaning comes in waves of intensities, at first like a faint yellow glow from a sunset, deepening to rich oranges and sometimes burnt reds. At first glance the individual words feel indeterminate, but as I look the shapes become 'meanings' and the context given by the most familiar of the words, sets the rest in place as I move along the page.

However this is a story about my reading of Bachelard in the cold bay of windows, looking upon the colourful trees and houses of an old suburban valley. I read The Poetics of Space and my thoughts began to drift. At Berkeley I studied phenomenology; Heidegger and Merleau-Ponty. I charmed my professors and sat in on graduate seminars, only daring a few times to speak in heated debates of details, where fists were thumped upon the solid redwood table. Hence, Bachelard's casual claims of what a phenomenologist does, began to lose me. I was disenchanted, though I read on:

\footnotetext{
iv [Bachelard, 1958, -]
} 
We should therefore have to say how we inhabit our vital space, in accord with all the dialectics of life, how we take root, day after day, in a 'corner of the world.'

My 'corner of the world' seemed cold and fragile, built in a rush to only last a few years while the initial occupiers tried their luck in this last outpost of one 'new world'.

Another habit of mine is to indulge the wandering of my thoughts while reading. I consider it ad hoc meditation. Ad hoc in temporality, for it commences unplanned, however the direction of the meditation is led by the writer's ideas on the page. Some of my best ideas of love came to me while staring at a book of rhetoric. For while the author's words bounce the playground is controlled by me.

I accepted the The Poetics of Space as a work of art in this sense. One man's obsession with space, one man's experience in memories. Bachelard opened a world and beckons people to share his experiences. He synthesises his experiences in a collection of words that whirl around a fundamental idea; ones of the paradoxes of childhood; love for one's own inquisitive and contented nature.

I determined that if I was to write a thesis concerning the experience of architectural space then it followed that I needed a fitting space within which to write. I saw a structure that was sympathetic to my existing house just more solid, warm and scaled to my reach; a ladder that presented challenges as I responded to its beckoning to ascend, doors that opened upon a gentle pull with handles that invited my palms. It was something simple, but 'honest' in its materiality - the beams seen are the beams that carry the gable, the floor walked on, is rock siting on the rock in the ground, the heat felt comes from the fire smelled and seen, and the colours move about the space from the sun's exchange with the glass.

It is all very well to have a fantasy of a perfect space and then get on and write. But I drew and I talked, and a month later I was turning in my forms to the city's planning department, and making deals with builders. The deals with builders were what wrecked me. The plans looked simple, but the details were particular: the space was made by the details. Given that I had never built before slight differences in understanding between myself, the builder and the people on site escaped my attention. I stumbled on.

It was a morning in spring when I stood in my old kitchen, shades

v [Bachelard, 1958, 4] 
drawn, watching a man in the garden with a shovel. I realised the strangeness of my situation. My partner, whom I had lived within two previous countries, had tired of my fixation with creating 'space' (among, I'm sure, other things). Delays and bureaucracy, set up in hopes of catching cheap developers, tangled my unsavvy steps. The unfamiliar tradesman across the kitchen bench asked if I was Christian. In an attempt to be polite, I replied that I had grown up such. He asked me, "can I pray for you?" Unnerved, I answered "yes". Still, not expecting his hand to jut across the bench, on to my forehead and loud cries of "The Lord" to plea for my soul. I remained still.

As I write, I sit at my desk, in the space I 'created'. The sun is sinking into the hillside, the sky is pastels (remarkably so) and the pinks fill the wooden ceiling with warmth. The fire is lit, the stone is warm on my feet, herbs dry above my desk. The trees outside my window are growing back. It is now that I compose my thoughts. 


\section{Chapter 1}

\section{Introduction}

The fact that the Modernist idiom has not been able to penetrate the surface of popular taste and values is due to its one-sided visual emphasis; Modernist design has housed the intellect and the eye, but it has left the body and the other senses, as well as our memories and dreams, homeless. ${ }^{1}$

It is commonly assumed that we are best served by our tactic environment when we scarcely notice its presence. If the skin is indeed knowing, standard Western interior design does not often give it much to think about. ${ }^{2}$

'Natural geometry' or 'natural judgement' are myths in the Platonic sense, intended to represent the envelopment or 'implication' of a significance in signs, neither signs nor significance being yet posited and explicitly contained in thought, and this is what we must elucidate by returning to perceptual experience. ${ }^{3}$

\subsection{The problem}

This section uses a tripartite structure in which I offer a critique of contemporary architecture. I initially survey architectural theory to support the

\footnotetext{
${ }^{1}$ [Pallasmaa, 1996, 10]

2 [Classen, 2005, 29]

${ }^{3}$ [Merleau-Ponty, 1962, 257]
} 
claim that contemporary architecture fails to adequately engage with the human body. I regard this lack as due to a failing to understand the intellectual faculties of the body. I argue that Merleau-Ponty's research about the thinking body offers architecture a constructive method for considering the body. Furthermore, I outline my critique of how Merleau-Ponty's thought has been adopted by an architectural theorist. Specifically I suggest that the predominate solutions offered by the discipline lie within a superficial understanding of the phenomena of the human experience of space, leading to an architectural theory promoting the manifold of the senses. Overall, this chapter establishes a 'want' in architecture and sets out how I respond.

\subsubsection{Accounting for the lack}

Contemporary architecture often falls short of creating environments that offer a richness of experiences that cater to the capacities of the human body. Various architectural theorists critique architecture's disinterest in the body. ${ }^{4}$ Those surveyed in this section each propose a two-part argument. The first proposition is that geometrical or visual elements dominate architectural spaces and the second is that architecture ought to consider experiential space. This study supports the claim that architecture lacks adequate engagement with the human body.

Christian Norberg-Schulz opened the phenomenologically inspired architectual critiques with his 1971 work, Existence, Space and Architecture. ${ }^{5}$ In it he maintains that, "studies of geometry or visual perception only grasp relatively superficial aspects of the problem". ${ }^{6}$ He continues to state that architectural spaces ought to be about a more experiential space. ${ }^{7}$ More recently Juhani Pallasmaa, in The Eyes of the Skin, suggests that an architectural climate of visual dominance has failed in creating spaces that adequately engage the human body. ${ }^{8}$ In his words, the "ocular bias and the visual hegemony in the art of architecture have never been more apparent

\footnotetext{
${ }^{4}$ [Norberg-Schulz, 1971, 16], [Pallasmaa, 1996, 19], [Pérez-Gómez and Parcell, 2004, 31], [Gregotti, 1996, 99], [Grosz, 2001, 14], [Imrie, 2003, 58]

${ }^{5}$ [Norberg-Schulz, 1971, -]

${ }^{6}$ [Norberg-Schulz, 1971, 16]

7 [Norberg-Schulz, 1971, 16]

${ }^{8}$ Juhani Pallasmaa's career ranges from practitioner, lecturer, writer to theorist. $\mathrm{He}$ trained in the technical field of architecture in the mid-1950s and began publishing essays in the late 1960s [Pallasmaa, 2005a, 11]. In the 1970s, a trip to Ethiopia "disillusioned" Pallasmaa's "faith and confidence in rationality" [Pallasmaa, 2005a, 17]. He has since examined other fields to provide support for a new architectural theory [Pallasmaa, 2005a, 18]. His 1996 book, The Eyes of the Skin established Pallasmaa as a leading Architectural theorist of Merleau-Ponty.
} 
than in the past thirty years" ${ }^{\prime \prime}$ He claims that this bias has created spaces that utilise the rhetorical tools of advertising to persuade the user immediately at the cost of flexibility and richness of an embodied experience. ${ }^{10} \mathrm{~A}$ central thread of Pallasmaa's later work is that the architecture of industrial man is flawed due to a 'retinal infatuation' and a disregard for the haptic encounter. ${ }^{11}$ In a 2005 article he writes:

\begin{abstract}
Our current obsession with the seductive visual image in all areas of contemporary life, promotes a retinal architecture, which is deliberately conceived to be circulated and appreciated as instant and striking photographed images, rather than being experienced slowly in an embodied manner through a physical and full spatial encounter. ${ }^{12}$
\end{abstract}

Pallasmaa states that retinal infatuation permeates every aspect of society which leads to its manifestation in architecture. ${ }^{13}$ He postulates a causal link between "contemporary life", "architecture", and how people "encounter" space. ${ }^{14}$ That is to say that the "seductive[ness]" of the "visual image" causes a visually-flooded architecture, which in turn causes the human experience of designed spaces to lack the "full[ness]" afforded by the human body. ${ }^{15}$ Pallasmaa concludes that this retinally-centric architecture is inferior to an architecture that affords embodied experience. ${ }^{16}$ In the same regard he argues that this retinal preference is a shortcoming for the architectural field because it "distance[s] itself from other-sense realms". ${ }^{17} \mathrm{Pal}-$ lasmaa critiques the trends of retinal-centralism and lack of spaces catering to the sensual body. He proactively claims that it is better to design space to engage the body. ${ }^{18}$

Architectural theorist Alberto Pérez-Gómez categorises the current state of architecture as a product of the "rationalist program", and calls for its

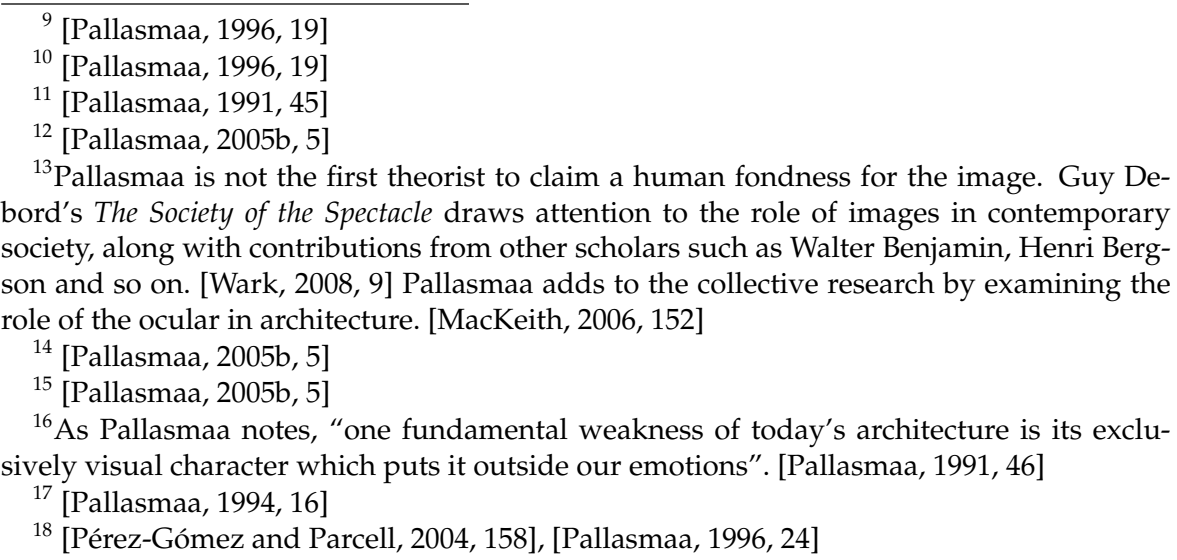


metamorphosis. ${ }^{19}$ He suggests the need to transcend these circumstances where "plans, elevations and sections are ultimately expected to predict with accuracy an intended meaning as it may appear for an embodied subject in built work" ${ }^{20}$ To do this, architects must project themselves into the design similar in the same way modern artists and existential phenomenologists imagine the world. ${ }^{21}$ In other words, he advocates carefully considered "different use of projection, related to modern art and existential phenomenology" to bring about a "truly relevant poetic practice [of architecture] in a Post-Modern world". ${ }^{22}$ In this manner Pérez-Gómez is an advocate for a more phenomenological and poetic understanding when creating spaces.

In a variation to Pérez-Gómez's position, but reverberating Pallasmaa's account, Vittorio Gregotti argues that the memory of philosophers' contributions lingers in architects' minds while the philosophical details are forgotten. Gregotti states:

The relationship between image and perception that was central to those [philosophical] texts now forms a distant, almost always forgotten background, while everyday language, and especially the everyday language of architects, encompasses increasingly insistent talk that makes image, along with its constriction and communication, into a primary objective in design, or even a measure of the quality of a project. ${ }^{23}$

Gregotti attributes this 'forgetfulness' to architecture's "preoccupation with the market image" and to economic forces as contributing to problems of the current state of "single-dimensional flatten[ed]" built spaces. ${ }^{24} \mathrm{He}$ feels that commercial pressures drive architects to design spaces which reach their height of appeal in the still image. Or in his words, "all this leads to the apparent triumph of the figurative gesturality of the 'architect-creator' and his compulsion for repetition, driven above all by the need to create a

\footnotetext{
${ }^{19} \mathrm{He}$ states, "to transcend aestheticism, reductive functionalism, and either conventional or experimental formalism, architecture must consider seriously the potential of narrative as the structure of human life, a poetic vision realized in space-time, in the inbetween or metaxy implied by Gelassenheit". [Pérez-Gómez and Parcell, 2004, 31] Consider also the claim, "this intuition [of rationalist architecture] must now be radicalized if we are to transcend the technological enframing". [Pérez-Gómez and Parcell, 2004, 30]

${ }^{20}$ [Rattenbury, 2002, 3] Found in the essay; The revelation of order - perspective and architectural representation.

${ }^{21}$ [Rattenbury, 2002, 5]

22 [Rattenbury, 2002, 5]

${ }^{23}$ [Gregotti, 1996, 95]

24 [Gregotti, 1996, 99, 98]
} 
marketable image" ${ }^{25}$ He positively proclaims that architects ought to "construct new pieces of reality, thus modifying and enriching the world of our experiences". ${ }^{26}$ Gregotti's argument is fourfold. Primarily the importance of an experiential perception of space lies in the background of architecture. However, due to commercial forces, architecture is dominated by the image. Furthermore the power of the architectural image leads to vapid and mundane spaces. Thus architecture must reconsider how to create spaces that enrich human experience of the world.

Analogous to Gregotti's position, Elizabeth Grosz sees the body as superficially situated in contemporary architecture due to economic implications. She claims that the body is accepted as part of architecture - "it is not that architecture excludes embodiment" - but that architecture fails to meaningfully engage with the details of the body such as sexuality. ${ }^{27}$ She proposes that architecture needs a shift in "values by which to make it profitable for architecture to think its own in investments in corporeality". ${ }^{28}$ Like Gregotti, Grosz targets the economic drives of the building industry as requiring change in order for the built environment to account more equally for the experience of the body.

Alternatively, Rob Imrie finds an exclusion of embodiment through his study architect's conception of the human body. He finds that architects are predominately guided by Cartesian principles resulting in designs either "absent" or with "reductive conceptions" of the human body. ${ }^{29}$ He claims that due to the structure of the discipline, the experience of the human body is neglected.

This same argument for the limitations of architecture is seen in the discipline of philosophy, as Henri Lefebvre argues that the architect's space is "a visual space, a space reduced to blueprints, to mere images - to that "world of the image' which is the enemy of the imagination". ${ }^{30}$ Lefebvre goes on to claim that in practice the architect imagines that they have "complete freedom". However, Lefebvre maintains, it is their duty to create spaces that encourage poetic bodily thought. ${ }^{31}$ He writes:

\footnotetext{
${ }^{25}$ [Gregotti, 1996, 98]

${ }^{26}$ [Gregotti, 1996, 100]

${ }^{27}$ [Grosz, 2001, 13]

28 [Grosz, 2001, 14] Full sentence, "the point is to affirm that it's[the body] there, and to find the right kind of terms and values by which to make it profitable for architecture to think its own in investments in corporeality."

${ }^{29}$ [Imrie, 2003, 58 and 63] respectively.

${ }^{30}$ [Lefebvre, 1991, 361]

31 [Lefebvre, 1991, 360]
} 
In what does sensory space, within social space, consist? It consists in an 'unconsciously' dramatized interplay of relay points and obstacles, reflections, references, mirrors and echoes - an interplay implied, but not explicitly designated, by this discourse... a welcoming space is called for - the space of nature, filled with non-fragmented 'beings', with plants and animals. (It is architecture's job to reproduce such a space where it is lacking.) $)^{32}$

Lefebvre prescribes the intact quality of "being" to the spaces of architecture. ${ }^{33}$ I turn to another philosopher to analyse this concept.

\title{
1.1.2 Merleau-Ponty to the rescue
}

Christian Norberg-Schulz, Juhani Pallasmaa, Rob Imrie, Alberto Pérez-Gómez, Vittorio Gregotti, Elizabeth Grosz, and Henri Lefebvre each claim that architecture lacks valuable corporeal qualities. A phenomenological study of the human experience establishes corporeal qualities for architectural spaces. The research of Maurice Merleau-Ponty provides this study. David Krell expresses Merleau-Ponty's contribution as:

\begin{abstract}
Merleau-Ponty's body is not the Cartesian flesh cadaver, with its pliable springs and levers infinitely stilled... Merleau-Ponty's theme is the kinaesthetic body that moves through a world that is its own, a world that is in some uncanny way itself flesh. ${ }^{34}$
\end{abstract}

Linking Merleau-Ponty's account of the human body's experience of space with the previously discussed theorists' critiques of architecture creates grounds for designing rich corporeal architecture. In other words, some architectural theorists claim contemporary spaces are lacking something; that our built spaces are flat, reductive, instantly digested and expelled. ${ }^{35}$ They further call for architects to look at the experiential body and the experience of engaging with space. Merleau-Ponty's understanding of the body is unique in that it proposes a non-reflective bodily intelligence. ${ }^{36} \mathrm{It}$ is this understanding of the body that I aim to explain in the second and third chapters of this thesis.

\footnotetext{
${ }^{32}$ [Lefebvre, 1991, 210]

${ }^{33}$ [Lefebvre, 1991, 210]

${ }^{34}$ [Krell, 1997, 140]

35 [Gregotti, 1996, 98], [Imrie, 2003, 48], [Pallasmaa, 1996, 19]

${ }^{36}$ [Smith and Thomasson, 2005, 273]
} 


\section{phenomenology}

Phenomenology is the study of finite experiences of the world. ${ }^{37}$ It is the study of human experiences within space. ${ }^{38}$ A phenomenologist understands events as available for study only through perception. ${ }^{39}$ The subject of a phenomenologist's investigation is a phenomenon but, unlike the physicist, the phenomenologist accounts for the perception of the observation rather than just the observation. The origins of phenomenology lie in the work of Edmund Husserl. ${ }^{40}$ Merleau-Ponty describes phenomenology as:

The study of essences... It tries to give a direct description of our experience as it is, without taking account of its psychological origin and the causal explanations which the scientist, the historian or the sociologist may be able to provide. ${ }^{41}$

This suggests that a phenomenologist does not postulate back stories for why the experience happens as it does. Rather, the phenomenologist describes and structures the manifold of human experiences. ${ }^{42}$ A phenomenologist has no justification for positing non-perceivable explanations for experience. ${ }^{43}$ In the Phenomenology of Perception, Merleau-Ponty derives a system of existence accounting for human experience. He claims that phenomenology is the "return" to the "world of actual experience" which is prior to the world created by analytical reflection. ${ }^{44}$ In this paper I abstract an account of the human experience of space that is implicit in MerleauPonty's work.

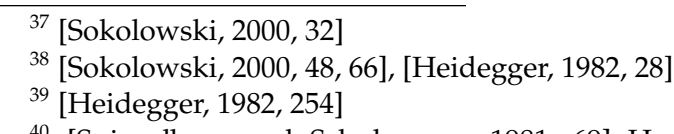

40 [Spiegelberg and Schuhmann, 1981, 69] Husserl developed a phenomenological method to account of the structure of the mental representations. [Dreyfus, 1989, 2] Husserl defines this method as follows, "phenomenology: this term designates a science, a complex of scientific disciplines; but it also designates at the same time and above all a method and an attitude of thought: the specifically philosophical attuned of thought, the specifically philosophical method". [Husserl, 1999, 19] "Husserl's mature conception of the phenomenological method includes the idea of descriptive clarification of the content (meaning) of our acts through the procedure of free variation in imagination and through the analysis of the "origins" of content". [Smith and Smith, 1995, 457]

${ }^{41}$ [Merleau-Ponty, 1962, vii]

${ }^{42}$ [Merleau-Ponty, 1962, 257]

${ }^{43}$ [Merleau-Ponty, 1962, 243]

${ }^{44}$ [Merleau-Ponty, 1962, 57] Merleau-Ponty's argument here is not to indicate that intuition is more reliable than critical thought. Rather, it is the critical study of human engagements with the world that are apart of everyday life. This notion is analised in greater detail is section 2.1. 
I examine the work of Merleau-Ponty rather than Martin Heidegger because, plainly said, Heidegger handles the "big picture" of existence and Merleau-Ponty fleshes out the details of daily living. ${ }^{45}$ Heidegger is the "source" for Merleau-Ponty's phenomenology (as well as a key influence for many continental philosophers, e.g. Michel Foucault and Pierre Bourdieu. $)^{46}$ However, Heidegger's vocation is a study of the grandness of Being and not the details of the everyday. ${ }^{47}$ At present, I am captivated by the commonplace qualities of architecture and for this reason my concentration is on Merleau-Ponty's theory of the human experience in space.

\section{a few words about Merleau-Ponty}

Merleau-Ponty is considered, "one of the most original and important philosophers of the past century". ${ }^{48}$ In 1945 he distinguished himself with the work Phenomenology of Perception. ${ }^{49}$ Primarily he is a phenomenologist, although his thinking does not afford pigeon-holing. ${ }^{50}$ As a phenomenologist he follows in the footprints of Edmund Husserl and Martin Heidegger. ${ }^{51} \mathrm{He}$ is often mistaken as drawing more influence from Husserl (due to a note in the preface of Phenomenology of Perception). However this was the strategic manoeuvre of a Frenchman, in direct response to Heidegger's unpopular associations with the Nazi Party. ${ }^{52}$ Philosophically, Merleau-Ponty "could never accept Husserl's doctrines, however enthusiastically he embraced the spirit of the enterprise as a whole". ${ }^{53}$ Furthermore various Merleau-Ponty scholars, for instance; Charles Taylor, Richard Shusterman, Judith Butler, Hebert Dreyfus and Sean Kelly each argue that

45 [Dreyfus, 2005b, 2]

${ }^{46}$ [Dreyfus, 2005b, 1]

${ }^{47}$ [Dreyfus, 2005b, 1]

${ }^{48}$ [Carman and Hansen, 2005, 1]

49 [Merleau-Ponty, 1962, -] The Phenomenology of Perception is notably the richest of Merleau-Ponty's works, and according to Dreyfus it is the only book necessary in my bibliography. [Dreyfus, 2008, -]

${ }^{50}$ [Carman and Hansen, 2005, 1]

${ }^{51}$ Husserl who took phenomenology from Hegel and developed a "more precise" methodology and Heidegger who was a crucial "figure" of the discipline [Dreyfus and Wrathall, 2006, 2]. Dreyfus explains Husserl's understanding of phenomenology as follows, "for Husserl, phenomenology is a study of the structures of consciousness itself, so that one can proceed to reflect on and systematically describe the contents of the conscious mind in terms of their essential structures. This was a method, Husserl believed, which could ground our knowledge of the world in our lived experience, without in the process reducing the content of that knowledge to the contingent and subjective features of that experience". [Dreyfus and Wrathall, 2006, 2]

52 [Carman and Hansen, 2005, 5]

53 [Carman and Hansen, 2005, 8] 
Merleau-Ponty's account of the human body's capacity for non-reflective, yet intentional, engagement with its surroundings is "his most profound and original contribution to philosophy" ${ }^{54}$ This idea, is the central philosophical notion which I take from Merleau-Ponty and apply to architecture.

It is important to note that Merleau-Ponty is well known for his bewildering writing manner and to avoid emulating this style I use two tactics. ${ }^{55}$ Firstly, in chapter two I employ Hebert Dreyfus' technique for framing Merleau-Ponty's structure of the bodily faculty for thought, i.e., what I call the form. ${ }^{56}$ Secondly, I use my own term the-thinking body-for the principal concept I take from his theory. One of the first challenges with reading Merleau-Ponty is determining whose argument is whose. This is due to a style that involves diving into a leading view and elegantly arguing for it with his own writing voice, then abruptly challenging that view with the traditionally opposing philosophical camp and persisting to follow the second view's reasoning through, only to then dispute both views with his own ideas. ${ }^{57}$ At the same time Merleau-Ponty avoids itemising, defining and consistently employing terminology. ${ }^{58}$ Rather, he "cultivates a deliberately non-adversarial dialectical strategy that is bound to seem alien, even disconcerting, to anyone educated in the explicit theoretical assertions". ${ }^{59}$ Because Merleau-Ponty rarely uses a single term to indicate his philosophical ideas, I choose to apply the term thinking body to Merleau-Ponty's concept of the faculty that affords intentional engagement with space. Merleau-Ponty describes the phenomenon of the human

\footnotetext{
${ }^{54}$ [Carman and Hansen, 2005, 10] and [Dreyfus, 2005a, 2] and Kelly- "there is a peculiarly bodily type of understanding of objects is the central point of Merleau-Ponty's category of motor intentionality: motor-intentional activity is a way of being directed toward objects that essentially involves a motor or behavioural component". [Robert C. Solomon, 2003, 132]

${ }^{55}$ [Carman and Hansen, 2005, 4]

${ }^{56}$ Hebert Dreyfus is a leading scholar is the field of phenomenology. "Hubert L. Dreyfus is Professor of Philosophy in the Graduate School at the University of California, Berkeley". [Carman and Hansen, 2005, 12] And, "Hubert Dreyfus demonstrate[s]... one of the most important insights at work in Merleau-Ponty's own phenomenology" [Carman and Hansen, 2005, 12] The following is written as an introduction of Dreyfus for the book Heidegger, Authenticity, and Modernity. "For more than a quarter of a century, Hubert L. Dreyfus has been the leading voice in American philosophy for the continuing relevance of phenomenology, particularly as developed by Edmund Husserl, Martin Heidegger, and Maurice Merleau-Ponty. Dreyfus has influenced a generation of students and a wide range of colleagues" [Wrathall and Malpas, 2000a, back-cover] There are numerous quotation praising Dreyfus' work, but this one more from Sean Kelly shall have to be enough, "Hubert Dreyfus... [is] the foremost commentator on the work of the founders of modern phenomenology - Martin Heidegger and Maurice Merleau-Ponty - not to mention a gifted phenomenologist himself". [Wrathall and Malpas, 2000b, 161]

${ }^{57}$ [Carman and Hansen, 2005, 4] and [Spiegelberg and Schuhmann, 1981, 572]

${ }^{58}$ [Dreyfus, 2005a, 2]

${ }^{59}$ [Carman and Hansen, 2005, 4]
} 
body through chapters of poetic writing and never isolates the concept of the thinking body with particular terminology. However words approaching a denotation are: "body schema", "field of presence", a "primal acquisition", or the phrase "a grouping of lived-through meanings which moves towards its equilibrium" and "my body... as system of possible actions, a virtual body with its phenomenal 'place' defined by its task and situation". 60

The thinking body has the capacity for a non-rule governed, non-reflective, normative directiveness towards the spaces and elements that one distinct from the individual's body. ${ }^{61}$ For consistency, I call this directiveness bodily intentionality. ${ }^{62}$ Merleau-Ponty introduces his concept of motor intentionality as: "something which is an anticipation of, or arrival at, the objective and is ensured by the body itself as a motor power". ${ }^{63}$ A minor example of bodily intentionality is the experience of walking through a gallery, being drawn to the left, dancing briefly in small steps back and forth, to find oneself admiring an artist's painting. ${ }^{64}$ The thinking body is that which directed the individual to a particular position that offers an optimal view of the painting. Yet this example is merely an introduction to the concept of the thinking body that breaks into two ideas -its form and functionwhich I analysis in chapters two and three. The conceptualisation of the thinking body is complex, even though the concept is intended to describe our everyday experience. As Merleau-Ponty wrote, "it is not easy to reveal pure motor intentionality: it is concealed behind the objective world which it helps to build up" ${ }^{\prime 65}$

\footnotetext{
${ }^{60}$ [Merleau-Ponty, 1962, 206, 265, 216, 153, 250] Respectively.

${ }^{61}$ [Merleau-Ponty, 1962, 110, 138]

${ }^{62}$ I use the term bodily intentionality consistently for discussing Merleau-Ponty's term 'motor intentionality' [Merleau-Ponty, 1962, 110] or 'motor intention' [Merleau-Ponty, 1962, 317] or Dreyfus' terms 'motor intentionality' [Carman and Hansen, 2005, 144] and 'bodily intentionality' or Sean Kelly's 'motor intentionality' [Wrathall and Malpas, 2000a, 161] David W. Smith's term "non-positional consciousness" [Smith and Thomasson, 2005, 273] or J. N. Mohanty's 'bodily intentionality' [Dreyfus and Wrathall, 2006, 75] or D Seamon's "pre-cognitive intelligence of the body" [Seamon, 2000, 157].

${ }^{63}$ [Merleau-Ponty, 1962, 110] Sean Kelly makes the further distinction between 'movement as a third person process' as "reflex" movement and a bodily thinking movement [Robert C. Solomon, 2003, 132] "thought as a representation of movement".

${ }^{64}$ Along with the argument in chapter two, consider the following quotation from a published Interview with Hebert Dreyfus, "the basic idea in Merleau-Ponty is that we're always moving to get an optimal grip... and he talks about how in a museum your body is led by a picture to move to the optimal distance where you see the maximum richness, as he puts it, of the detail and the maximum clarity of the form. And when you perceive ordinary objects there's a further thing, you move around them, and so forth, and you are led by the object calling on your body - it's just outside of what your mind does or could do. The object just calls you to get in the best relation to see it. If you're looking at a house from the front, you also sense that you'd see it even better if you could also see the back". [Dreyfus, 2005b, -]

${ }^{65}$ [Merleau-Ponty, 1962, 138]
} 


\subsubsection{Investigating architectural theorists who have walked down this path}

A second inquiry regarding the theorists who promote the role of the phenomenological body in architect results. The lack of architectural attention to the experience of the human body. I suggest that some theorists who claim something is missing in contemporary architecture omit the thinking body as they put forward the solution of phenomenology. Furthermore by disregarding bodily intentionality their rendering of the phenomenon is not correlative with the human experience of space.

To address this I critique the works of Juhani Pallasmaa and Steven Holl. Pallasmaa is an architectural theorist who employs the work of MerleauPonty and Gaston Bachelard. ${ }^{66}$ Bachelard's work lends itself to contemporary theorists, who abstract elegantly composed sentences as evidence of the importance of designing for the body. The outcome of this practice achieves superficial conclusions; such as Michel Tournier's paraphrase of Bachelard in which Tournier literally concludes that "every true house has a cellar and an attic". ${ }^{67}$ In chapter Four I analysis Pallasmaa's assertions that architecture should be "creating existential microcosms [and] embodied representations of the world" to observe if they are just as skin-deep as Tournier's. ${ }^{68}$ Pallasmaa promotes an architecture that caters to all the body's senses; placing the traditional five senses at centre stage, but this is not an architecture that is phenomenologically founded. ${ }^{69}$

Pallasmaa advocates a system of design criteria based on Merleau-Ponty's phenomenological research. ${ }^{70}$ I shall argue that elements of his theory fail to line up with Merleau-Ponty's work. ${ }^{71}$ In chapter Four I identify the divergence between Pallasmaa's and Merleau-Ponty's phenomenology and consider how the differences effect an architectural theory for the thinking body. Likewise I identify the dissimilarities between the principles that architect Steven Holl has professed to employ and those of Merleau-Ponty. Holl's work is briefly analysed in chapter Five, where I also indicate an architectural direction for Merleau-Ponty's theory through a study of three architectural volumes created by Carlo Scarpa. I propose a pair of contex-

\footnotetext{
${ }^{66}$ Author of The Poetics of Space. Gaston Bachelard is considered to have contributed to phenomenological architectural theory [Ballantyne, 2005, 33, 42, 43, 44] [Norberg-Schulz, 1971, 15]" and [Leach, 1997, 351]

${ }^{67}$ [Ballantyne, 2005, 46] and [Tournier, 1998, 49]

68 [Pallasmaa, 2000, 2]

${ }^{69}$ [Pallasmaa et al., 2006, 29]

70 [Pallasmaa, 2005a, 59], [Pallasmaa, 2005b, 4], [Pallasmaa, 2000, 2], [Pallasmaa, 1996, 31] and 1999 article, Lived Space [Pallasmaa, 2005a, 129].

${ }^{71}$ [Pallasmaa, 2005b, 5] and [Pallasmaa, 1991, 45]
} 
tual design solutions. The design solutions are a product of the analysis of Merleau-Ponty's implicit structure of the human experience of space which is drawn out in chapters two and three. In short, after establishing MerleauPonty's implicit theory, these examines the manner in which architectural theorists and architects render Merleau-Ponty's research of the role of bodily experience of space.

\subsection{Aim}

The aim of this research is to illuminate how the vividness of MerleauPonty's understanding of the human body's experience of space translates to designing an impressive built world. The aims are threefold. Firstly, to draw out a clear and sound account of Merleau-Ponty's implicit structure of the human experience of space. Secondly, to use this structure to critique architectural theorists who are considered to have provided architects with a translation of Merleau-Ponty's research. Finally, to demonstrate a pair of contextual design solutions aiming toward an architecture that caters to the thinking body by looking at architectural volumes. The predominate value of this work is the theoretical undertaking of accounting for MerleauPonty's theory of the bodily experience of space.

In acknowledging contemporary critiques of the field, I respond by offering an account of Merleau-Ponty's research and a reaching of how people within the field have responded to it. Considering that architects are intrinsic in the design of the built environment, it is critical that an awareness of the thinking body plays a role in design. Through clarifying the experience of the body in space my intention is to shift the emphasis of design from the analytical to the corporeal. As Merleau-Ponty notes: "nature is not itself geometrical, and it appears so only to a careful observer who contents himself with macrocosmic data" ${ }^{72}$ The particular designs that result from this thinking process should be as varied as the designers who created them.

\subsection{Scope}

In order to establish a stronger essence of human bodily experience within the field of architecture the scope of this paper is limited. It is confined to an

\footnotetext{
72 [Merleau-Ponty, 1962, 56]
} 
individual human engagement with his or her surrounding built environment. I examine the semi-private spaces of offices, museums and houses. I consider the entrance ways to buildings, and their façades, as the building's introductory impact. As well as the details of architectural elements such as door knobs and light switches, I will address a scale between the details of thresholds and the proportions of a room.

I also examine individual adults who are able-bodied and move about their environment by foot. To achieve this I draw upon the works of theorists who have bound their research to this type of human engagement. Since World War II the number of white-collar workers in Western or Global cultures has dramatically increased. For example, in the United States white-collar workers today account for almost fifty percent of the labour force, outnumbering blue-collar workers by approximately eleven million persons. ${ }^{73}$ The environments made for such workers restrict physical challenges to the body in order to funnel an individual's efforts to analytical task solving. This streamlining extends beyond the desk, outside the office and to the whole of a business district, where the built-environment affords only the challenges of what style of coffee to order, or how to best take advantage of sharing an elevator ride with the company's head. It is these spaces and this quality of human organisation that I address.

\subsection{A profile of the thesis}

This thesis is comprised of three primary components. In short; a philosophy of the body's experience of space, a critique of the theoretical application of the thinking body to architecture, and finally a study of built architecture that approaches this philosophy. More precisely this breaks down to the following outline.

I firstly justify the call for attention to the bodily experience of space within architectural theory (chapter One). I then provide an understanding of the form of the thinking body (chapter Two). I follow this by explaining the function of the thinking body, a topic that engages with the metaphysical act of determining space (chapter Three). From these two chapters, I tease out an implicit structure of human experience resident in MerleauPonty's philosophy. In turn, I use this structure to critique Juhani Pallasmaa's popular account of Merleau-Ponty's work (chapter Four). Lastly, I consider architectural volumes in line with the theory, via a comprehensive case study of the architectural practices of Carlo Scarpa (chapter Five).

\footnotetext{
${ }^{73}$ [CEE, 2003, -]
} 
Although I strive to adopt the writing style of the discipline of architecture, I have deliberately incorporated a few useful devices I acquired from my previous philosophical training. One practice is to use the footnotes to stratify the relevance of information. Throughout this thesis I provide supplementary points, comments, and support in the footnotes. The supplementary discussion is an additional layer of richness to the overall argument that is not strictly essential for my justification. With this noted the majority of the footnotes are merely citations of texts. I shall mention that I attempt to prioritise the use of simple words and descriptions over the employment of philosophical jargon. I limit philosophical terms to those that justify the time to be adequately explained and historically contextualised. Lastly, due to the lack of a he or she pronoun in the English language, I have chosen to the practice of alternating pronouns each paragraph. ${ }^{74}$ As such, I use he for the architect in the first paragraph and she for the architect in the following paragraph and so on.

\footnotetext{
${ }^{74}$ [Williams, 2000, 35]
} 


\title{
Chapter 2
}

\section{The Form; identifying the thinking body}

\begin{abstract}
Our own body is in the world as the heart is in the organism: it keeps the visible spectacle constantly alive, it breathes life into it and sustains it inwardly, and with it forms a system. When I walk round my flat, the various aspects in which it presents itself to me could not possibly appear as views of one and the same thing if I did not know that each of them represents the flat seen from one spot or another, and if I were unaware of my own movements, and of my body as retaining its identity through the stages of those movements. I can of course take a mental bird's eye view of the flat, visualize it or draw a plan of it on paper, but in that case too I could not grasp the unity of the object without the mediation of bodily experience, for what I call a plan is only a more comprehensive perspective: it is the flat 'seen from above', and the fact that I am able to draw together in it all habitual perspectives is dependent on my knowing that one and the same embodied subject can view successively from various positions. ${ }^{1}$
\end{abstract}

Within this chapter I expound Merleau-Ponty's phenomenological depiction of the thinking body as a means of understanding human experiential space. I do not critique Merleau-Ponty's rendering of the phenomenon. Rather I analyse it so that I can then use it to critique phenomenological architectural theorists and derive design solutions. In the previous chapter I introduced a range of architectural theorists to support my claim that

${ }^{1}$ [Merleau-Ponty, 1962, 203] 
contemporary architecture falls short of providing for the human body's experience of space. I proposed that Merleau-Ponty's investigation into the field of perception is relevant to designing spaces for humans, even though he never directly investigated the field of architecture.

In representing the thinking body I will first explain the concepts phenomena and embodiment. Secondly, I will walk through the experience of acquiring a new skill. This description assumes that a close examination of the process of an adult learning a new skill exhibits the phenomenon of the thinking body. That is, as an individual person acquires a skill, the skill is housed, not as a representation in the mind, but as a bodily readiness to respond to situations in the spatial world. In Merleau-Ponty's words, "what counts for the orientation of the spectacle is not my body as it in fact is, as a thing in objective space, but as a system of possible actions". ${ }^{2}$ This system of possible actions is the form of the thinking body. This chapter provides the reader with a practical understanding of this bodily faculty of thought. In the following chapter I progress to the central act of the thinking bodythe synthesis of one's spatial situation.

\subsection{Phenomena}

A phenomenon, simply put, is an individual's finite experience that is afforded to all human beings. ${ }^{3}$ For example, an experience that I individually have of hearing the bells of the clock-tower is a phenomenon. While I perceive the ringing individually, the experience is available for others to also have. Merleau-Ponty describes phenomena, both more obscurely and more

\footnotetext{
${ }^{2}$ [Merleau-Ponty, 1962, 250] The sentence concludes as, “. . . a virtual body with its phenomenal 'place' defined by its task and situation".

${ }^{3}$ During a long telephone conversation with my mother - one of those where I endeavoured to explain what exactly I had been doing; the cupcake metaphor transpired. I have since become rather fond of this analogy, due to its effects on those unexpectant people who receive an honest answer to, "And, what do you do?" Talk of cupcakes seems to afford the inquirer to breath out and dispense with any armour that discussion of my thesis often provokes. The idea is that, if the whole of experience - the world, the imagination of all that is imaginable, and all that can be experienced, i.e. that-which-is, that-which-exists is a grand, multi-layered and tiered cake, with fillings and frostings and sprinkles; then, a phenomenon is a cupcake. Some phenomena have fillings, some have frosting, some have all the above and more. The art of the phenomenologist is to choose the right ones to study. As Merleau-Ponty states, "we must examine some exceptional case in which it disintegrates and reforms before our eyes". [Merleau-Ponty, 1962, 244] The difference between the world and a phenomenon is like the difference between the grand cake and a cupcake; that is, a cupcake, can be picked up with one hand and tasted in one bite. Phenomenon are small and limited, like cupcakes; they are thereby the more easily understandable experiences of the world.
} 
entirely as, "the layer of living experience through which other people and things are first given to us, the system 'Self-others-things' as it comes into being". ${ }^{4}$ The idea is that phenomena compose the murky substance that is an individual's link to that outside one's self. Phenomena are the links themselves, rather than that which is linked to. Hence, when hearing the clock tower bells ringing - the phenomenon is the individual's connection to the tower bells sounds; there are two 'things', i.e., the individual and the bells. The connection exist between the sounding of the bells and the individual hearing it. The link is that, "perceptual 'something' " that "is always in the middle of something else". 5 The link is the phenomenon. Employing the example of the person hearing the clocktower bells ring, Merleau-Ponty's description of "self-other-things" can be drawn as : 6

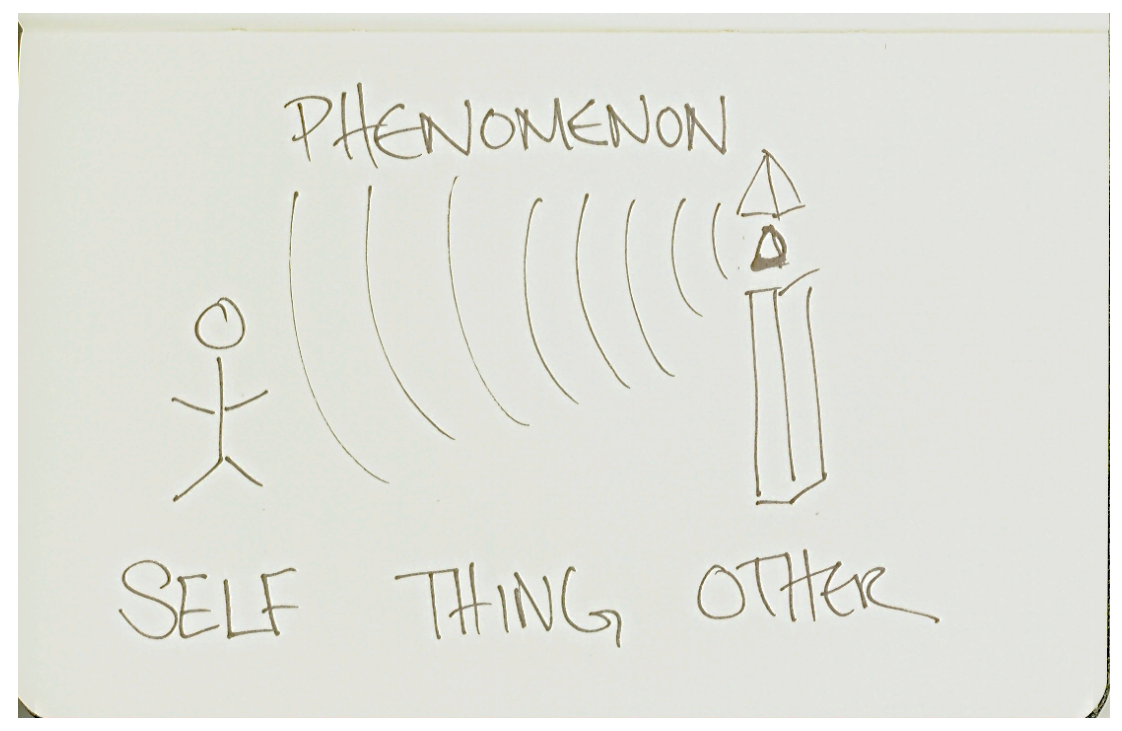

Figure 2.1: Self-thing-other i.e., a phenomenon

Although the link is a "perceptual something", it is not confined to the cognitive realm. ${ }^{7}$ Merleau-Ponty asserts that "the 'phenomenon' is not a 'state of consciousness', or a 'mental fact', and the experience of phenomena is not an act of introspection or an intuition". ${ }^{8}$ A phenomenon is some-

\footnotetext{
${ }^{4}$ [Merleau-Ponty, 1962, 57]

${ }^{5}$ [Merleau-Ponty, 1962, 4]

${ }^{6}$ [Merleau-Ponty, 1962, 57] The drawing is a working drawing I developed during the research for this thesis.

${ }^{7}$ [Merleau-Ponty, 1962, 4]

${ }^{8}$ [Merleau-Ponty, 1962, 57]
} 
thing above and beyond the creative powers of the mind. ${ }^{9}$ Hence, the study of phenomena is an investigation into the links between individual human beings and things within space. ${ }^{10}$ And, this investigation is not confined to the thoughts and imaginations of individuals.

In short, a phenomenon has the following qualities; (a) it is not the same as one's subjective experience of something, $(b)$ technically, two different people can have different phenomena of the same phenomenon, and (c) the temporal extension of a phenomenon is not well defined; although it is necessarily finite and usually short. ${ }^{11}$ The art of the phenomenologist is in picking the right phenomenon to study. As Merleau-Ponty sees it: "we must examine some exceptional case in which it disintegrates and reforms before our eyes". ${ }^{12}$

\subsection{Embodiment, a body as more than flesh and bones}

Our body, to the extent that it moves itself about, that is, to the extent that it is inseparable from a view of the world and is that view itself brought into existence, is the condition of possibility, not only of the geometrical synthesis, but of all expressive operations and all acquired views which constitute the cultural world. ${ }^{13}$

The body of embodiment is not the body of science which is researched and examined as a thing. Merleau-Ponty claims, "the scientist... see[s] his body as others saw it, and conversely see[s] the bodies of others as mechanical things with no inner life". ${ }^{14}$

\footnotetext{
${ }^{9}$ While the finer details of the philosophical implication of this link or "phenomenal field" being part of an inner world or outer world are crucial to philosophers who interpret Merleau-Ponty as idealist or realist; greater study into the distinction goes beyond the confines of this paper and the role for an architectural understanding of the potential impacts of Merleau-Ponty's philosophy [Merleau-Ponty, 1962, 57]

${ }^{10}$ In the following section, 'things within space' is defined further.

${ }^{11}$ [Merleau-Ponty, 1962, 57-59]

12 [Merleau-Ponty, 1962, 244] For example "the cases of vision without retinal inversion". [Merleau-Ponty, 1962, 244] or Wertheimer's mirror experiment [Merleau-Ponty, 1962, 250].

${ }^{13}$ [Merleau-Ponty, 1962, 388]

14 [Merleau-Ponty, 1962, 95]
} 


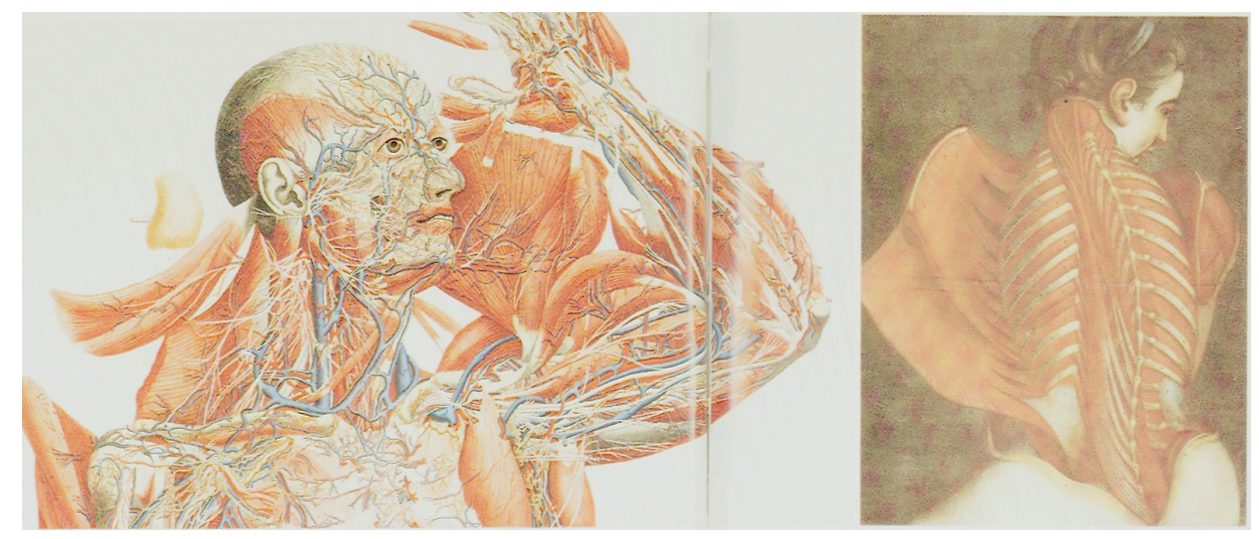

Figure 2.2: Paolo Mascagni, Anatomiae universae icones (Images of Universal Anatomy), (1755-1815)

The scientific body can be metaphorically understood as a theatre with the floodlights on: valuable for critiquing the interior elements, but obstructive for viewing the performance on stage. ${ }^{15}$ Embodiment concerns the experiential human body; the body as a theatre with the floodlights off, ideal for taking in the play. ${ }^{16}$ The body of embodiment is the body as experienced during the act of living.

This leads to claiming that when architects envision human space, the embodied human cannot be represented by a cubic meter volume. That is, the phenomenological body is not the architect's geometrical body, which Andrew Ballantyne depicts as, "a 'forth' dimensionally, between a twodimensional plane and a three-dimensional volume". ${ }^{17}$ Instead, the embodied human postulates the actions of the metaphorical actor on stage. The theoretical move is to understanding the human body as extending into its surroundings and engaging with objects in a non-reflective yet directed fashion. This shifts the emphasis away from mathematical dimensions towards descriptive phenomenon while retaining awareness of the body as described by science.

Merleau-Ponty analyses embodiment through an experience of the phantom limb. In particular, he considers a patient who continues to experience

\footnotetext{
${ }^{15}$ The metaphor of the theatre with the floodlights arose in Professor Dreyfus' Lectures on the Phenomenology of Perception in 2002.

${ }^{16}$ [Merleau-Ponty, 1962, 100]

${ }^{17}$ [Ballantyne, 2005, 254]
} 
his missing limb as if it were still present as it was before amputated. ${ }^{18}$ To explain this phenomenon he draws on empirical research and discovers that the patient experiences the absent limb for example, a hand as a correlate of those aspects of the world which speak to the hand, namely, the doorknob to be opened, the coffee mug to be grasped and so forth. ${ }^{19}$ When the patient restructures his world in such a manner that the things no longer beckon to the lost limb, then the experience of the phantom limb vanishes. Merleau-Ponty explains that "the body is our general medium for having a world." ${ }^{20}$ In the practical sense, the patient's environment has changed when the the doorknob no longer affords to be grasped from the right, and likewise it is the left hand which knows to reach out and grasp the coffee mug.

For Merleau-Ponty, "a world" is the spatial situation within which an individual is mentally and physically positioned. ${ }^{21}$ The body is orientated in a world by means of three classifications; innate structures, basic general skills and cultural skills. ${ }^{22}$ Innate embodiment refers to the most basic physical qualities of the human body, such as cells, blood, organs and the likes. The basic general skills are simple means by which the body engages with a world, such as "dancing" or walking. ${ }^{23}$ Cultural skills are when tools are conceived of and employed by the body. I further distinguish a subsection of cultural skills as the style in which the individual engages with the world.

\subsubsection{Innate structures}

Innate structures are the physical shapes and inherent capacities of the human body, i.e, the "biology" of the body. ${ }^{24}$ Innate structures include the fact that the body has two arms, two legs, two hands, one head, all of a certain size, consistency and so on.

In granting a physical body Merleau-Ponty also grants the existence of physical things independent to the body. ${ }^{25}$ One way the metaphysical world can be metaphorically sliced exposes the world as composed of

\footnotetext{
${ }^{18}$ [Merleau-Ponty, 1964, 142]

${ }^{19}$ [Merleau-Ponty, 1964, 142]

${ }^{20}$ [Merleau-Ponty, 1962, 146]

${ }^{21}$ [Merleau-Ponty, 1962, 146]

22 [Dreyfus, 1996, 1]

${ }^{23}$ [Merleau-Ponty, 1962, 146]

24 [Merleau-Ponty, 1962, 146]

${ }^{25}$ This idea is given detailed analysis in section 3.2.
} 
physical things. In this regard the innate structure of the human body is a physical thing. He maintains: "I have hands, feet, a body, I sustain around me intentions which are not dependent upon my decisions and which affect my surroundings in a way which I do not choose" ${ }^{26}$ In stating this, Merleau-Ponty asserts three metaphysical aspects; (a) human beings have physical bodies, $(b)$ there exists something other than the body that is independent of the body's perception of it, and (c) there is a fundamental and necessary causal connection between the physical body and that which exists independently of it. ${ }^{27}$

\subsubsection{Basic general skills}

Embodiment is more than the innate structures and "it is inadequate to say that my body is... a phenomenon in which the totality takes precedence over the parts". ${ }^{28}$ In accounting for the phenomenon the basic general skills category encompasses the physical body, the space in which the body moves, and the learned connection between the two; i.e. 'motor habits'. ${ }^{29}$ Consider the following quotation in which Merleau-Ponty examines the experience of holding a smoking pipe:

If I stand holding my pipe in my closed hand, the position of my hand is not determined discursively by the angle which it makes with my forearm, and my forearm with my upper arm, and my upper arm with my trunk, and my trunk with the ground. I know indubitably where my pipe is, and thereby I know where my hand and my body are, as primitive man in the desert is always able to take his bearings immediately without having to cast his mind back, and add up distances covered and deviations made since setting off. ${ }^{30}$

\footnotetext{
${ }^{26}$ [Merleau-Ponty, 1962, 440]

${ }^{27}$ ' $\mathrm{B}$ ' is a claim against Idealism, and to a relevant extent is analysis in chapter three. That which is outside the confinements of this paper, is the placing Merleau-Ponty in either the Realist or Idealist camp. It is also in direct response to the notion of freedom argued in Sartre's L'Etre et le Neamt. Consider the following assertion which targets Sartre's argument regarding the freedom of striding over mountains, "these intentions are general in a double sense: firstly in the sense that they constitute a system in which all possible objects are simultaneously included: if the mountain appears high and upright, the tree appears small and sloping; and furthermore in the sense that they are not simply mine, they originate from other than myself, and I am not surprised to find them in all psycho-physical subjects organized as I am". [Merleau-Ponty, 1962, 440]

${ }^{28}$ [Merleau-Ponty, 1962, 100]

${ }^{29}$ [Merleau-Ponty, 1962, 146] Additionally, "Merleau-Ponty uses 'habit' as synonymous with 'skill,' so when he wants to refer to skill acquisition he speaks of 'the acquisition of a habit' " [Dreyfus, 1996, 2]

${ }^{30}$ [Merleau-Ponty, 1962, 100] emphasis my own.
} 


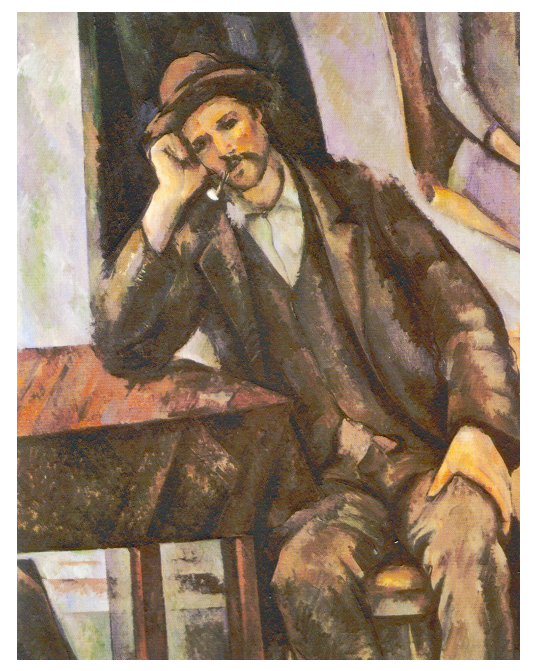

Figure 2.3: Paul Cézanne, Man Smoking a Pipe, 1895-1900

Basic general skills (such as smoking, or reaching to a coffee mug) are the links between the physical structures of the body along with its surrounding elements of space. The body's ability to recognise that which affords walking on, squeezing through, reaching for, and so on, fall under the classification of basic general skills of embodiment. ${ }^{31}$ These basic skills are generally catered for in contemporary architecture. ${ }^{32}$ That is, buildings are structurally sound, doors are human size, and countertops are reachable to the general populous.

\subsubsection{Cultural skills}

Lastly, cultural skills relate to the elements in our living environment that vary from culture to culture. Dreyfus explains this cultural embodiment as, "each person not only incorporates his culture, but also his sub-culture and the understanding of human beings". ${ }^{33}$ Cultural skills represent instruments of the built world which the body knowingly engages with but are distinct in time and place.

\footnotetext{
${ }^{31}$ [Dreyfus, 1996, 1]

32 [Gins and Arakawa, 2002, 43]

33 [Dreyfus, 1989, 4] In regards to the Idealism vs. Realism issue the sentence continues to note "... which is, of course, not private but is a variation on the shared public world".
} 


\title{
styles of engagement
}

I distinguish the variation of style of engaging within embodied cultural skills. Styles of cultural skills can be an individual's vocation - such as architect, mathematician, plumber, artist, monk, computer programer, teacher - or the person's defining characteristic - for instance questioner, fighter, critic, child, political, spiritual and the likes. In the final paragraph of Phenomenology of Perception, Merleau-Ponty heralds the subdivision of cultural skills:

\begin{abstract}
I am a psychological and historical structure, and have received, with existence, a manner of existing, a style. All my actions and thoughts stand in a relationship to this structure, and even a philosopher's thought is merely a way of making explicit his hold on the world, and what he is...this certain significance of nature and history which I am, does not limit my access to the world, but on the contrary is my means of entering into communication with it. ${ }^{34}$
\end{abstract}

The individual's style of cultural skills effects how the limits of the things independent to human beings show up to the individual. This is more fundamental than how the individual conceives of the limitation associated with her surrounding environment. The limit can seem pre-established when the individual considers them. However, the limits only become established when the body grasps them and they manifest the details or richness of the individual's spatial situation. Style also effects how the individual works within the limits. For instance, a stack of wood blocks outside my window will show up differently in terms of what it is and what it can be used for, variously, the architect, the firefighter, the farmer, or the child. ${ }^{35}$

\section{an example to illustrate these structures}

To draw out these distinctions of embodiment, particularly cultural embodiment, consider the phenomena of engaging with an elevator button. Physically elevator buttons are placed where human hands can reach them, fulfilling the innate structural element of embodiment. Secondly, the pushing skill is a basic hand motion. Thirdly, the reaction to push an elevator button

\footnotetext{
${ }^{34}$ [Merleau-Ponty, 1962, 455] Emphasis my own.

${ }^{35}$ I return to this topic in the following chapter and in the final conclusion.
} 
is a cultural skill. ${ }^{36}$ That elevator buttons afford pushing is unique to contemporary global people. A given person steps into an elevator and finds a dozen buttons along the wall at about hand height, the person reaches out and pushes a single button which indicates a stop at a signal floor level; viz. just one of the dozen buttons affords my hand's push, and the hand reaches out and appropriately pushes it.

However, the cultural skill of elevator button pushing was not established amongst the the modern businessman of the 1950s. Similarly, consider a person from a remote and non-global environment. Both people have the innate structure and basic general skills to push the elevator buttons, yet lack the cultural skills that afford the buttons to show up as pushable. ${ }^{37}$ Hence push-ablity is a cultural constant.

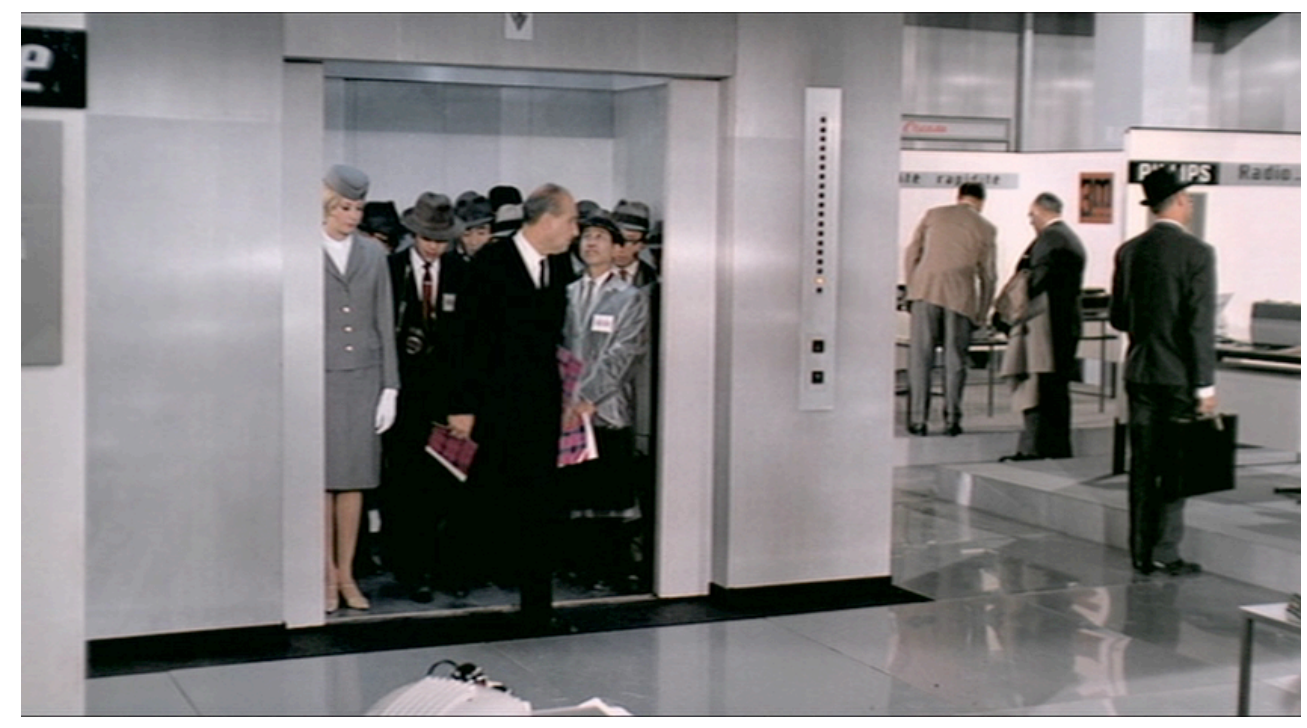

Figure 2.4: Elevator Attendant in Jacques Tati's film Play Time

\footnotetext{
${ }^{36}$ For further discussion of culture skills see J.J. Gibson or Hubert Dreyfus, such as, "J.J. Gibson, like Merleau-Ponty, sees that characteristics of the human world, e.g. what affords walking on, squeezing through, reaching, etc. are correlative with our bodily capacities and acquired skills, but he then goes on, in one of his papers, to add that mail boxes afford mailing letters. This kind of affordance calls attention to a third aspect of embodiment. Affords-mailing-letters is clearly not a cross-cultural phenomenon based solely on body structure, nor a body structure plus a skill all normal human beings acquire. It is an affordance that comes from experience with mail boxes and the acquisition of letter-mailing skills. The cultural world is thus also correlative with our body; this time with our acquired cultural skills". [Dreyfus, 1996, 1]

${ }^{37}$ [Zhou, 2008, 4]
} 
In the 1950s, elevator technology developed to have automatic landing positioning and no longer required a human elevator operator using the complex motor controller. ${ }^{38}$ However, elevators in corporate offices were still manned with human operators up until the nineteen sixties. ${ }^{39}$ The cultural embodiment of the modern business class of the 1950s did not encompass an elevator interface that afforded the cultural skill of button pushing.

For a five year old, in the same elevator, all the buttons afford pushing. The variance of the child's embodiment of cultural skills to those of adults, accounts for the child's reaction to elevator buttons. For children, more buttons physically afford pushing. Children live in the same culture, but have a different style, with differing norms and governing principals. Human engagement with elevators demonstrates a structure in which a given space appears to users through a multitude of spatial compositions. Hence, designing for an embodied human involves consideration of the body's innate structures, basic general skills, cultural skills and to some degree styles of cultural engagement.

\subsection{Skill acquisition as a means of recognising the think- ing body}

Some designs have elements arranged so obscurely that the design impairs the body's ability to learn. Consider a room with a maverick light switch concealed behind the entry door and at knee level. Or think of a step only one hundred millimetres placed in an otherwise banal quarter of a room. Lastly, consider the clear glass opening doors inserted into neo-classical buildings with no forwarding of their existence. These elements each require reflective analysis of the spatial situation. An individual engaging with the hidden, knee-high light switch has to think to herself, where is the light switch? Even after multiple experiences with the hidden switch, it still remains a tricky element to learn, because it diverges from the rest of the individual's experience of the urban surroundings, and because of the lack of increments of divergent switches in the space leading to the knee level one. Likewise, the small step in the room corresponds to no other elements, and the body has to learn to engage with its existence exclusively through memory, rather than, a general understanding of causal connections; i.e. if there's a narrowed space, then there might be a step. ${ }^{40}$ Lastly,

\footnotetext{
${ }^{38}$ [Garris, 2006, 76]

${ }^{39}$ [Taub, 1998, 12] and [Eggener, 2004, 194]

${ }^{40}$ The concept of causal connection is given detailed attention in section 5.2.3.
} 
a clear glass door hide its existence until a body crashes into them. It is the analytically reflective understanding that warns the body, 'slow down, this is a post-modern district of town, shops usually have doors, there's probably something there blocking that opening'.

In this section, I discuss an example in which the body learns to nonreflectively engage with it surrounding space. The point of this section is twofold. On one hand, I aim to draw the reader's attention to the existence of the thinking body. And on the other, I work to illustrate elements that enable the body to learn.

Many of the skills we employ are learnt over time and at a young age via trial and error (such as walking and talking). ${ }^{41}$ These skill sets comprise simple yet important ways in which we engage with our surroundings. For instance, "the light of a candle changes its appearance for a child when, after a burn, it stops attracting the child's hand and becomes literally repulsive".$^{42}$ Learning a new skill changes the way things emerge to the learner. Once the child knows that fire can burn, the fire itself is less attractive to the child's hand. It is not the case that the candle still draws the child's hand, but that the child no longer reaches for it because, upon reflection, he remembers the experience of the heat. Rather, the flame itself shows up to the child's body as something that is not desirable to touch and no reflection about the possibility of touch is undertaken.

In Dreyfus' framework for skill acquisition there are five phases through which a person ascends when learning a new skill. These are the phases of Novice, Advanced Beginner, Competence, Proficient and Expertise. ${ }^{43}$ This ordering is consistent, but it is not necessarily the case that an individual will progress through all the stages to become an expert. ${ }^{44}$ The examination reveals various stages by which the body interacts with space, which can translate to a number of ways an individual engages with space. ${ }^{45}$ Secondly, it illustrated elements that enable the body to learn.

In précis the skill phase proceed as follows. The novice is unobstructed by tangential tasks, but is well known to be slow and awkward due to the need to bring to mind all of the instructor's rules. ${ }^{46}$ In the following phase

\footnotetext{
${ }^{41}$ [Dreyfus, , 1] Dreyfus uses the effective examples of learning to drive a manual automobile and learning to be a master chess player. While his work is most convincing, his terminology is embedded within the language of the philosophical discipline.

${ }^{42}$ [Merleau-Ponty, 1962, 52]

${ }^{43}$ [Dreyfus, , 1] I am aware that these are not all the same parts of speech. However, I have chosen to draw upon the work of Hubert Dreyfus, and I shall employ his labels.

${ }^{44}$ [Dreyfus, , 1] and [Dreyfus, 1996, 1]

45 [Merleau-Ponty, 1962, 268]

${ }^{46}$ [Dreyfus, 1996, 2]
} 
the advanced beginner takes in related aspects of the situation and extends the task to include situational context. ${ }^{47}$ Here the student begins to understand his activity effects beyond the original set of the instructor's consequential rules. Then the competent learner begins to make ad hoc judgements based on logical analysis while reacting to circumstantial elements in addition the taught actions. ${ }^{48}$ This is the first phase where the student begins to take responsibility for the outcome of his decisions. Due to a shift in motivation brought about via positive and negative experience, in the proficient phase the student intuitively feels the problem, without reflection but must decide logically how to respond. ${ }^{49}$ Finally, the expert intuitively feels the problem and feels the best way to respond. ${ }^{50}$ Hence for the expert, time is not occupied with calculating decisions, as elements in space intuitively afford response. The expert uses bodily intentionality of the thinking body. For the expert, as aspects of space become present, the thinking body syntheses elements and responds to them independently of the reflective capacities of the mind. This process creates the uninterrupted flow of intentionality that is observable in people highly developed of particular skills.

Consider case of a person leaning to tramp in a wilderness reserve. The instructor of the novice tramper reduces the actions of tramping to a few essential rules which do not require interpretation. For instance, if the trail looks unstable, then the novice is directed to probe the ground gently prior to putting weight on it and to rest every fifty minutes to avoid over-straining. The student is taught a set of rules that are independent from the overall experience of tramping. This allows the novice to be unencumbered by tangential tasks and focus on employing the instructor's rules. During this phase, the learner reflects on abstracted rules and does not engage with the potential aptitude of the thinking body. Still following rules, the advanced beginner tramper learns more consequences of her actions; such as when climbing down a steep track, it can be helpful to grab onto the nearby trees for support. Once the tramper reaches the competent phase, she is exposed to more challenging paths; perhaps involving river crossings, steeper grades, and muddy bogs. When hiking down a steep grade, the learner still watches the ground and nearby trees to see where to place her feet and hands, but the judgement is quicker because more spaces show up as affording the foot or hand. However, when walking along a path that has become a bog with a few logs arbitrarily floating in the mud, the competent tramper must slow her gait and consider the size

\footnotetext{
${ }^{47}$ [Dreyfus, 1996, 3]

48 [Dreyfus, , 3]

${ }^{49}$ [Dreyfus, , 6]

${ }^{50}$ [Dreyfus, , 6]
} 
of the log and the flatness and slipperiness of the surface before proceeding. The competent learner still depends on reflecting on abstract rules, but begins to experience non-reflective engagement as some physical surfaces and tools show up to the learner. The proficient tramper response is swifter and more efficient than the competent tramper but still slower than the expert tramper. For example, if the proficient tramper is descending a steep trail that has recently suffered massive slips due to prolonged rains and the ground ahead begins to fall away as she proceeds, then proficient tramper intuitively realises that the path may slip away under her feet in the next few steps. ${ }^{51}$ She must then analytically reflect to respond, i.e., whether to leap across the path quickly or halt and ease her way across the trail. ${ }^{52}$ Valuable time is lost while reflecting on the consequences of the decision, but the tramper is more likely to negotiate the trail smoothly than the competent tramper who spends additional time deciding what the problem is, based on ground saturation, angle of descent, gravitational forces and her own speed of movement. ${ }^{53}$ The proficient learner utilises a more streamlined and non-reflective engagement as the spaces and elements around her that form affordances calling for use or avoidance. ${ }^{54}$

The expert tramper moves along the trail with her mind unconcerned with consequential rules. Certain surfaces show up as affording her foot, while others do not. She does not decide which surface to use, her feet and hands reach for the optimal spaces. She no longer looks at the ground or the path and think about how best to negotiate it. Rather, the positions show up and movements are performed intuitively. ${ }^{55}$ The expert learner depends only on the non-reflective engagement with space, i.e. the capacity of the thinking body. Analytical reflection slows down the bodily response to the situation. ${ }^{56}$

\footnotetext{
${ }^{51}$ [Dreyfus, , 4]

52 [Dreyfus, , 4]

53 [Dreyfus, , 5]

${ }^{54}$ In other words the dominance of analytical intentionality gives way to bodily intentionality.

${ }^{55}$ Merleau-Ponty describes this in terms of a table, "the surface which I am about to recognize as the surface of the table, when vaguely looked at, already summons me to focus upon it, and demands those movements of convergence which will endow it with its 'true' aspect" [Merleau-Ponty, 1962, 318]

${ }^{56}$ The expert learner engages with the situation with her bodily intentionality rather than analytical intentionality. For further persuasion, consider Dreyfus' example of an expert action. "The expert driver, not only feels in the seat of his pants when speed is the issue; he knows how to perform the appropriate action without calculating and comparing alternatives. On the off-ramp, his foot simply lifts off the accelerator and applies the appropriate pressure to the brake. What must be done, simply is done. As Aristotle says, the expert 'straightaway' does 'the appropriate thing, at the appropriate time, in the appropriate way.' " [Dreyfus, , 6]
} 


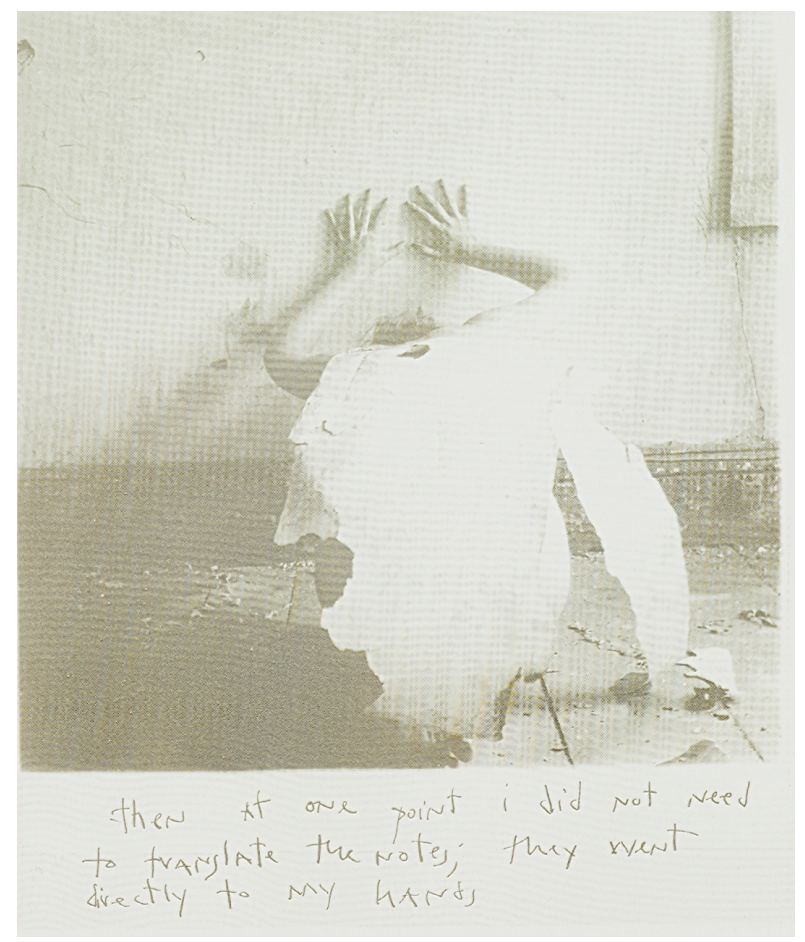

Figure 2.5: then at one point $i$ did not need to translate the notes; they went directly to my hands, Francesca Woodman, Providence, Rhode Island, 1976

\subsection{Conclusion}

As humans, we find ourselves in spatial situations that our bodies physically and intuitively engage with. We acquire skills through our experience of living in a complex and varied world and our capacity to learn through engaged experience. Looking at the phenomenon reveals the theory that human beings have a mode of engagement with space, in which the body responds to situations in the designed environment in a non-rule-governed fashion with non-representational motivators. All bodies are thinking, the expert learn is simply further developed. Examining the phases of learning a skill demonstrates the role of the thinking body and how it can learn.

I return to this conclusion in chapter Five by considering architecture that provides space to develop the skills of bodily intentionality by avoiding the tricking the body with designs such as the maverick light-switch 
and instead sets up opportunities for the body to recognise causal connection. In the following chapter, I look into the metaphysical ramifications of this human faculty in regards to creating spaces. Following that, I use this analysis of the experience of being in space to critique contemporary architectural theorists. 


\section{Chapter 3}

\section{The Function; the thinking body as maker of space}

Space is not the setting (real or logical) in which things are arranged, but the means whereby the position of things becomes possible. ${ }^{1}$

In the previous chapter the thinking body was addressed through a sequence of examples constructed to draw the reader's attention to the body's capacity to intentionally engage with space and elements of space. The aim of that chapter was to identify the inherent structure that affords the intentional actions of the human body. The present chapter analyses the actions afforded by that faculty. In other words, the previous chapter focused on the form of the thinking body. This chapter focuses on the function, an the activity Merleau-Ponty describes as the "motion which generates space". 2

The function of the thinking body is the act of intentionally drawing upon that which is independent of human beings, and through engagement determining the sensual richness of the independent "in-itself". ${ }^{3}$ MerleauPonty's implicit structure of the human experience of space postulates a non-reflective intentional engagement with indeterminate possibilities that constructs determinate spatial situations. This account of human experi-

\footnotetext{
${ }^{1}$ [Merleau-Ponty, 1962, 243]

2 [Merleau-Ponty, 1962, 387]The purpose of this chapter is to explain the action of the thinking body, that is, how the actions of the thinking body create space.

${ }^{3}$ [Merleau-Ponty, 1962, 294] Note citation is for quoted concept only. Could also be referred to as "the thing itself" or "the ipseity of the thing" [Merleau-Ponty, 1962, 233] This chapter's objective is accounting for this claim.
} 
ence suggests that a closer reading of associated philosophical texts will provide new avenues for architectural exploration.

Rob Imrie and Alberto Pérez-Gómez are contemporary theorists who have sought to call attention to the architectural study of phenomenological texts. I shall begin this chapter with a brief overview of what these scholars have added to the discipline of architecture. I then analyse the function of the thinking body. I start the analysis by summarising the source and meaning of the term, intentionality. I go on to examine the function of bodily intentionality and its relationship to architecture. This chapter provides an account of Merleau-Ponty's implicit structure of the human experience of space, which I then employ in the following two chapters as a means of theoretical critique and a starting point for design solutions.

\section{Rob Imrie's contribution}

In an article titled, Architects' Conceptions of the Human Body, geography professor Rob Imrie surveys contemporary architects' conceptions of the human body. ${ }^{4}$ Parallel to the theorists I discussed in chapter one, Imrie sees the contemporary state of architecture as reflecting the "dominance of bodily reductive conceptions in architecture" and he "call[s] for an architecture that recognises, and responds to, the diversity of bodily needs in the built environment". ${ }^{5}$ What Imrie adds to the dialogue on phenomenological architecture is a summary of how architects have considered the human body.

Imrie concludes that architects generally give scant regard to the body. ${ }^{6}$ He provides the following segment of an interview with a practising architect as representative of architect's conceptualisation of the human body:

Interviewer: "When you think of the body you seek to design for what sort of body is that?"

Respondent: "You mean a human body?"

Interviewer: "Yes."

Respondent: "That is an obscure question. Gosh."

\footnotetext{
${ }^{4}$ [Imrie, 2003, 51]

${ }^{5}$ [Imrie, 2003, 48, 64] Respectively.

${ }^{6}$ Or that "architects also tend to operate with partial and reductive conceptions of the human body". [Imrie, 2003, 63]

${ }^{7}$ [Imrie, 2003, 55]
} 
Imrie argues that architects need to acknowledge and cater to the multiplicity of bodily needs. ${ }^{8}$ He directs his readers to Merleau-Ponty's view of the body as "conjoined" to the built environment. ${ }^{9}$ Imrie identifies a dominant reductive notion of the human body and points to Merleau-Ponty's theory in his conclusion. He offers Merleau-Ponty's claim that, "far from my body being for me no more than a fragment of space, there would be no space at all for me if I had no body". ${ }^{10}$ However, he rests there without accounting for why the reader should believe the body is united with space, or how such a connection would transpire.

This move is similar to that of Alberto Pérez-Gómez, who also identifies Merleau-Ponty as a source for understanding the human body. Yet again, Pérez-Gómez undertakes a project different to explaining how and why Merleau-Ponty's understanding of the human body functions in nonphilosophical terminology. Pérez-Gómez writes that: "according to MerleauPonty we don't merely 'have' a body, we 'are' our bodies". ${ }^{11}$ Explaining how and why this metaphysical structure is possible, and how it works, is explain in the remainder of this chapter.

\title{
3.1 Intentionality, and its metamorphosis
}

\author{
A new conception of intentionality... which treats the experience of \\ the world as a pure act of constituting consciousness. ${ }^{12}$
}

To account for the notion of intentionality I begin by relating the origin and development of the term itself. I then clarify the distinctions that MerleauPonty adds to the term. Finally (in the following section) I analyse the fundamental act of the thinking body as a "mediator of a world". ${ }^{13}$

\footnotetext{
${ }^{8}$ [Imrie, 2003, 64]

${ }^{9}$ [Imrie, 2003, 64]

${ }^{10}$ [Imrie, 2003, 64]

11 [Pérez-Gómez, 2006, 95] Consider also the following description. "For Merleau-Ponty, our bodies can recognize and understand, despite our so-called scientific common sense and its Cartesian isotropic space, the wisdom embedded in a place, in a culture-its profound, untranslatable expressive qualities. This understanding is made possible particularly by works of art, capable of disclosing places that speak back to us and resonate with our dreams, opening up the space of desire that allows us to be at home, while remaining always incomplete and open to our personal death". [Pérez-Gómez, 2006, 95]

12 [Merleau-Ponty, 1962, 243]

${ }^{13}$ [Merleau-Ponty, 1962, 145]
} 


\subsubsection{Origin and development of the term}

Intentionality is a phenomenological term used by Merleau-Ponty to express a "directive" engagement with the world. ${ }^{14}$ However, the term was originally coined with a slightly different meaning. Franz Brentano resurrected the term intentionality into modern philosophy with the following statement; "every mental phenomenon is characterized by... the intentional inexistence of an object, and what we might call...direction toward an object" ${ }^{15}$ According to Brentano, mental states such as perception, memory, desire, fear, etc., are all of something, or about something. Dreyfus notes that, "it is this directedness, or intentionality, Brentano claimed, which is characteristic of the mind and of nothing else" ${ }^{16}$ The particularity of Brentano's meaning of intentionality is less significant here, than his professorship at the University of Vienna where he taught Edmund Husserl. ${ }^{17}$ Brentano and Husserl both saw intentionality, "as the mark of the mental" $^{\prime 18}$ For Brentano and Husserl, who are respectively the forerunners of this terminology and the discipline of phenomenology, a phenomenon is strictly a mental directiveness towards something.

Merleau-Ponty then develops intentionality as a concept applicable to more than just the mental ideas of human minds. ${ }^{19}$ He claims, "the natural reference of the stuff to the world leads us to a new conception of intentionality". ${ }^{20}$ This "new" mode is an embodied directiveness towards the world-i.e., bodily intentionality. ${ }^{21}$

\footnotetext{
${ }^{14}$ [Dreyfus, 1989, 3]

15 [Brentano, 1995, 88] Emphasis my own.

${ }^{16}$ [Dreyfus, 1989, 1]

${ }^{17}$ Edmund Husserl studied under Professor Brentano between the years of 1884 and 1886

${ }^{18}$ [Dreyfus and Wrathall, 2006, 123] and "Husserl developed a detailed account of what Brentano called the 'intentionality' of consciousness, that is to say, its object-directedness, its of-ness, or 'aboutness.' Husserl's theory of intentionality marks a watershed in the history of late modern philosophy because, although Brentano was responsible for importing the term into our technical vocabulary, it was Husserl who effectively put the concept to work against many of the guiding assumptions that had dominated psychology and the philosophy of mind since Descartes". [Carman and Hansen, 2005, 5]

${ }^{19}$ It should also be noted the Martin Heidegger developed the term prior to MerleauPonty. "In this sense Heidegger is even a more radical phenomenologist than Husserl. By enlarging and deepening the notion of intentionality from a mere consciousness of essences into the direction of Dasein as man's concreate thinking, living, loving and concernful Being-in-the-world, Heidegger's rejection of Husserl's transcendental subjectivism has increased his faithfulness to Husserl's phenomenological maxim:'to the things themselves.' " [Spiegelberg and Strasser, 1975, 100]

${ }^{20}$ [Merleau-Ponty, 1962, 243] Here "new" is opposed to the Husserlian "classical conception" of intentionality. [Merleau-Ponty, 1962, 243, 53] In other words, in addition to the "classical" intentionality, there is Merleau-Ponty's "new" mode of intentionality.

${ }^{21}$ [Merleau-Ponty, 1962, 53]
} 
Merleau-Ponty identifies two modes of engaging with the world; bodily intentionality of the thinking body and analytical intentionality of the thinking mind. ${ }^{22}$ Dreyfus writes:

\section{To distinguish this body-based intentionality from the representational intentionality studied by Husserl and Cognitive Science, Merleau- Ponty calls the body's response to the affordances of the situation, mo- tor intentionality. ${ }^{23}$}

Here, the term 'motor intentionality', is what I call bodily intentionality, and is the act of the thinking body. ${ }^{24}$ Furthermore, bodily intentionality is the body's directiveness towards that which is independent of the individual's body.

\subsubsection{Distinguishing the two modes}

Merleau-Ponty employs the famous Schneider case study, which is linked to Gestalt psychiatrist Goldstein and Gelb as a means of drawing out the distinctions between bodily and analytical intentionality, Merleau-Ponty describes the complications of physical movement for a war veteran who has lost his analytical intentionality but retained his bodily intentionality:

A patient whom traditional psychiatry would class among cases of psychic blindness is unable to perform 'abstract' movements. . [however] localization of stimuli, and recognition of objects by touch... become possible with the aid of the preparatory movements... one notices a dissociation of the act of pointing from reactions of taking or grasping: the same subject who is unable to point to order to a part of his body, quickly moves his hand to the point where a mosquito is stinging him. Concrete movements and acts of grasping therefore enjoy a privileged position for which we need to find some explanation. ${ }^{25}$

\footnotetext{
${ }^{22}$ [Merleau-Ponty, 1962, 53]

${ }^{23}$ [Dreyfus, , 13]

${ }^{24}$ To repeat from the introduction, the thinking body is my term for discussing the form or the factuality, of Merleau-Ponty's "motor intentionality" [Merleau-Ponty, 1962, 110] or Dreyfus' terms "motor intentionality" [Carman and Hansen, 2005, 144] and "bodily intentionality" or Sean Kelly's "motor intentionality" [Wrathall and Malpas, 2000a, 161] David W. Smith's term "non-positional consciousness" [Smith and Thomasson, 2005, 273] or J. N. Mohanty's "bodily intentionality" [Dreyfus and Wrathall, 2006, 75]

${ }^{25}$ [Merleau-Ponty, 1962, 103] emphasis my own.
} 
Merleau-Ponty finds this "explanation" with the thinking body. ${ }^{26}$ In this case a hand grenade damaged parts of the patient's body resulting in disabled analytical intentionality to the extent that the patient cannot fulfil orders which demand him to pause and logically regard the situation from a detached perspective. ${ }^{27}$ At the same time, the patient is able to complete requests situated with an embodied perspective, such as swatting a stinging insect. ${ }^{28}$ Merleau-Ponty accounts for this discrepancy by distinguing two modes of intentionality.

Analytical intentionality is the detached reflective engagement with a situation. The exercise of analytical intentionality effects the individual's abstract or theoretical conception of the world. It is a significant occupation of a human being, but it is not the only one. Bodily intentionality is the attached, non-reflective engagement with a spatial situation. Moreover, Merleau-Ponty argues that it is the primary means by which spatial situations emerge. $^{29}$

Both modes of intentionality distinctly determine particular manifestations of space. Merleau-Ponty claims that with reflection, there is "geometrical space" and that without reflection there is "physical space". ${ }^{30}$ Here he is claiming that the space we experience while engaging with the world via the thinking body is physical space. And that physical space is different than geometrical space. Skills applied in physical space are in relation to the task at hand. These skills are without reflection and conducted by the thinking body. In this mode, space appears unified and understandable. Merleau-Ponty explains that, "my body and things, their concrete relationships expressed in such terms as top and bottom, right and left, near and far, may appear to me as an irreducibly manifold variety". ${ }^{31}$ However, he writes that, upon reflection "I discover a single and indivisible ability to trace out space". ${ }^{32}$ This geometrical and traceable space is similar to the "slice or piece of space" that Henri Lefebvre calls architectural space. ${ }^{33}$ Space is abstracted and decontextualised from the experience of living in the world. However, Merleau-Ponty also claims that it is upon reflection that we realise that the relationships underlying the world "live only through the medium of a subject who traces out and sustains them". ${ }^{34}$

\footnotetext{
${ }^{26}$ [Merleau-Ponty, 1962, 103]

${ }^{27}$ Without seeking a more empirical study of the object of the brain, Merleau-Ponty studies the experience of the patient. [Merleau-Ponty, 1962, 103].

${ }^{28}$ [Merleau-Ponty, 1962, 103]

${ }^{29}$ [Merleau-Ponty, 1962, 297]

${ }^{30}$ [Merleau-Ponty, 1962, 244]

31 [Merleau-Ponty, 1962, 244]

32 [Merleau-Ponty, 1962, 244]

${ }^{33}$ [Lefebvre, 1991, 360]

34 [Merleau-Ponty, 1962, 244]
} 
That space is not "the results of analytical reflection". ${ }^{35}$ If geometrical space is the result of reflective thinking and only exists in the minds of those who think of it, and that space itself is not the process of reflective thinking, then these claims raise questions about how the two modes of intentionality relate to each other.

\section{relation of the two modes}

The two modes of human engagement with space link in an essential fashion. Merleau-Ponty explains that we fundamentally engage with our surroundings via our "experience of the world". ${ }^{36}$ This bodily engagement is the starting point. Upon this, we can "analytically reflect" (via analytical intentionality) on abstract concepts that do not necessarily exist in our experiential world-e.g. unicorns, or the King of France riding a bicycle, or the next Frank Gehry project. ${ }^{37}$ Analytical reflection is the capacity to mentally tear apart manifolds of conceptual information. In specific situations this connection makes possible the mental act which leads to a metaphysical understanding of the world. Philosophically reflecting upon that which is fundamentally happening, reveals a necessary "all-embracing synthesis" of the world. ${ }^{38}$ In other words the employment of analytical intentionality reveals the act of the thinking body. Similarly, writing about the nonreflective thinking function of the thinking body is an analytical activity.

As architects are also people who are embodied and embedded within spatial situations, they employ this connection when designing new spaces. The spatial and embodied world is the starting point of creativity. Built upon that, analytical reflection constructs a conceptual web spun with extracted ideas. ${ }^{39}$ These ideas amass from individual experiences, cultural influences - both contemporary and historical—and intuitive understandings of logical and causal connections. In this designs that are constructed and then occupied by a following generation of architects, work into the cultural influences of the creative process. Although the design process can be removed from the physical world, and can reside in ephemeral discussions and sketches, the ideas created are, at least in part, reflections upon the lived-in space.

\footnotetext{
${ }^{35}$ [Merleau-Ponty, 1962, 387]

${ }^{36}$ [Merleau-Ponty, 1962, ix] "Analytical reflection starts from our experience of the world and goes back to the subject as to a condition of possibility distinct from that experience, revealing the all-embracing synthesis as that without which there would be no world".

${ }^{37}$ [Merleau-Ponty, 1962, ix]

${ }^{38}$ [Merleau-Ponty, 1962, ix]

39 [Merleau-Ponty, 1962, ix]
} 

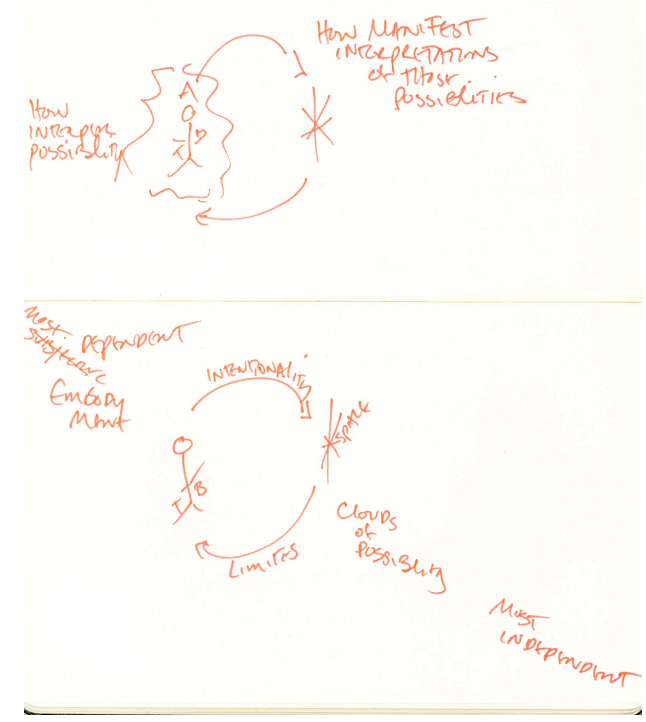

Figure 3.1: Working hand drawing

\subsection{The fundamental act of the thinking body}

\section{Merleau-Ponty's implicit account of the human experience of space}

The act of the thinking body is the intentional drawing from a cloud of possibilities that renders objects determinate for a finite span of time. This objectification of indeterminate possibilities is a bodily synthesis which forms a spatial situation. It is the act of making space. ${ }^{40}$

Merleau-Ponty most clearly defines this action as follows:

The object which presents itself to the gaze or the touch arouses a certain motor intention which aims not at the movements of one's own body, but at the thing itself from which they are, as it were, suspended. And in so far as my hand knows hardness and softness,

\footnotetext{
${ }^{40}$ Please note, the reasoning for this definition is the focus of this section. As with the following quotation, the emphasised words are explained in following sub-subsection
} 
and my gaze knows the moon's light, it is as a certain way of linking up with the phenomenon and communicating with it. ${ }^{41}$

As with the previous definition, the emphasised words are taken up in the following segments.

\section{the thing itself}

That which exists independently of human perception is the "thing itself" or the "in-itself". ${ }^{42}$ I prefer to use the term 'in-itself' because I find it the least misleading. The in-itself is not something that is turning into one thing when engaged with, but rather the whole collection of all possible groupings of possibilities, of which the possibilities are made determinate into one thing. ${ }^{43}$ The 'thing itself' or the 'in-itelf' could also be referred to as "the ipseity of the thing" ${ }^{\prime 44}$ Here ipseity means selfhood, as in the selfhood of the thing or the thing itself. Merleau-Ponty maintains that engagement with a situation "is this opening upon a world which makes possible perceptual truth" and determinate objects. ${ }^{45}$ Determinate objects can be understood as objects affording truth qualifications. ${ }^{46}$ Human engagement with the in-itself opens a spatial situation composed of determinate objectsi.e. objects that can be grasped and possessed by humans, e.g. door knobs and walls. The in-itself is the totality of possibilities of what can be perceived. As such, the in-itself is an indeterminate manifold of potential. The in-itself is never reached and "each aspect of the thing which falls to our perception is still only an invitation to perceive beyond it". ${ }^{47}$ The in-itself is the aggregate of possibilities of what can be perceived through the act of intentionality.

\section{the linking up via bodily intentions, i.e. synthesis}

In the act of intentional engagement with the in-itself, the individual determines perceivable qualities and during the temporal span of this engagement, i.e., synthesises that which is possible into the richness of determinate

\footnotetext{
${ }^{41}$ [Merleau-Ponty, 1962, 317] Emphases my own.

42 [Merleau-Ponty, 1962, 317] and [Merleau-Ponty, 1962, 294] respectively. Note citation is for quoted concept only.

${ }^{43}$ This concept is explained further in the following sub-subsection.

${ }^{44}$ [Merleau-Ponty, 1962, 233]

${ }^{45}$ [Merleau-Ponty, 1962, 297], emphasis my own.

${ }^{46}$ [Merleau-Ponty, 1962, 269]

47 [Merleau-Ponty, 1962, 233]
} 
things that exist. ${ }^{48}$ Merleau-Ponty states this as, "the synthesis of both time and space is a task that always has to be performed afresh. Our bodily experience of movement... provides us with a way of access to the world and the object" ${ }^{49}$ This means that the active thinking body draws out a collection of possibilities and solidifies those possibilities into objects composing a spatial situation for a finite period of time.$^{50}$ In Merleau-Ponty's words: "this passage from the indeterminate to the determinate, this recasting at every moment of its own history in the unity of a new meaning, is thought itself". ${ }^{51}$ And this is the thought of the thinking body. ${ }^{52}$ The body "understands its world" without analytical intentionality while moving and creating a spatial situation. ${ }^{53}$ This spatial situation is finite and must be constantly redefined. Space is not something already there like an "ether" but is created each time "afresh", when intentionality engages with the possibility of it. ${ }^{54}$ The act of bodily intentionality synthesises the particular possibilities of what can be, into what is. ${ }^{55}$

Furthermore, this-space-creating-synthesis is not the "Kantian synthesis" that requires detached reflection. ${ }^{56}$ Merleau-Ponty argues that this synthesis is a "transition-synthesis" requiring bodily responses to engage with independent possibilities. ${ }^{57}$ This is an additional distinction between space as created by analytical reflection and space as created by bodily engagement. Merleau-Ponty's theory accounts for both modes of creating space, yet divides the spaces as lived-in space and thought-about space. Kantian synthesis creates the "geometrical space" of analytical intentionality; which is a useful conceptual tool, but is not the space human beings move about in. ${ }^{58}$ This is similar to the link between the theories of mathematics and

48 [Merleau-Ponty, 1962, 233] and [Merleau-Ponty, 1962, 140]

49 [Merleau-Ponty, 1962, 140] Emphasis, my own.

${ }^{50}$ That is, "it emerges from its liberty of indifference and gives itself a present object". [Merleau-Ponty, 1962, 31]

51 [Merleau-Ponty, 1962, 31]

${ }^{52}$ Through analytical reflection humans determine cultural systems and orderings. Through bodily engagement, humans determine spatial systems and orderings. "Everything throws us back on to the organic relations between subject and space, to that gearing of the subject onto his world which is the origin of space". [Merleau-Ponty, 1962, 251]

53 [Merleau-Ponty, 1962, 251]

${ }^{54}$ Respectively, [Merleau-Ponty, 1962, 140] and "instead of imagining [space] as a sort of ether in which all things float, or conceiving it abstractly as a characteristic that they have in common, we must think of it as the universal power enabling them to be connected". [Merleau-Ponty, 1962, 243]

55 "We withdraw this synthesis from the objective body only to transfer it to the phenomenal body, the body, that is, in so far as it projects a certain 'setting' round itself". [MerleauPonty, 1962, 232]

56 [Merleau-Ponty, 1962, 265]

57 [Merleau-Ponty, 1962, 265]

58 [Merleau-Ponty, 1962, 244] 
logic. For example, imaginary numbers can be useful tools for working out connections between numbers and certain logical rules, however they do not determine how we live in the world. ${ }^{59}$

\section{the clouds of possibilities}

In employing the metaphor of clouds I am deliberately invoking their characteristic of indeterminability. I engage with the common notion of clouds as vague forms of amorphous density and qualities, which change shape, form, mass and location readily. As people look at the clouds they serve as gestures to what weather may come. Or, in time of reverie, the clouds serve as abstract substance upon which the imagination draws familiarity.

I will note that this characterisation of in-itself as the possibility of that which is, is only my inference from Merleau-Ponty. ${ }^{60}$ His project does not concern the particularities of "the ipseity of the thing". ${ }^{61}$ Rather, for MerleauPonty, the in-itself is relevant through the analysis of human engagement with space, such that the engagement is with something independent of humans. ${ }^{62}$ My characterisation of the in-itself as the aggregate of possibilities and the potential object as a cloud of possibilities, in part stems from the following passage that discusses the ordering of human space as built on "non-human space". ${ }^{63}$ Merleau-Ponty surmises:

Natural and primordial space is not geometrical space, nor, correspondingly, is the unity of experience guaranteed by any universal thinker arraying its contents before me and ensuring that I possess complete knowledge of, and exercise complete power over it. It is

\footnotetext{
${ }^{59}$ Or how much money we owe our contractors...

${ }^{60}$ [Merleau-Ponty, 1962, 216, 266]

${ }^{61}$ [Merleau-Ponty, 1962, 233] Ipseity meaning selfhood, as in the selfhood of the thing. Furthermore, concerns of the nature of the selfhood of the thing are perhaps inconsistent with the practice of phenomenology. See section 1.1.2 for explanation of the aim of phenomenology.

${ }^{62}$ Moreover, Merleau-Ponty avoids idealism with this metaphysical structure-that our engagement is with the in-itself, rather than with our perceptions of the thing. "I run through appearances and reach the real colour or the real shape when my experience is at its maximum of clarity, in spite of the fact that Berkeley [famed Idealist] may retort that a fly would see the same object differently or that a stronger microscope would transform it: these different appearances are for me appearances of a certain true spectacle, that in which the perceived configuration, for a sufficient degree of clarity, reaches its maximum richness". [Merleau-Ponty, 1962, 318]

63 "I never wholly live in varieties of human space, but am always ultimately rooted in a natural and non-human space". [Merleau-Ponty, 1962, 293]
} 
merely foreshadowed by the horizons of possible objectification, and it frees me from every particular setting only because it ties me to the world of nature or the in-itself, which includes all of them. ${ }^{64}$

The "horizons of possible objectification" is a multitude of possibilities which afford objectification. Here, I interpret Merleau-Ponty's use of the word "objectification" as the act of making an object. ${ }^{65}$ Metaphorically, the "horizons of possible" can be conceived as clouds of possibilities. ${ }^{66}$

Together, the clouds of possibilities compose the totality of the in-itself. ${ }^{67}$ Alone, a cloud of possibilities loans itself to objectification. "Objectifying acts are not representations". ${ }^{68}$ Objectifying acts are the bodily synthesis of particular clouds of possibilities onto an object-i.e. an object humans can grasp, such as the door knob or the size of a room. The synthesis occurs as an individual intentionally engages with the cloud of possibilities. ${ }^{69}$ Merleau-Ponty argues that the objects individuals engage with are never the entirety its possibilities. ${ }^{70}$ These clouds of possibilities are the building blocks for the human world. ${ }^{71}$

The concept of clouds of possibilities is similar to the concept of an atom. The physical model that represents an atom assumes two parts, one of confinement and the other of possibility:

\footnotetext{
${ }^{64}$ [Merleau-Ponty, 1962, 294]

65 [Merleau-Ponty, 1962, 294] This is opposed to an early use of the word, meaning to analytically or reflectively form an object, in, "my body has its world, or understands its world, without having to make use of my 'symbolic' or 'objectifying function". [MerleauPonty, 1962, 140] I base this interpretation on the context of the text in both locations.

${ }^{66}$ [Merleau-Ponty, 1962, 140]

${ }^{67}$ Consider from the above quotation '... the in-itself, which includes all of them.'

${ }^{68}$ [Merleau-Ponty, 1962, 294]

${ }^{69}$ [Merleau-Ponty, 1962, 233]

${ }^{70}$ [Merleau-Ponty, 1962, 216]

${ }^{71}$ We can grasp the idea of clouds of possibilities by analytical reflection and teasing the concept out from the whole of that which is possible. I employ the metaphor here of building blocks to convey the bodily arrangement of space and not the metaphysical make up of the whole.
} 


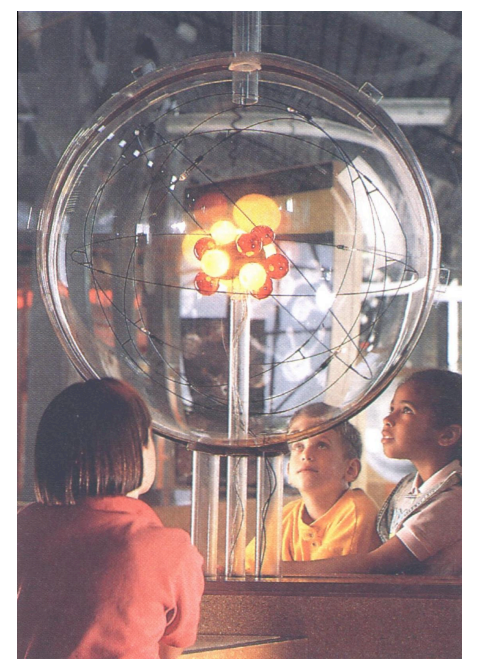

Figure 3.2: J. Boyd Hildebrant's Model of an Helium Atom

One of the reasons for introducing the concept of clouds of possibilities is to draw out the issue of confinement and acknowledge that, even in a metaphysical system centred on human experience, there are limits to what is possible. The limits are independent from human existence. Relating this to the concept of style of cultural skills, one's style effects how the clouds of possibilities show up and then how the individual person renders and and transforms the clouds into determinate objects. In other words, via a style of embodiment, the thinking body engages with the in-itself and from it makes space and elements.

\section{putting it all together}

The composition of a spatial situation occurs when the thinking body synthesis various clouds of possibilities. Consider the human space of a workshopthe adequate lighting, noisy tools, flat and solid bench tops, non-offensive wall coverings, etc. In the workshop I perceive determinate objects and spaces with fixed qualities. As I engage with the situation, the characteristics of the tools and surfaces vary. In this manner the spatial situation which my thinking body is synthesising, adjusts to the varying demands of my project-that is, the spaces and elements adjust to my use of them. ${ }^{72}$ That is to say that, as I go about working on my model, my embodiment and

\footnotetext{
${ }^{72}$ [Merleau-Ponty, 1962, 250, 254]
} 
my engagement with the project create the particularity in which I draw out possibilities, making clouds of determinant tools and spaces. This is logically justified because the block of wood I am working with is understood as independent-of-my-perception-of-it, i.e. as a cloud of possibilities. Merleau-Ponty addresses the make up of the wood as follows:

Every thing appears to us through a medium to which it lends its own fundamental quality; this piece of wood is neither a collection of colours and tactile data, not even their total Gestalt, but something from which there emanates a woody essence [the cloud of possibilities];... the natural world [non-human world], is nothing other than the place of all possible themes and styles. ${ }^{73}$

The piece of wood I engage with exist independently of me as a cloud of possibilities. The thinking body first asserts itself in the non-human world. ${ }^{74}$ Or, as in the previous example, as I work on my model in the workshop, my body initially relates to the clouds of possibilities, and secondly to the forms in which I render those clouds as "verified and full" blocks of wood, hammers, counter tops, personal space, light from the overhead fluorescent lights and so on. ${ }^{75}$ while it is my engagement with the clouds that form the wood or space, it is not the case that my engagement could have made the hammer a cleaver. ${ }^{76}$ The wood may grow heavier and stronger as I nail into it, but it will never become a block of marble, because synthesis is confined to what is, and is not, possible for an independent cloud of possibilities. Thus the, cloud of possibilities which is 'wood', cannot be objectified as 'marble'. ${ }^{77}$ Merleau-Ponty regards this sovereignty of the thing and then argues that thinking body's first asserts itself in the non-human world.. ${ }^{78}$ That is, "only by projecting me in the first place into a natural world which can always be discerned underlying the other, as the canvas underlies the picture and makes it appear unsubstantial". ${ }^{79}$ The thinking body first task is to occupy space within the non-human space of the possibilities of that which is. This non-human space of indeterminate possibilities; it is what affords the determinate space of human space. Considered at an elemental level my bodily habit to reach for the coffee cup

\footnotetext{
${ }^{73}$ [Merleau-Ponty, 1962, 450]

74 [Merleau-Ponty, 1962, 293]

75 [Merleau-Ponty, 1962, 293]

76 [Merleau-Ponty, 1962, 293]

77 [Merleau-Ponty, 1962, 297]

78 "Prior to and independently of other people, the thing achieves that miracle of expression: an inner reality which reveals itself externally, a significance which descends into the world and begins its existence there..." [Merleau-Ponty, 1962, 320]

${ }^{79}$ [Merleau-Ponty, 1962, 293]
} 
(a skill of the thinking body) makes determinate the indeterminate possibilities of the coffee cup. ${ }^{80}$ It is the when intentionality engages with the coffee cup, the non-human possibilities of the coffee-cup become "verified and full ${ }^{\prime 81}$ or determinate and rich in sensual detail. ${ }^{82}$

The act of synthesising is not the synthesis of ready-made objects. ${ }^{83}$ Merleau-Ponty's analysis of this synthesising act is of an active engaging with the totality of possibilities rather than of ready-made objects. In other words, it is not the act of walking into a room, and acknowledging the table, the light and the rug, and then fusing these objects into the space of a room. Such a rendering of the phenomenon underestimates the individual's influence in the situation. Likewise, Merleau-Ponty's theory of bodily synthesis is not the unification of design elements. For instance, when I approach a house, I tend to notice the door, the window colours, etc., and the thinking body's act of synthesis is not the act of composing these elements. This would be an example of an analytical act of intentionality. The thinking body performs the synthesis of sensory information prior to any analytical reflection of that sensory information. The thinking body synthesises the possibilities of the door, and renders the door in a certain fashion for my body-e.g. as affording my entrance, welcoming, smooth, heavy, creaky... and so on.

In contemporary philosophy there is a classic thought experiment that questions the existence of 'the tree in Siberia'; if there is no one to see the tree, does it exist? Some theories lead to claims that the tree would not be there if no one perceived it. ${ }^{84}$ Other theories lead to claiming that the tree is always there, with all the qualities just as they would be if someone

\footnotetext{
${ }^{80}$ Merleau-Ponty covers this with an example of the ashtray. "The significance of the ash-tray... is not a certain idea of the ash-tray which co-ordinates its sensory aspects and is accessible to the understanding alone, it animates the ash-tray, and is self-evidently embodied in it". [Merleau-Ponty, 1962, 329]

${ }^{81}$ [Merleau-Ponty, 1962, 329]

${ }^{82}$ This makes way for an explicit picture of how the thinking body engages with the initself and makes space. Merleau-Ponty maintains that, engagement with a situation "is this opening upon a world which makes possible perceptual truth" and determinate objects. [Merleau-Ponty, 1962, 297], emphases my own. Determinate objects can be understand as objects affording truth qualifications. Human engagement with the in-itself opens a spatial situation composed of determinate objects-i.e. objects that can be grasped and possessed by humans.

${ }^{83}$ “The world around us must be, not a system of objects which we synthesize but a totality of things, open to us, towards which we project ourselves". [Merleau-Ponty, 1962, 387]

${ }^{84}$ Idealism, as in based on Ideas. The most classic Idealist being George Berkeley, who eventually wiggled his way out of this one by claiming that God sees the tree, so its always there.
} 
was perceiving the tree. ${ }^{85}$ For Merleau-Ponty, the tree would exist as the cloud of possibilities-indeterminate. And only as someone perceived and engaged with the tree, would the richness of it sensual qualities become determinate. ${ }^{86}$

\section{the architect's possibilities}

Applying Merleau-Ponty's theory of embodied synthesis to the discipline of architecture results in understanding the designer's influence over space as ambiguous, and renders the potential richness of designs as exponentially complex. The architect's control of the constructed spatial situation is more ambiguous in comparison to the conventional conception of architects as installers of a certain experience of a space, and the phenomenological qualities of designed space are not determined by the designer. Instead, the individual's engagement with the space draws out the richness of experience. Architecture provides the building blocks with which to make the space, and the individual's engagement with the situation provides the tools. This understanding of what it is to be human entails a perspective change with regard to architecture's engagement with its jurisdiction.

Ambiguity here is due to the inevitability that an architect is an embodied being, and as such his thinking body draws on the independent clouds of possibilities and synthesises the objects and spaces he engages with. Hence an architect chooses between objects and spaces that he has made determinate. But these objects and spaces are independent of him, and hence when he utilises the determinate objects in designs, he is in fact employing the indeterminate clouds of possibilities rather than the objects and spaces his bodily intentionality has made determinate. The following is a series of drawings that picture the relationship between the architect, clouds of possibilities, objects and users:

\footnotetext{
${ }^{85}$ This would be Realism, where people directly perceive objects as brute facts. John Searle is a famed believer in brute facts.

${ }^{86}$ It is feasible to argue that should a beetle be on the tree in Siberia, the possibilities of the tree would be rendered in regards to the beetle's embodiment. I imagine the qualities of the beetle's tree are be very different than the tree I would engage with and that what it is like to be a beetle is as unimaginable to me, as what it is like to be a bat. However for further study of this topic see Thomas Nagel's What is it like to be a bat? [Pojman, 2004, 303]
} 


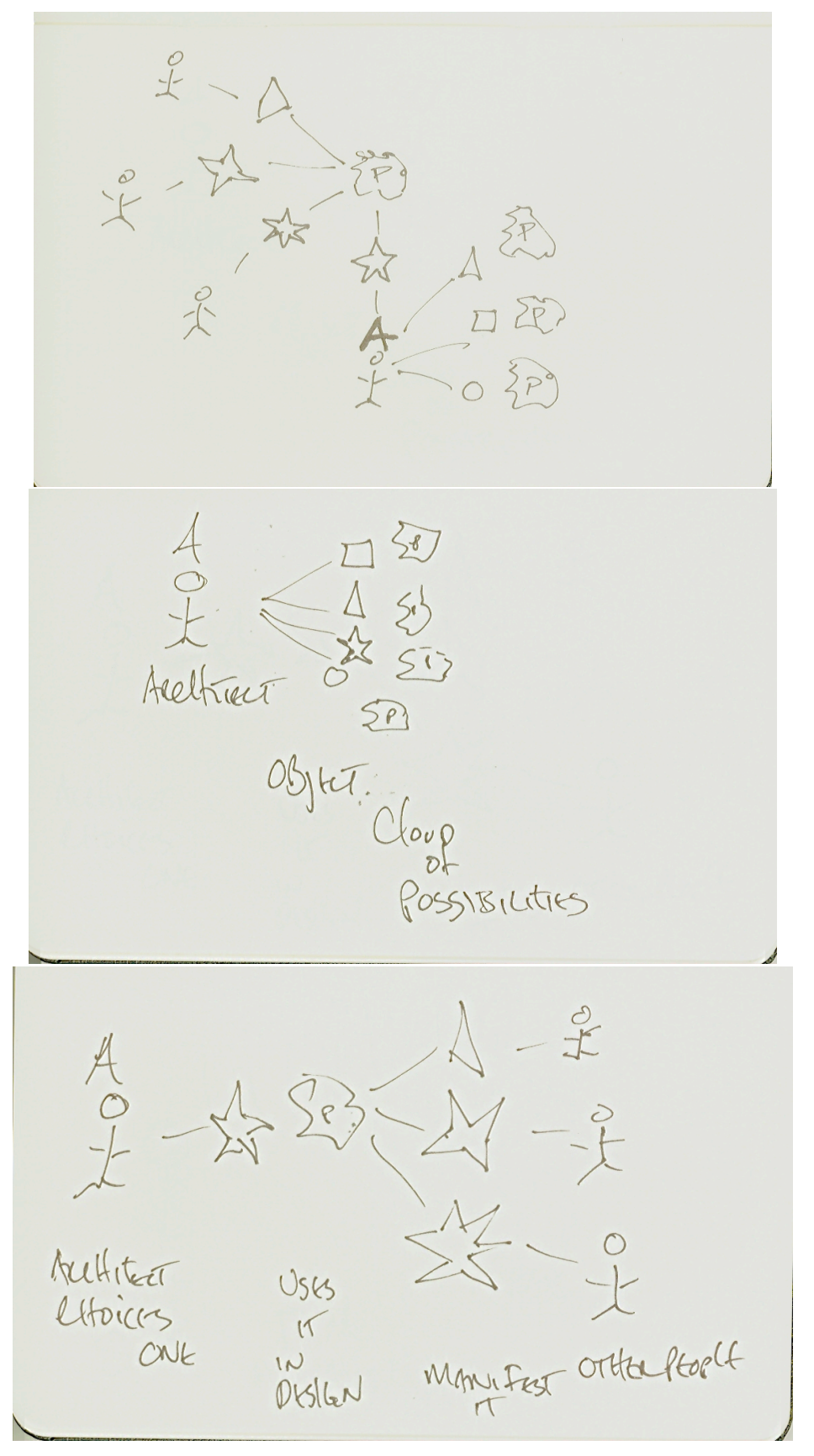

Figure 3.3: Working hand drawing 
If we compare the idea to the clouds of possibilities, we can then account for how different people have slightly different understandings of an object, material, or spatial situation. An architect does not have a privileged relationship with the clouds of possibilities, but has a different style of embodiment, due to their disposition and training, which can develop greater understanding of experiential links. For example, architects could be trained to widen their range of embodiment - for a greater understanding of the effects designs can have on different people. Architects could also expand the style of their own embodiment - for a greater understanding of the reach their spatial practices. This would increase architects' awareness of the causal links that other people employ in experiencing their designs, as the users or other people with other styles and render the space in accordance with their individual embodiment. ${ }^{87}$

A brief example. When designing a wall, an architect decides on the character of the wall as she engages with its determinate qualities. Perhaps she elects the solid smooth finish of stained concrete, a tall arch and an absence of edging details with the floor and the ceiling. Analytically, the architect engages with the wall as a solid division of private spaces and a smooth surface that avoids the collection of dust and signs of wear. However, the wall that is constructed is more than the summation of the qualities that the architect analytically understands, because the wall exists independently as a cloud of possibilities. Hence when different users of the design engage with the wall, different experiences of the physical qualities of the wall become determinate. For example, the experience of a softness associated with the smoothness, or an entrapment associated with the use of concrete in prisons, or a banality or familiarity coming from the height, or a loudness coming from the hard surface, or a coldness coming from the absorbent nature of concrete or a coolness or a heaviness and helplessness coming from the strength of the wall. Additionally, and perhaps more interestingly, less psychological qualities of the wall may become manifest; such as, the more physical properties of height, colour, temperature. Ryo Hatano describes his experience of a concrete wall designed by Kiyoshi Takeyama for the D-Hotel in Osaka in yet another light. He writes:

The fair-faced concrete which forms huge wall which drew the arc gently serves as an overwhelming lump, and a feeling of coercion is given to what is seen. Isn't that because it is demonstrated in order that weightiness, density, etc. which concrete has may resist the maximum to a city? ${ }^{88}$

\footnotetext{
${ }^{87}$ Further analysis of this concept is carried out in the fifth chapter.

${ }^{88}$ [Tak, , - ]
} 
The various styles in which the individual thinking body engages with the wall contributes to the overall composition of the space and influences an individual's overall experience of the space. While the system of embodiment does afford cultural influences, rendering space is not simply a matter of psychological associations or memories. The metaphysical structure of the thinking body engaging with independent possibilities proposes a radically different view compared with the more dominant Cartesian or the "post-Galilean view, which conceives of the physical body as a machine and as a subject of mechanical laws". ${ }^{89}$

\subsection{Conclusion}

In the act of embodied being the individual synthesises particular possibilities and draws out from that-which-could-be-the cloud of possibilities-a unified system of that-which-is-experienced or that-which-I-percieve-myworld-to-be. The intentionality of reflection composes the world of thoughts - dreams, futures, art, politics, logic, and impossibilities such as unicorns "from which the great poetry of our world is ma[d]e up". .90 The intentionality of the thinking body arranges the physical space and manifests the architectural qualities that surround it - the heat of a fire place, the strength of a wall, the size of a window, the desirability of a doorway, the darkness of a hallway, the softness of driftwood, or the brittleness of a brick wall.

These elements of the world are not solely constructed by the individual because they are working with the materials of that-which-is-independent of the perceiver. Or, as Merleau-Ponty explains: "prior to and independently of other people, the thing achieves that miracle of expression". ${ }^{91}$ This claim asserts an understanding of the actions of the human body as creating the space in which it exists from the independent and thereby indeterminate clouds of possibilities. The architect's responciblity is to act on those possibilities.

The phenomenon that Merleau-Ponty is reaching for is the fundamental metaphysical act of being. He regards ideas as having "philosophical value" only when they are able to "teach us anything concerning the structure itself of consciousness". To not have philosophical value is to "present us merely with contents of human experience".$^{92}$ Merleau-Ponty seeks to

\footnotetext{
${ }^{89}$ [Imrie, 2003, 47]

${ }^{90}$ [Merleau-Ponty, 1962, 321]

${ }^{91}$ [Merleau-Ponty, 1962, 320]

92 [Merleau-Ponty, 1962, 288]
} 
understand how it is that I find this world as such, with its warm, solid, grey ground, and a feeling that there is a past to my life and this space, within which I, myself, decide to walk, that I know the ground will support my mass, or that I can observe causal connections and interject within their processes. He questions how it is that I have come to be here and now, and in a situation that seems slightly different, but not altogether conflicting with the experience relayed by another.

A fundamental act of synthesis is at the centre of Merleau-Ponty's explanation of how ' $\mathrm{I}$ ' come to find myself in a world rich in spatial possiblitities. ${ }^{93}$ This act is the employment of intentionality, and intentionality is always directed at something. To understand the phenomenon of synthesis more easily, Merleau-Ponty introduces two modes of intentionality: one that is performed by the body, and one that is executed by the mind. The main difference between these intentionalities is the act of reflection. The bodily intentionality does not abstract the decision from the flow of engagement with a situation. However, analytical intentionality halts engagement with a situation to reflect and make decisions. The occupation of both intentionalities is the act of drawing out particular possibilities and solidifying those elements for finite periods of time. This is the act of making space.

\footnotetext{
${ }^{93}$ [Merleau-Ponty, 1962, 387] Again this is not the detached Kantian synthesis, but rather is an embodied synthesis.
} 


\section{Chapter 4}

\section{An Enquiry into a Prior Translation of Merleau-Ponty's Philosophy into Architectural Theory}

In contemplating the value of phenomenology for architecture I have come to believe that it can provide a framework that connects and strengthens the architect's intuitive approach to human experience of space, with the theorist's more reflective or critical approach. As phenomenology is embedded within the discipline and history of philosophy, its readers are required to employ particular methods and assumptions. The challenges of these particularities often lead to misinterpretations of primary philosophical text. In this chapter I argue that Juhani Pallasmaa's theoretical undertaking to expose architects to Merleau-Ponty's understanding of space fails to incorporate the philosophy's key premises. ${ }^{1}$

If architecture is to benefit from the phenomenological research of MerleauPonty then a logical starting point is to clarify how the leading architec-

\footnotetext{
${ }^{1}$ My critique of Pallasmaa's theory is limited to his account of the human experience of space, in particular his rendering of Merleau-Ponty's philosophy. As an aside, I acknowledge that Pallasmaa is an accomplished and "esteemed" architectural writer and critic, and has been praised by Timo Kiukkolar as, "Juhani Pallasmaa is a phenomenon!". [MacKeith, 2006, 8, 11] Respectively.
} 
tural Merleau-Ponty theorist, Juhani Pallasmaa, translates philosophy. ${ }^{2}$ As examined in chapter one, Pallasmaa critiques contemporary architecture as being retinal-centric. Pallasmaa's reasoning for seeking a new design criteria is based on an analysis of architecture as inadequately engaging with the human body. Pallasmaa's critique of architecture is positioned in line with the other theorists surveyed in my first chapter; i.e., Christian Norberg-Schulz, Rob Imrie, Alberto Pérez-Gómez, Vittorio Gregotti, Elizabeth Grosz, Henri Lefebvre and David Krell. ${ }^{3}$ In response to this critique, Pallasmaa proposes a new design criteria described as a phenomenology of architecture. ${ }^{4}$ He successfully offers architecture an initial gesture towards Merleau-Ponty. ${ }^{5}$ However, in this chapter I argue that Merleau-Ponty's and Pallasmaa's structures of the human experience of space are incompatible.

Herein lies the problem; architecture merits an accurate rendering of Merleau-Ponty's theory, Pallasmaa claims to provide it, yet his account fails to incorporate Merleau-Ponty's key concept of a non-reflective intentional body that engages with indeterminate possibilities, to make determinate spatial situations. In other words, Pallasmaa's theory ignores the thinking body and works with an account of human spatial experience that is incompatible with Merleau-Ponty's. Pallasmaa's interpretation leads to a superficial set of phenomenological design criteria that promote an architectural engagement with the senses of the human body, rather than MerleauPonty's thinking body. ${ }^{6}$

\footnotetext{
${ }^{2}$ [MacKeith, 2006, 92] Additionally, Juhani Pallasmaa's career ranges from practitioner, lecturer, writer to theorist. [MacKeith, 2006, 8] In the publisher's note to a collection of essays celibrating Pallasmaa's 70th Birthday, Gunnel Adlercreutz notes "he has received innumerable prizes and awards for excellence in architectural design and in architectural criticism." He trained in the technical field of architecture in the mid-1950s and began publishing essays in the late 1960s [Pallasmaa, 2005a, 11]. In the 1970s, a trip to Ethiopia "disillusioned" Pallasmaa's "faith and confidence in rationality". [Pallasmaa, 2005a, 17]. He has since examined other fields to provide support for a new architectural theory [Pallasmaa, 2005a, 18]. His 1996 book, The Eyes of the Skin established Pallasmaa as a leading Architectural theorist of Merleau-Ponty and has sought to emphasis the metaphysical experience of space and architecture. [MacKeith, 2006, 220]

${ }^{3}$ [Pallasmaa, 2000, 2], [Pallasmaa, 1994, 16] Refer to sub-section 1.1.1 for further analysis.

4 [Pérez-Gómez and Parcell, 2004, 143]

5 [Pallasmaa, 2005a, 59], [Pallasmaa, 2005b, 4], [Pallasmaa, 2000, 2], [Pallasmaa, 1996, 31] and 1999 article, Lived Space [Pallasmaa, 2005a, 129]. Additionally, Pallasmaa introduces some of Merleau-Ponty's terminology, i.e. the "flesh" [Pallasmaa, 2005b, 5], [Pallasmaa, 2005a, 59] and "body scheme" [Pallasmaa, 1991, 46] In Merleau-Ponty's final incomplete work The Visible and the Invisible, he intrudes an understanding of the totality of that which exist and dubs it the flesh.

${ }^{6}$ [Pallasmaa, 2000, 85]
} 


\title{
4.1 Exhibiting Pallasmaa's view
}

For comparison, consider the follow two essences of how human bodies experience space:

\author{
Merleau-Ponty's implicit structure: \\ (BODILY INTENTIONALITY)(SYNTHESISES)(CLOUDS OF POSSIBIL- \\ ITIES) \\ Pallasmaa's structure: \\ (A MODE OF ANALYTICAL INTENTIONALITY)(SYNTHESISES)(COLLECTION \\ OF SENSE EXPERIENCES)
}

These two accounts of the human experience of space are incompatible. This is in part due to Pallasmaa's failure to distinguish the two modes of intentionality. Without this distinction, Pallasmaa works only with a muddled version of analytical intentionality and some lingering notion of the subconscious. In this section I argue that, for Pallasmaa, the experience of space occurs by the act of analytical intentionality synthesising the collective experiences of the senses.

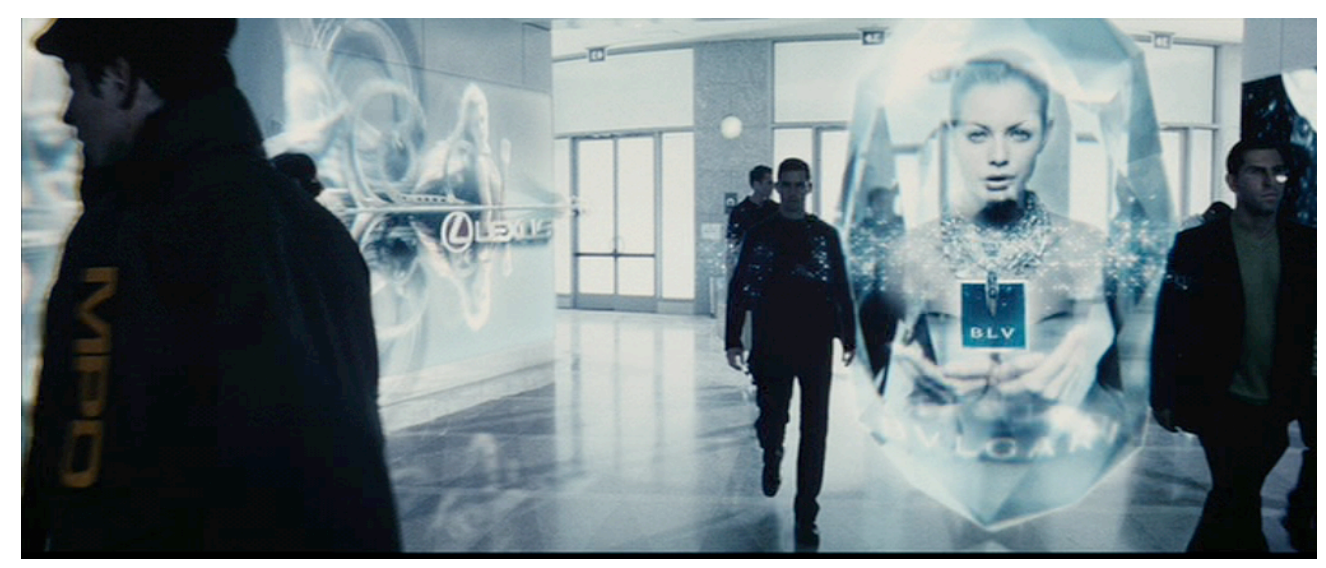

Figure 4.1: Steven Spielberg, Minority Report, 2002 


\subsubsection{Muddled; the two modes of intentionality}

Merleau-Ponty's account distinguishes two modes of intentionality in which human beings engage with their surroundings. ${ }^{7}$ This distinction is necessary to reach Merleau-Ponty's rendering of human experience. Pallasmaa's writings reveal a confusion between these two modes of intentionality. Sometimes Pallasmaa accounts for the experience of space with the notion of the imagination or a consciousness, as in this example of the nightscape of a city:

One who has half-risen to the sound of a distant train at night and through this sleep, experienced the space of the city with its countless inhabitants scattered around its structures, knows the power of sound to the imagination; the nocturnal whistle of a train makes one conscious of the entire sleeping city. ${ }^{8}$

At other times, Pallasmaa uses the term mind to engage with the experience of space. Writing:

We need an architecture that does not aspire after the dramatic, but rather aims at lyricising the real things of everyday life. We yearn for radical ordinariness and mundanely, a natural architecture of the type that fills our minds with good feelings when we enter an old peasant cottage or sit upon a Shaker chair. ${ }^{9}$

Moreover, the poetry of Pallasmaa's writing style can lend itself to understanding the mind as a non-reflective intentionality such that, in the passage, the mind feels good by means of how it engages with the peasant cottage. ${ }^{10}$ This passage can, however, equally lead to understanding the mind as a faulty that reflects to itself 'this feels good'.

We are again confronted with the indistinction between mind and body perceiving the world in the following excerpt, where Pallasmaa expresses the phenomenological quality of the interwoven existence of a person and space:

\footnotetext{
body.

${ }^{7}$ The analytical intentionality of the mind and the bodily intentionality of the thinking

[Pallasmaa et al., 2006, 30]Emphasis my own.

9 [Pallasmaa, 1991, 3]

10 [Pallasmaa, 1991, 3]
} 
Place and event, space and mind, mutually define each other and fuse inevitably into a singular experience. The mind perceives the world and the world exists through experience. Experiencing a space or a house is a dialogue, a kind of exchange: I place myself in the space and the space settles in me. ${ }^{11}$

This passage draws on the phenomenological notion that an individual creates the space around himself and the space around him influences that process of generation. Pallasmaa incorporates the "mind" into the experience of space at the fundamental level of being-in-the-world. ${ }^{12}$ In Pallasmaa's account, the mind acts as fuser of individual's experiences of the world and the world engages with the individual through a set of sensory experiences affecting the mind. In other words, analytical intentionality is used to synthesise a collection of sense experiences.

Pallasmaa identifies good architecture as what he calls "life-enhancing" architecture, he claims that it must address the "senses" and that the architect must "fuse our image of self with our experience of the world." ${ }^{13}$ In this account, architecture is the actor that fuses a self image with an experience of the space. Moreover, this entails that the image of the self contributes to the experience of the space. The image of self appears again as Pallasmaa discusses the phenomenological thesis of being-in-the-world: ${ }^{14}$

Architecture articulates the experiences of being-in-the-world and strengthens our sense of reality and self; it does not make us inhabit worlds of mere fabrication and fantasy. ${ }^{15}$

Whether or not this is analytical reflection remains unclear, but it is certain that there is no argument being made for a phenomenological, nonreflective, bodily intentionality.

Deficiencies in Pallasmaa's philosophical understanding additionally surface when he endeavours to phenomenologically describe the experience of space:

\footnotetext{
11 [Pallasmaa, 2005a, 61]

12 [Pallasmaa, 2005a, 61]

${ }^{13}$ [Pallasmaa, 2006, 2] "It is evident that 'life-enhancing' architecture has to address all the senses simultaneously and fuse our image of self with our experience of the world."

${ }^{14}$ As noted perviously, I have chosen to avoid philosophical jargon throughout this thesis. The phrase being-in-the-world here is due to Pallasmaa's use of it. I have used words such as engaging with space or a spatial situation.

15 [Pallasmaa, 2006, 2] Emphasis my own.
} 
I can say that for me the strongest experience of a warm, intimate and protective interior space is the sight of a house with lit windows in the evening dusk of a snow-covered landscape. This is space experienced through the cells of the skin. ${ }^{16}$

Pallasmaa's characterisation renders the cells of the skin as something that feel and receive but do not influence the space. Underlying this depiction is the assumption of the separation between observer and world, of which the skin is the boundary. Merleau-Ponty would interpret the experience as manifesting the intentionality of the thinking body. Contrarily, Pallasmaa suggests the experience takes root in a manifold of sensory parts-one of which is skin cells. Likewise, in the following passage, the feeling on the skin must be "recognize[d]" by the "I" to be felt: ${ }^{17}$

The details of the roofs or hearths of the familiar buildings of my childhood have escaped from my memory, but I still recognize the pleasure on my skin when hearing the beating of rain under a sheltering roof... ${ }^{18}$

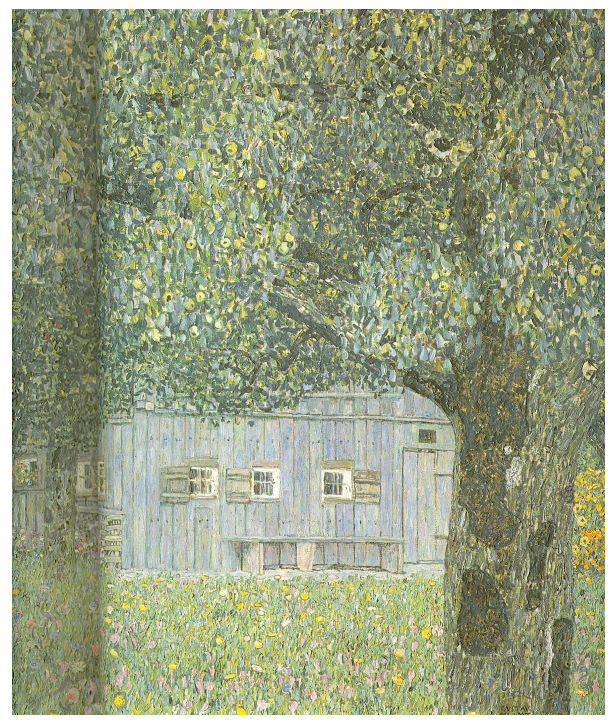

Figure 4.2: Gustav Klimt's Pine Forest (Forest of Firs I) (1902)

\footnotetext{
16 [Pallasmaa, 1991, 45]

${ }^{17}$ [Pallasmaa, 2005a, 92]

18 [Pallasmaa, 2005a, 92] Emphasis my own.
} 
In the following passage I attempt to provide a first-person description draws attention to the difference between Pallasmaa's and Merleau-Ponty's account, by emphasising different aspects of the experience of approaching a cabin in the woods. ${ }^{19}$ In this depiction bodily intentionality, and analytical intentionality, are differentiated and the act of recognition plays no role in the bodily engagement which determines the spatial situation. ${ }^{20}$ This is an experience where the familiarity of past moments are irretrievably intertwined with a current physical state:

A state of well worked limbs, an active heart rate, a raised body temperature, the isolation of wondering about the dappled moon light through still life stretching upright far past my reach, and as I come to identify the amber light, as someone that can talk with me and I quietly pause to take in the new possibilities, and the warmth gained by my movement dissipates into the night's air, it's become clear that a choice needs to be made and I find myself standing on the cusp of the woods staring at a strangers window, cool from the indecision of my thinking body that forwarded the options to my reflective, analytical intentionality.

The consciousness of the thinking body guided the individual through the woods, rendered the night sky clear, the trees tall, weaved the body through their girth, and brought me to pause at the edge. It is also what alerted my analytical intentionality to the situation of choosing to engage with whomever may be awaiting my appearance in that isolated cabin. ${ }^{21}$

Comparing the two style of phenomenological description reveals that Pallasmaa does not distinguish between modes of intentionality. Pallasmaa's description postulates a separate entity that is called the "cells of the skin" which take in an emotional situation, but does not effect how that situation is perceived. ${ }^{22}$ The lack of distinction between the thinking body and the thinking mind leads Pallasmaa to claim that it is an act of the mind perceiving the world that creates the experience of space.

\footnotetext{
${ }^{19}$ [Merleau-Ponty, 1964, 153]

${ }^{20}$ Description, my own.

${ }^{21}$ Description, my own.

22 [Pallasmaa, 1991, 45]
} 


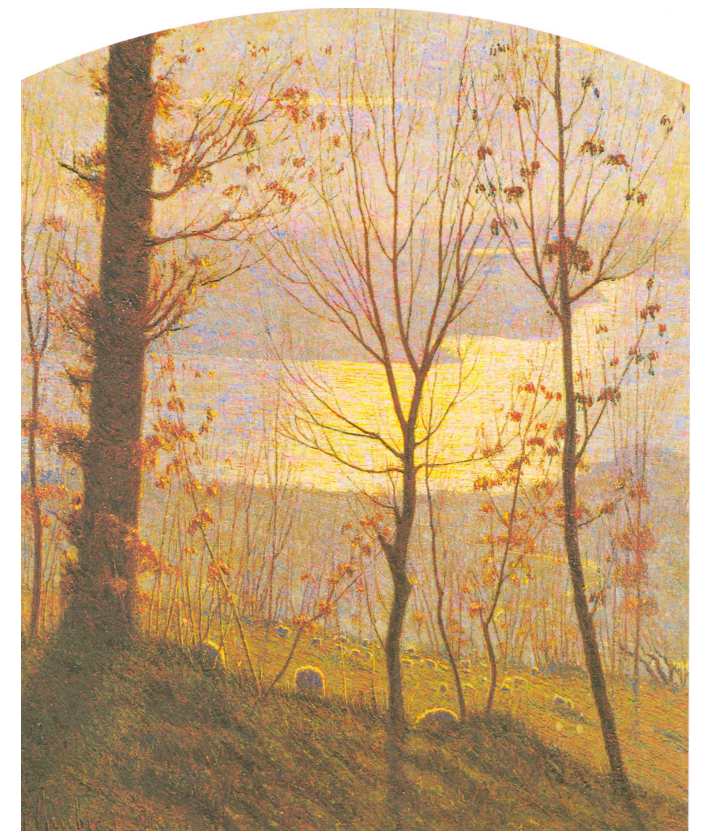

Figure 4.3: Vittore Grubicy De Dragon, Winter (Inverno), 1898

\subsubsection{The matter of the sub-conscious}

Lingering in Pallasmaa's metaphysics are notions of the "subconscious" and "unconscious". ${ }^{23}$ This leads to further ambiguities when rendering the phenomenon of experiencing space. Importantly, Merleau-Ponty explicitly rejects the concept of the sub- or unconscious because it assumes a bracketing-off of human experiences, that, in turn, postulates the existence of experience that are as inaccessible to the human experience of them, i.e. experiences that are in-experience-able. Pallasmaa evokes the imagery of an unconscious experience in writing: "Touch is the unconsciousness of vision..." 24 He portrays the tactile qualities of an object being "unconsciously" perceived through vision. His observation of the phenomenon are in accord with Merleau-Ponty's account of cross-sensory experience, i.e. "synaesthetic perception". ${ }^{25}$ However, Pallasmaa's account diverge because the individual lacks accessibility to the experience and participation of the body.

\footnotetext{
${ }^{23}$ [Pallasmaa, 2007, 7], [Pallasmaa, 1994, 4], Receptively.

${ }^{24}$ [Pallasmaa, 2005b, 10]

25 [Merleau-Ponty, 1962, 229]
} 
In another passage Pallasmaa additionally falls short of classifying the phenomena:

In environmental experience there is an unconscious bodily identification with the object, a projection of the body scheme onto what is experienced, or a physical mimesis, an unconscious mimicry. ${ }^{26}$

Merleau-Ponty does employ the notion of a "bodily scheme" or "body image" as an element of embodiment, of particular relevance to basic general skills. ${ }^{27}$ The body scheme is how the thinking body conceives itself. ${ }^{28}$ If I engage with spatial situations with a walking cane, or eyeglasses, then my thinking body will account for these tools as part of my body; thereby the body scheme is the physical body and the tools that are intimately employed when engrossed with the world..$^{29}$

In recent Merleau-Ponty scholarship the issue of Mirror Neurones has become popular. ${ }^{30}$ Mirror Neurones were discovered by the "Italian neurophysiologist, Giacomma Rizzo-latti [who] found that certain cells in monkey frontal lobes respond to specific actions not only in the subject, but also when the subject observes another perform that same action". ${ }^{31}$ This is an instance where scientific neurological research supports Merleau-Ponty's observations of the phenomena regarding the thinking body's reaction to people. However, this mimicry is an exchange between two living beings and acted out by the thinking body. Pallasmaa's proposition confuses two separate elements of scholarship of Merleau-Ponty theory; that is how the body sees itself through embodiment (i.e. body scheme), and how the body learns through other living beings (i.e. motor neurones).

In the above passage addressing "unconscious mimicry", Pallasmaa again advances the notion of the unconscious which Merleau-Ponty's rendering of human consciousness does not afford. ${ }^{32}$ Postulating a subconscious entails a stream of reflective and detached judgements that the individual has no access to, but none-the-less effects the individual. Contrarily, phenomenology is the study of experience with the maxim; do not create back stories of how things work because looking at the experience itself

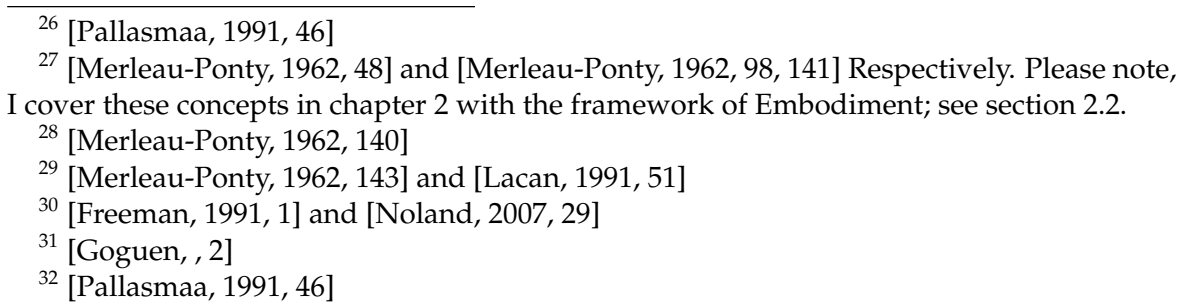


provides enough richness for explanation. ${ }^{33}$ This hinges on the notion that the sub-conscious is not experience-able, but the thinking body is. While in the flow of engaging with a situation, an individual might not be saying to himself-wow, I'm really cooking now-but the individual still experiences the act of engaging with the situation and has access to that experience. Even if that access is bodily and not reflective, there is still access. Merleau-Ponty summarises this as: "Consciousness is neither the positing of oneself, nor ignorance of oneself, it is not concealed from itself..." meaning that no elements of consciousness are inaccessible to the individual experiencing them. ${ }^{34}$ Merleau-Ponty writes: "In this sense there is no unconscious." ${ }^{\prime 35}$ In this way he rejects the characterisation of unconscious concept.

Philosophical theorist David Pettigrew claims that this "'de-entification' of the unconscious... evokes a motif that lies at the heart of Merleau-Ponty's project" ${ }^{36}$ Dismissing the unconscious and establishing the thinking body works symbiotically; weighting the emphasis on the negative argument however, neglects Merleau-Ponty's project of phenomenologically studying the experience of the body to find out "anything concerning the structure itself of consciousness". ${ }^{37}$ Merleau-Ponty's aims at demonstrating structures rather than demolishing obsolete ideas.

Because Pallasmaa fails to distinguish the two modes of intentionality he only works with a vague notion of analytical intentionality. For him, the experience of being in space requires a reflective and mindful synthesising faculty rather than a bodily synthesising faculty. This interpretation of the phenomenon also ignores the participatory aspect of the thinking body. For Pallasmaa, the human being takes in sensory data, synthesises that data, and creates the experience of space. For Merleau-Ponty, the thinking body intentionally draws from clouds of possibilities to render objects determinate for a finite span of time. In Merleau-Ponty's theory, the act objectifies indeterminate possibilities; the body draws out from that which could be, to make that which is, making a rich and solid spatial situation while it goes about its way. ${ }^{38}$

\footnotetext{
${ }^{33}$ [Merleau-Ponty, 1962, 243]

34 [Merleau-Ponty, 1962, 296]

${ }^{35}$ [Merleau-Ponty, 1962, 296]

${ }^{36}$ [Olkowski and Morley, 1999, 58]

37 [Merleau-Ponty, 1962, 288]

${ }^{38}$ See section 3.3 for further discussion.
} 


\subsection{Collection of sense experiences}

The strategic importance of these different accounts emerges when projecting their implications for designed space. Pallasmaa points to an architecture that prioritises sensory experiences synthesised by the mind. The design focus of Merleau-Ponty leads the architect to consider the continuous process of creating spatial situations through the interaction of the thinking body and that-which-is-independent-of-it. One account shifts the design emphasis from catering to the eye, to catering to the five senses, while the other radically alters the structure of the conventional mind/ body hierarchy. ${ }^{39}$

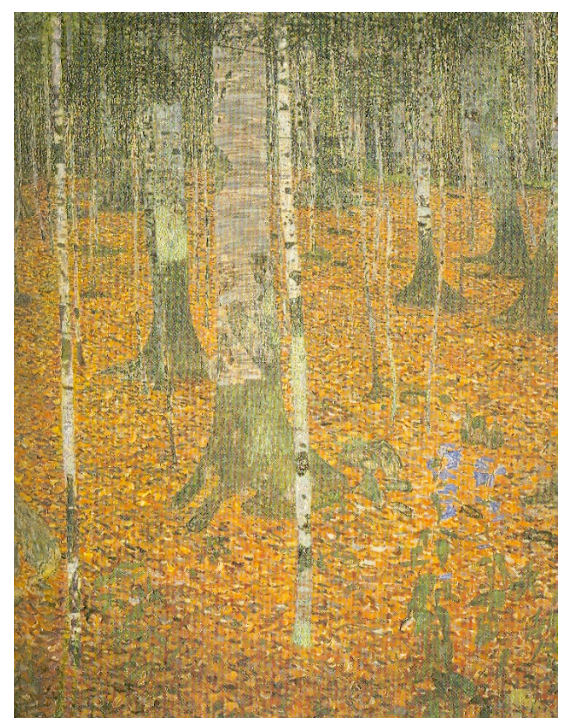

Figure 4.4: Gustav Klimt, Beech Forest (1903)

The weight of his proposition leans on the collaboration of the eye with the body. He claims architecture is the continuation of the healing nature of the forest, into the urban realm; and therefore the multi-sensory qualities of the forest should be regenerated in design. He additionally asserts the priority of the senses with the claim, "every touching experience of architecture is multi-sensory: qualities of space are measured equally by

\footnotetext{
${ }^{39}$ [Pérez-Gómez and Parcell, 2004, 158], [Pallasmaa, 1996, 24] “A walk through a forest is invigorating and healing due to the interaction of all sense modalities... The eye collaborates with the body and the other senses. One's sense of reality is strengthened and articulated by this interaction of the senses. Architecture is essentially an extension of nature into the man-made realm..." [Pallasmaa, 1996, 28]
} 
the eyes, ears, nose, tongue, skin, and muscles". ${ }^{40}$ Pallasmaa's theory understands the engagement of the body with space as an intermingling of the sensory faculties. While this is an adequate retort to his critique that, "architecture has distanced itself from other-sense realms and become a purely retinal artform", it is not a reasonable insight to gain from MerleauPonty's phenomenological theory. ${ }^{41}$ Finally, when Pallasmaa questions the metaphysical state of experiencing space and the architectural means for harmonising with it, he asks:

The art of architecture is engaged with metaphysical and existential questions concerning man's being-in-the-world... The task of architecture is to make visible how the world touches us, as Merleau-Ponty said of the paintings of Paul Cézanne. ${ }^{42}$

He provides his own answer ten years later in a retrospective article writing: ${ }^{43}$

With the title The Eyes of the Skin, I wished to express the significance of the tactile sense for our experience and understanding of the world, but I also intended to create a conceptual short circuit between the dominant sense of vision and the suppressed sense modality of touch. Since writing the original text I have learned that our skin is actually capable of distinguishing a number of colors; we do indeed see by our skin. ${ }^{44}$

We can conclude that Pallasmaa has accomplished an introduction of phenomenology to architecture. Yet, metaphorically speaking, he has introduced the new party guest with the correct name, but the wrong pronunciation. That is, when Pallasmaa employs Merleau-Ponty's research to justify his new design criteria for architecture, he gives a false impression of adequately providing architecture with a translation of Merleau-Ponty's phenomenology of the human experience of space.

\footnotetext{
${ }^{40}$ [Pérez-Gómez and Parcell, 2004, 158]

41 [Pallasmaa, 1994, 16]

42 [Pallasmaa, 1996, 31] Analysis is devoted to the implications of this association between Cézanne's paintings and the possibilities of architecture in the conclusion. See section 6.4 for consideration of architecture as art.

${ }^{43}$ Ten years later, Pallasmaa review his earlier work in an article titled: Eyes of the Skin: Architecture and the senses [Pallasmaa, 2006, 1]

${ }^{44}$ [Pallasmaa, 2006, 2]
} 


\subsection{Conclusion}

Pallasmaa identifies a deficiency in contemporary architecture's ability to create spaces that appeal to senses other than the eye. He suggests that architecture is retinal-centric. Drawing on Merleau-Ponty's research, Pallasmaa asserts that the experience of space, is more than the viewing of space, but clings to the need for an ' $I$ '. Pallasmaa's understanding of the experience of space postulates a central processing faculty to organise the five forms of sensory experience. He refers to this synthesising faculty as the "mind" or the "image of self". 45 By necessitating a faculty for reflective thought for the experiencing of space, Pallasmaa stands in immediate opposition to Merleau-Ponty's reasoning that the human experience of space is non-reflective being-in-the-world; that is, the continuous engagement of the thinking body. In other words, rather than fundamentally altering the conventional architectural understanding of human experience, Pallasmaa's account merely shifts the design emphasis from catering to the eye to catering to the five senses, while maintaining the dominance of the mind over the body.

\footnotetext{
${ }^{45}$ [Pallasmaa, 2005a, 61] and [Pallasmaa, 2006, 2], respectively.
} 


\section{Chapter 5}

\section{The Thinking Body in Built Architecture}

In the preceding chapter I argued that designing for the phenomenological body is not just about catering to the senses. This is because the body is capable of a non-reflective synthesis of sensory information, before the information engages the analytical intentionalities of the mind. In this chapter I explain what it might mean to design architecture that is sympathetic to the thinking body. I illustrate with a pair of contextual design solutions catering to the thinking body by studying three architectural volumes. I examine the architectural volumes of the entrance, a corridor and the window in three buildings by Carlo Scarpa. Scarpa's work is especially relevant due to the quality George Dodd's described as, "not about the body-as-object or the body-as-other; it is about how our bodies, not simply as sensing organs or viewing devices, but as sentient being fully engage in culturally specific constructs". ${ }^{1}$ Of the many constructions Scarpa completed I will consider the corridor space of the Castelvecchio Museum, an interior room of the Museo Canoviano, and the entrance space of the Querini Stampalia Foundation.

The contextual design solutions are drawn together from my prior analysis of Merleau-Ponty's implicit structure of the human body's experience of spatial situations. Through that analysis I concluded that there exists an intentional bodily flow of movement in space and a synthesis of possibilities into determinate objects. Taking these findings I propose that by

\footnotetext{
${ }^{1}$ [Dodds and Tavernor, 2002, 256]
} 
providing spatial affordances and veritable causal connections architects can forge ways towards catering for the thinking body.

In this chapter I first account for not simply taking the conclusions from the previous chapters to critique how well built examples manifest Merleau-Ponty's theory. I proceed describe why I chose to study the work of Carlo Scarpa. I go onto to introduce the pair of contextual design solutions by examining three constructed volumes. Each of the volumes could be employed to demonstrate both design solutions. However for clarity, my structure for examining the architectural spaces is tripartide. I pair my discussion of the corridor with the solution of spatial affordances. I pair the interior room with my concept of veritable causal connection. Finally, I further bring out the ramifications of designing veritable causal connections by explaining what not to do, through pairing the entrance with the new concepts of object façadism and analytical exercises.

\subsection{Why not a pure critique of a phenomenological ar- chitect?}

The American architect Steven Holl comes closest to the label of 'phenomenologist architect'. Holl's architecture has been noted as, "fundamentally... about phenomenology" as early as $1989 .{ }^{2}$ Or as plainly as Arthur Danto's description of, "Holl's architectural philosophy derives from the phenomenological writings of Maurice Merleau-Ponty, especially as set forth in Phenomenology of Perception". ${ }^{3}$ The phenomenological theme in Holl's work is particularly evident in his collaboration with Juhani Pallasmaa and Alberto Pérez-Gómez, writing, Question of Perception. ${ }^{4}$ In this publication, Holl references Merleau-Ponty and claims that the underlying question of architectural perception is intentionality. ${ }^{5}$ Merleau-Ponty's influence is also evident as Holl writes of a "consciousness of perception" and a "sensitized consciousness". 6 However, his analysis concludes that intentions are the non-real existences of mental phenomena. ${ }^{7}$ Given that Holl references Merleau-Ponty as he employs the term 'intentionality', the disjunct

\footnotetext{
${ }^{2}$ Kevin Lippert writes, "fundamentally, however, Holl's architecture is about phenomenology". [Holl, 1989, 9]

${ }^{3}$ Arthur C Danto [Danto, 2008, 123]

${ }^{4}$ [Pallasmaa et al., 2006, -] and [Danto, 2008, 124]

${ }^{5}$ [Pallasmaa et al., 2006, 41] 124

${ }^{6}$ [Pallasmaa et al., 2006, 40] and correlating with the conclusion found in [Danto, 2008,

${ }^{7}$ [Pallasmaa et al., 2006, 42]
} 
between Merleau-Ponty's and Holl's use of the term is significant. My previous study of the term intentionality suggest intentionality is a real and directed engagement with the world that is further divided into a bodily engagement and reflective analyses. ${ }^{8}$ Therefore, for Holl to explain intentionality as non-real mental phenomena, is not only nonsensical (because how is it possible to have a non-real phenomenon?), but misses the point of Merleau-Ponty's contribution to the study of the human body.

Holl further reveals a misinterpretation of Merleau-Ponty's words by attributing the motivation of an "intellectual and spiritual" seeking of understanding spatial entities, to a "duality of intention and phenomena". A duality that Holl claims, is "like the interplay between objective and subjective or, more simply, thought and feeling". ${ }^{9}$ Here, intentions are equated to the "objective" and then to "thought". ${ }^{10}$ In contrast, Holl relates "phenomena" to the "subjective" and then to "feelings". ${ }^{11}$ It is fruitful to distinguish the philosophical use of the words subjective and objective. "Subjective" cannot be merely equated with "feelings", rather it refers to that-which-is unique to an individual; i.e. an individual's perspectives, feelings, thoughts, experiences and so on. ${ }^{12}$ Likewise, "objective" cannot be transcribed as "thought", rather it refers to that which is universal and something that is not subject to an individual; i.e. logic, generalisations, principles. ${ }^{13}$ It is common for philosophical terms to develop new meanings in everyday language, however, when analysing philosophical ideas, it is necessary to determine the meaning of the employed terms. Hence, for Holl to link intentionality to objectiveness and then to thought, oversimplifies and obscures the force of Merleau-Ponty's argument. As Holl references Merleau-Ponty and discusses "consciousness of perception" and "intentionality", he abstracts word's without displaying an understanding of the word's context and thereby the position they occupy in MerleauPonty's overall composition of how human beings exist in space. ${ }^{14}$ Therefore, Holl postulates illogical concepts such as, intentions are non-real existences. And his readers potentially miss out on the more innovative arguments by taking the misinterpretations as representative of MerleauPonty's theory. Holl's review of Merleau-Ponty echoes the "classic image of the architect as using knowledge from many other disciplines without becoming an expert in any of them. (Vitruvius 1960, 5-11)"15

\footnotetext{
${ }^{8}$ [Merleau-Ponty, 1962, 53] also see section 3.1 for detailed analyses.

${ }^{9}$ [Pallasmaa et al., 2006, 42]

10 [Pallasmaa et al., 2006, 42]

11 [Pallasmaa et al., 2006, 42]

12 [Pallasmaa et al., 2006, 42] and [OED, 2008, -] and [SEo, , -]

${ }^{13}$ [Pallasmaa et al., 2006, 42] and [OED, 2008, -] and [SEo, ,-]

${ }^{14}$ [Pallasmaa et al., 2006, 41, 42]

15 [Piotrowski and Robinson, 2001, 5-11] Essay by David JT Vanderburgh and W Russell
} 
Despite this misunderstanding Holl later states that: "many of the ideas are positions that we can continue to work from today, but I also have my doubts. As soon as you make a statement, you want to transcend it".16 Therefore it is no surprise that Holl's work is less concerned with manifesting phenomenological architecture and more concerned with what he defines as "perceptual phenomena"; i.e. "touch, smell, sight, etc" ${ }^{17}$ In particular, his architectural works are predominately concerned with the use of light as a building material for making space. ${ }^{18}$

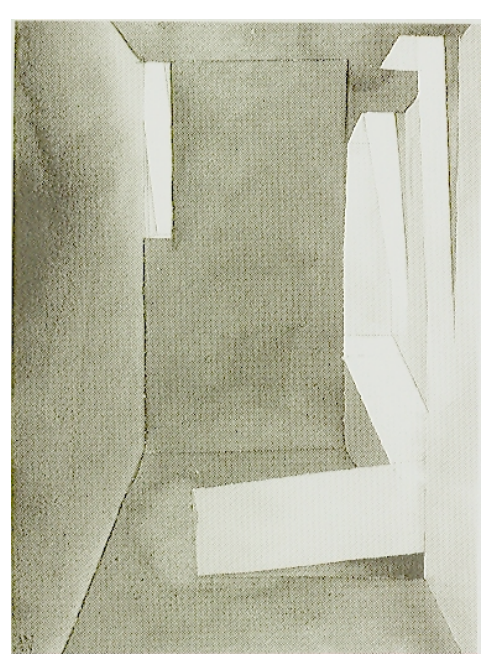

Figure 5.1: Steven Holl, Drawing Shadows, Oxnard, CA 1986

Holl's interest in light, or in this case "shadow as the 'material' for the spatial sequence" is even anticipated in the 1994 collaboration where his drawing emphasis the play of light and shadow in a space. ${ }^{19}$

Ellis, quotation discussing Vitruvius image of the tactless architect who conducts crossdisciplinary visits.

${ }^{16}$ [Holl and Futagawa, 1996, 33]

17 [Pallasmaa et al., 2006, 43]

${ }^{18}$ [Gannon, 2004, 17,18] and [Kipnis, 2007, 37] and [Holl et al., 1997, 82] and [Holl, 1996, 7]

${ }^{19}$ [Pallasmaa et al., 2006, 67] 


\subsection{Illustration of design solutions through architec- tural volumes}

There are a wealth of architects to consider when selecting architectural volumes to illustrate my findings. Tadao Ando, Friedensreich Hundertwasser, and Carlo Scarpa quickly come to mind. Ironically, none of these men studied architecture at university. ${ }^{20}$ Still, an enduring quality of understanding human engagement with space is evident in their works.

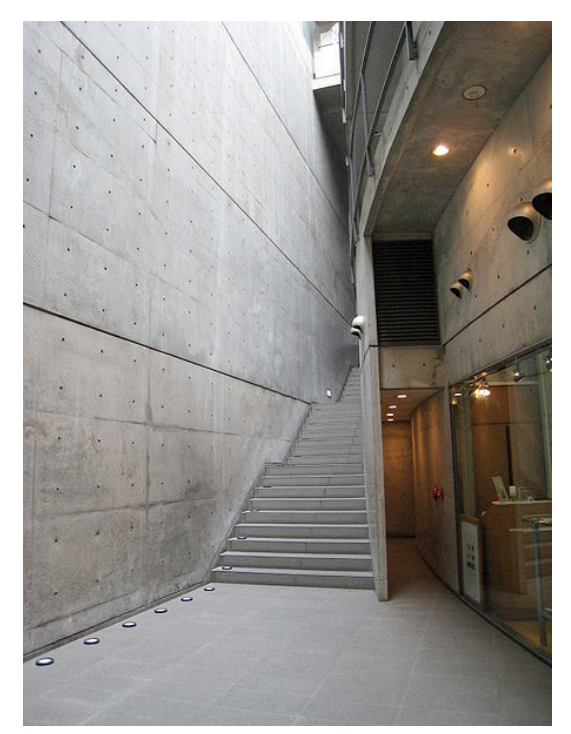

Figure 5.2: Tadao Ando, Galleria Akka, Osaka Japan, 1988

Architectural critique Ryo Hatanó describes Tadao Ando's Galleria Akka as:

Soft light which a ceiling part rubs against the well space of this construction. .. brings composure to internal space composition with high activity. Consequently, it has made from appearance space with the sufficient feeling which is hard to imagine. ${ }^{21}$

\footnotetext{
${ }^{20}$ For Ando [Tadao Ando, 2008, 514] and [Buck, 2000, 156], for Hundertwasser [Johnson, 1994, 179] and [Salingaros and Alexander, 2004, 7], and lastly for Scarpa [Zambonini, 1983, 22]

${ }^{21}[$ Hatano, 2008, -]
} 


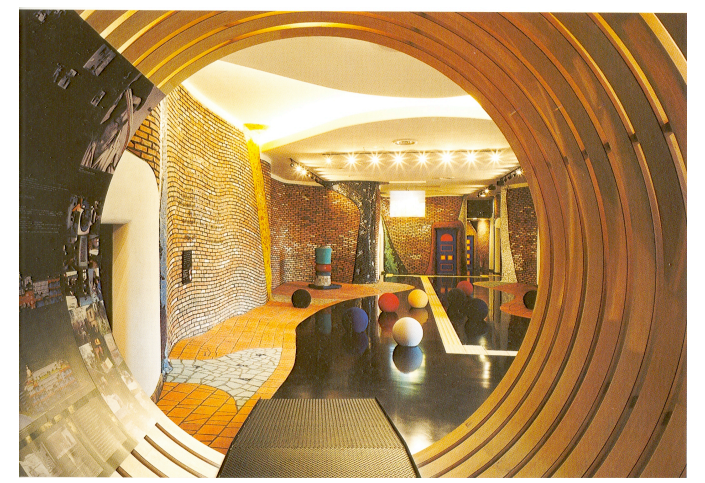

Figure 5.3: Friedensreich Hundertwasser, Maishima Sludge Centre, Osaka 1996-2003

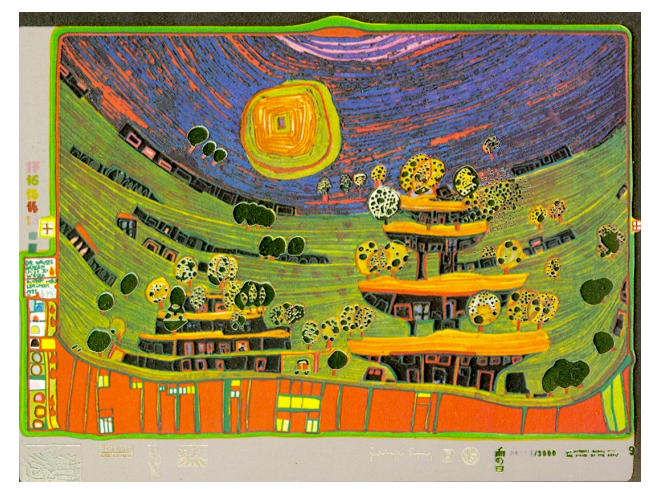

Figure 5.4: Friedensreich Hundertwasser, The houses are hanging underneath the meadows, 1971

Along side this painting, Hundertwasser writes the poem:

The roofs must become WOODLANDS

The Streets must become GREEN VALLEYS

The traffic should pass under ARCADES 22

Other architects, such as Peter Zumthor, Steven Holl, Sey Takeyama, and Terunobu Fujimori, all play influential roles in the contemporary practice of phenomenological architecture and could be studied in detail. ${ }^{23} \mathrm{But}$

\footnotetext{
${ }^{22}$ [Hundertwasser, 1973, 48]

${ }^{23}$ [Zumthor, 2006, -], [Pallasmaa et al., 2006, -], [AaP, 2009, -]
} 
of course, a selection needs to be made to simplify my demonstration, and I have limited my study to Carlo Scarpa.

Scarpa's works portray considerable attention to detail, dedication to projects and an ability to produce particular embodied experiences. George Dodds comments that Scarpa's designs move the body in such ways as to blur the line between an individual body and spatial situations:

\section{Body, landscape, and physical movement often combine in Scarpa's work to produce moments... [that] obscures the distinction between bodies and landscape. . ${ }^{24}$}

Dodds' comment reinforces my claim of the attention Scarpa grants to the experience of the body, although I do not find that Merleau-Ponty's structure of human spatial experience justifies a design solution of merging body with space or "figure and surrounding". ${ }^{25}$ Along these lines, Bianca Albertini affirms this experiential attunement, stating "it seems to me that Scarpa has fully achieved this level of authenticity, in every detail". ${ }^{26}$ The "authenticity" Albertini refers to is that of Christian Norberg-Schulz's aim, " 'to make architecture...human in the real sense of the word.' "27 This quality of design is achieved alongside Scarpa's attention to all architectural scales, such as elements, volumes and material. ${ }^{28}$

In terms of the qualities of Scarpa's designs, Richard Murphy observed that Scarpa's "artistry has always been universally acknowledged but his working method, his budgets, his clients and his collaboration with craftsmen were so unusual as to be condemned as irrelevant to the mainstream of architectural endeavour". ${ }^{29}$ Murphy's observation is stated with confidence in the "value" of Scarpa's labours. ${ }^{30}$ However, others have interpreted Scarpa's independence from the practices of his contemporaries as rendering his work inconsequential. ${ }^{31}$ For instance, Manfredo Tafuri criticises Scarpa, saying his "power lies in his creative use of low level technology, and, his own awareness of the disintegration of those economical conditions that have allowed his subjective poetry". ${ }^{32}$ Tafuri, like others

\footnotetext{
${ }^{24}$ [Dodds and Tavernor, 2002, 257]

25 [Dodds and Tavernor, 2002, 257]

${ }^{26}$ [Albertini, 1988, 7]

27 [Albertini, 1988, 7]

28 [Soroka, 1979, 3]

${ }^{29}$ [Murphy, 1993, 18]

30 [Murphy, 1993, 19]

${ }^{31}$ [Soroka, 1979, 2]

32 [Tafuri, 1975, -], quoted in [Soroka, 1979, 2]
} 
at the time just prior to Scarpa's death, found an insurmountable void between the "expressive, time consuming [and] luxurious" nature of Scarpa's works, and the conventions of architecture commonly practised during the 1970s. ${ }^{33}$ However, contrary to Tafuri's assertion, Scarpa embraced the "extension" of the craftsman by employing machines during the progression of refining a material, albeit the preliminary stage of working with a material and with the machine's work being completed and refinished by hand. ${ }^{34}$ Hence, with the knowledge that Scarpa is unconventional, and to some degree a controversial figure, I examine three of the volumes he created.

To repeat, each of the volumes considered demonstrates a combination of the design solutions. Although, I limit myself to drawing out the relevant qualities to explain the particular design solution afforded by MerleauPonty's research. My prior analysis led to understanding the body as existing in a spatial situation through a directed, knowing, purposeful, nonrule-governed, and non-reflective flow of actions. That is, intentionally bodily actions understand causal connections and respond to affordances. The primary objective in designing for the thinking body is to design spaces that are sympathetic to the intentional flow of bodily movement. Hence, the architect can design spaces for the thinking body by providing spatial affordances and veritable causal connection.

Designing for spatial affordances is a relatively established idea. ${ }^{35}$ Hence I shall quickly walk through the concept and my variation of emphasising the study of the style of embodied cultural skills and then move to the more singular solution of designing for veritable causal connections. ${ }^{36}$

\footnotetext{
${ }^{33}$ [Murphy, 1993, 19]

${ }^{34}$ [Zambonini, 1983, 30]

${ }^{35}$ In the essay, A dialectics of Determination: Social Truth-Claims in Architectural Writing, 1970-1995, David J.T. Vanderburgh and W. Russell Ellis refer to the "the 'pull' of phenomenology..." as a well known notion in contemporary architectural writing. [Piotrowski and Robinson, 2001, 122]

${ }^{36}$ See section 2.2.3 for discussion of styles of embodied cultural skills.
} 


\subsubsection{Corridor}

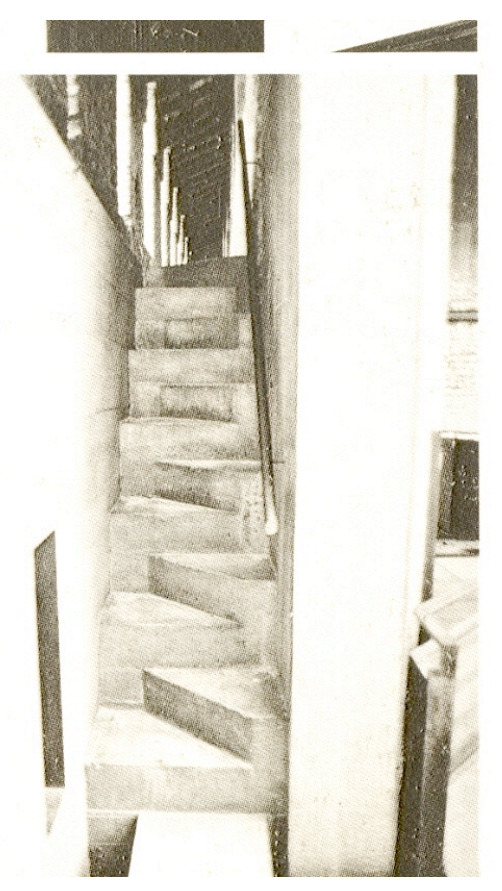

Figure 5.5: Carlo Scarpa, Castelvecchio Museum, Verona, 1964

Between 1957 and 1964 Carlo Scarpa and museum director Licisco Magagnato worked on the restoration of the Museo di Castelvecchio in Veneto. ${ }^{37}$ The corridor is one of the many spaces Scarpa created during the restoration. It is a small stairwell leading to the upper walkways of the gallery wing. The visitor arrives at the base of the stairwell either from a tunnel connecting the second floor of the palace with the watchtower or from a staircase descending past the "Cangrande Statue". ${ }^{38}$ The stairwell is a dark space, cave like, and constructed of concrete. The stairs are angled and jut out to the user. A small platform hovers above the ground and is employed as the first step. The steps engage the movement of the body. George Dodds argues that in the design of the Castelvecchio Museum, Scarpa sought to reverse the "mechanization of vision", labelled the "Viewing body" " by Jonathan Crary. ${ }^{39}$ Dodds further reasons that "Scarpa's intention was... to engage the sentient body through both the construction of views and the

\footnotetext{
${ }^{37}$ [Cas, 2008, 1]

${ }^{38}$ [Crippa, 1986, 300]

39 [Dodds and Tavernor, 2002, 242] Found in endnote 20. Details in endnotes [360].
} 


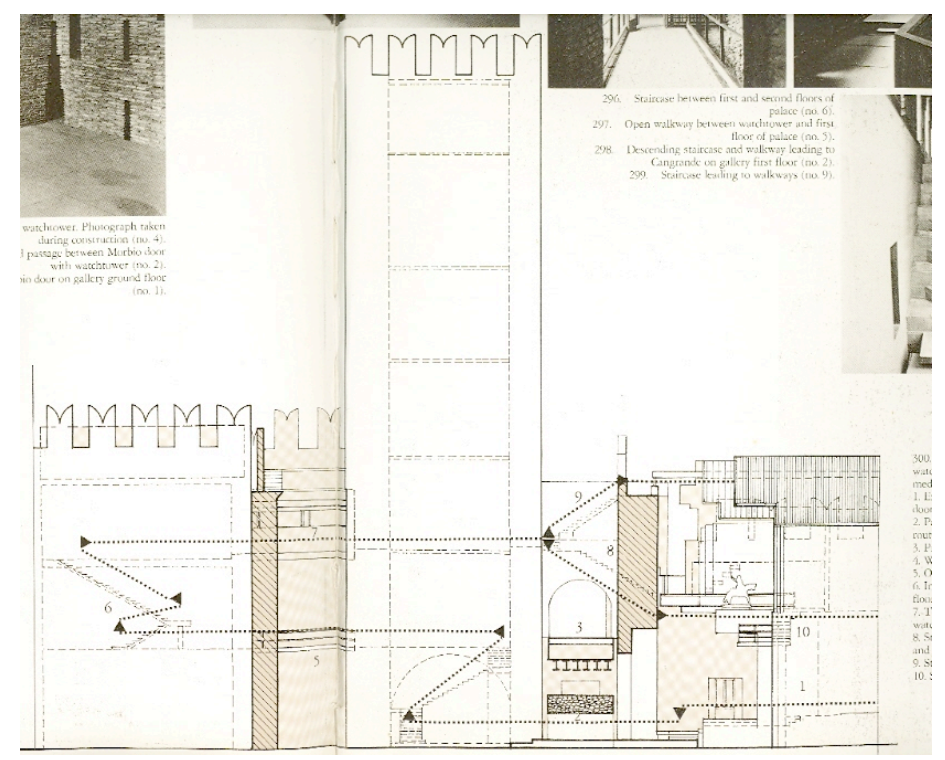

Figure 5.6: Carlo Scarpa, Hand drawing, Castelvecchio Museum, Verona, 1964

manipulation of the body of the viewer." ${ }^{40}$ In this way Scarpa's spatial practices are about how the arrangement of space can cater to the thinking body. Hence for the stairwell, as well as concrete steps, it is the experience of narrowing spaces or opening spaces, about rising spaces and falling spaces created by the protruding steps and the angled steps. The juxtaposition of horizontal and vertical planes powerfully reinforces the distinction between the two styles of step.

${ }^{40}$ [Dodds and Tavernor, 2002, 360] found in Footnote 20. 


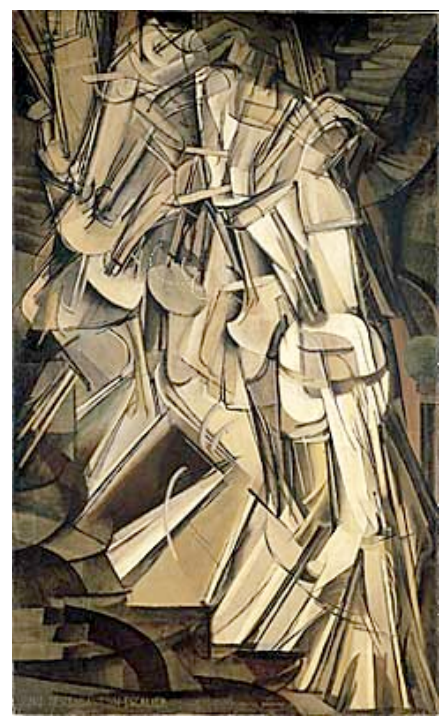

Figure 5.7: Marcel Duchamp, Nude descending a Straircase II, 1911-12

Architectural theorist, Neil Leach, discusses the experience of ascending a stairwell as a "mundane action". In Leach's recent (2006) book titled Camouflage, he argues for an assimilating characteristic inherent to human engagement with space. ${ }^{41}$ Although, this focus is different from MerleauPonty's, it still echo's the theory of bodily intentionality. Leach proposes a "psychic equilibrium" of the individual that engages with the experiential world. ${ }^{42}$ Leach points to the "way in which we climb a staircase..." and claims it "can be absorbed into our familiar world". ${ }^{43}$ The Castelvecchio Museum offers the visitor painting, sculptures, vistas and grand rooms. ${ }^{44}$ The stairwell plays a minor role in the overall experience of the museum. However, through the design of the angular planes, the steepness of the grade and the narrowness of the passage, the visitor is pulled through the space. Scarpa creates spatial form that avoids interrupting the flow of nonreflective engagement with a spatial situation. One means he did this was to design spatial affordances. Image of the stairwell from above:

\footnotetext{
${ }^{41}$ [Leach, 2006, 7]

42 [Leach, 2006, 7]

${ }^{43}$ [Leach, 2006, 7]

${ }^{44}$ [Dodds and Tavernor, 2002, 242]
} 


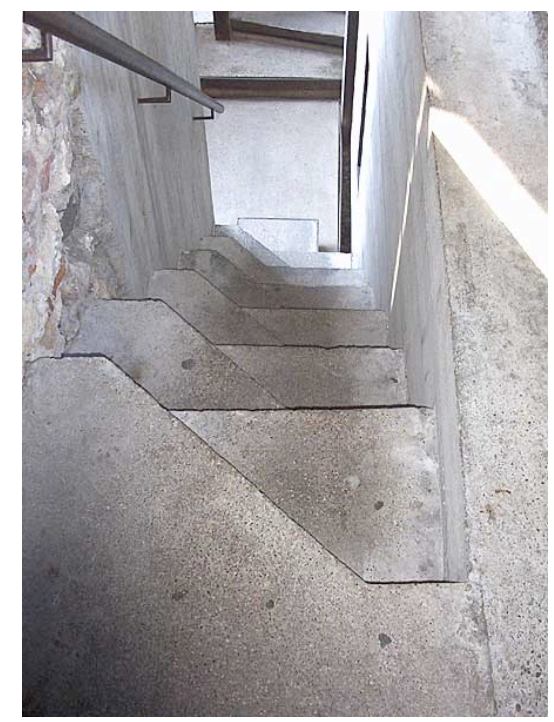

Figure 5.8: Carlo Scarpa, Bridge handrail details, Castelvecchio Museum, Verona, 1964

\section{spatial affordances}

In 1959, Steen Eiler Rasmussen discussed the phenomenon of spatial affordance as leading an individual through space. ${ }^{45}$ Designing for affordance can be as mundane as a how-to manual. In William Lidwell's recent book: Universal Principles of Design: 100 Ways to Enhance Usability, Influence Perception, Increase Appeal, Make Better Design Decisions, and Teach Through Design, Lidwell matter-of-factly explains that accounting for affordances improves design: "When the affordance of an object or environment corresponds with its intended function, the design will perform more efficiently and will be easier to use." 46 Tangentially, Lidwell's use of "affordance" and "intention" exemplifies Vittorio Gregotti argument that the memory of philosophers' contributions lingers in architect's minds while the philo-

\footnotetext{
${ }^{45}$ Rasmussen writes, "observe how you are naturally led from one [room] to the other". [Rasmussen, 1959, 33] In this case, something about the thresholds between the rooms affords the bodies entrance.

${ }^{46}$ [William Lidwell, 2003, 20] Lidwell gives further clarification: "for example, a door with a handle affords pulling. Sometimes, doors with handles are designed to open only by pushing-the affordance of the handle conflicts with the door's function. Replace the handle with a flat plate, and it now affords pushing - the affordance of the flat plate corresponds to the way in which the door can be used. The design is improved".
} 
sophical details are forgotten. ${ }^{47}$ The central idea is that certain aspects of spatial situations, e.g. openings, seats, handles beckon particular responses by the human body. That is, the door handle affords the hand to pull, while the flat plate on a door affords pushing. In chapter two I established that architects could adjust their perspective by further study of how things appear to individuals and what things show up as affording; i.e., styles of embodied cultural skill. In this sense, I have argued for a more detailed notion of embodiment. This richer understanding of embodiment leads to a change in perspective that effects how the designer understands the intentional bodily flow, and thus how to design for that flow.

Additionally, in chapter three, I argued that implicit to Merleau-Ponty's phenomenology is the metaphysical understanding of an object as indeterminate without human engagement. To an individual approaching the Castelvecchio Museum stairwell, the exact qualities that Scarpa set out to convey will differ from one individual to another. The angular steps, the smooth surfaces and roughly coloured concrete will attract some users and discourage others. Scarpa's spatial practices are deeply embedded in the traditions of Veneto region. ${ }^{48}$ Likewise, his designs and constructions emerged alongside local craftsmen and artist. ${ }^{49}$ The narrowness and hardness of the space echoes the traditions, culture and attraction of the Veneto region. ${ }^{50}$ The success of the Scarpa design is partly due to his understanding of spatial affordances and his lifelong study of the styles of embodied cultural skills. ${ }^{51}$ In general, an architect gains a more detailed understanding of designing spatial affordances by a change in perspective of how the designer understands embodiment.

\footnotetext{
${ }^{47}$ [Gregotti, 1996, 95]

${ }^{48}$ [Hawkes, 2008, 111]

${ }^{49}$ [Zambonini, 1983, 15]

${ }^{50}$ [Hawkes, 2008, 111]

${ }^{51}$ See section 2.2.3.
} 


\subsubsection{Interior room: windows and light}

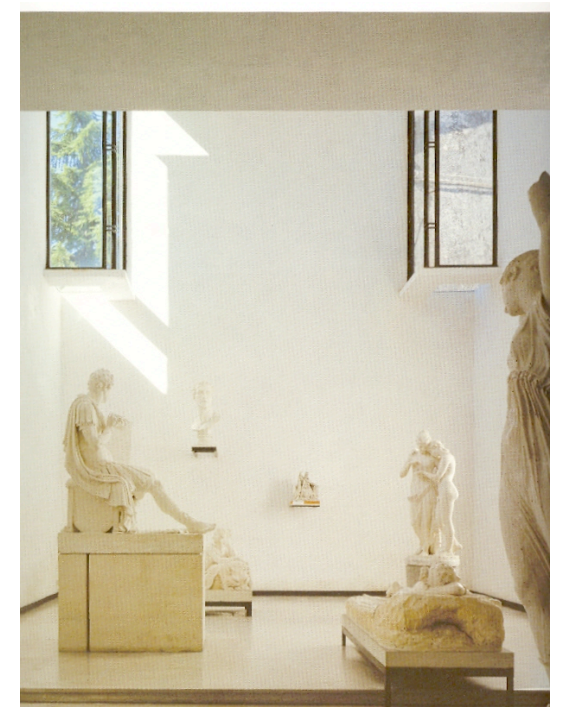

Figure 5.9: Carlo Scarpa, "The High Gallery", Museo Canovian, Possagno, 1957

Between 1955 and 1957 Scarpa designed an addition to the Museo Canovian, Possagno. Among the rooms added is a room outlined by three walls and a shallow step, called the "high gallery". 52 The gallery exhibits four floor sculptures and a few smaller, wall-mounted sculptures. With regard to the thinking body, the significance of this volume resides in the organisation of day light and moon light. Set in each corner of the room are volumes of light. Judith Carmel-Arthur describes the atmosphere that the skylights enable as:

Seductive plays of shadow across solid form... diffuse light illuminates the highly plastic values of the modelling, and profiles are relieved against gradations of light drifting across the background surface of the room. ${ }^{53}$

One pair of skylights is tucked above the ceiling of the approaching threshold. The other pair significantly impacts the experience of the space as the gallery is approached.

\footnotetext{
${ }^{52}$ [Judith Carmel-Arthur, 2002, 30]

${ }^{53}$ [Judith Carmel-Arthur, 2002, 15]
} 


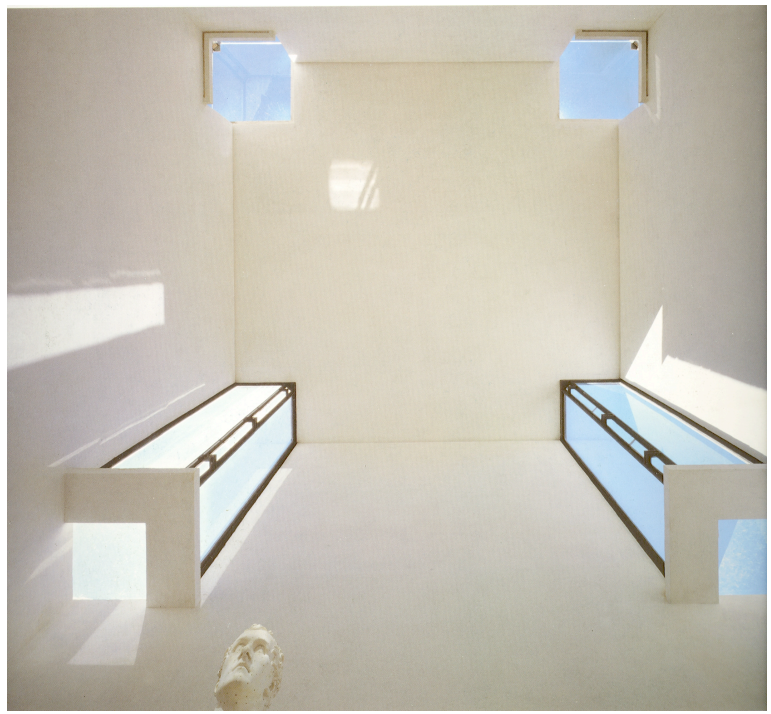

Figure 5.10: Carlo Scarpa, "The High Gallery", Museo Canovian, Possagno, 1957

The corner windows are above the body's height. They serve less as a means of seeing the outside world, as a way of translating the quality of light that the outside world offers to the visitor. ${ }^{54}$ "At Possagno, manipulation of glass by Scarpa was always an emphatic gesture. Glass is present in a selection of sub-narratives". ${ }^{55}$ In this sense, the intentional bodily engagement with the world is allowed to flow without interruption as an individual enters the space. The corner windows are volumes of light, not windows in the common looking-through or picture-framing sense. ${ }^{56}$ Boris Podrecca describes the distinction between Scarpa's corner windows and conventional windows as:

Scarpa's invention of the trihedral corner windows, simultaneously window and rooflight, that illuminate the 'high hall' is, environmentally and tectonically, the most remarkable element of the building... Their configuration admits light from all orientations and, unlike a conventional window set within a wall, casts light across the walls themselves. 57

\footnotetext{
${ }^{54}$ [Judith Carmel-Arthur, 2002, 15]

${ }^{55}$ [Judith Carmel-Arthur, 2002, 15]

${ }^{56}$ [Albertini, 1988, 213]

57 [Hawkes, 2008, 115]
} 
The skylights serve as gauges of the world outside, and connect the space to the time of year, day, and particularity of the weather pattern. This is consistent with the thinking body by illuminating the room through the external world, and proving a correspondence for the individual's flow. ${ }^{58}$

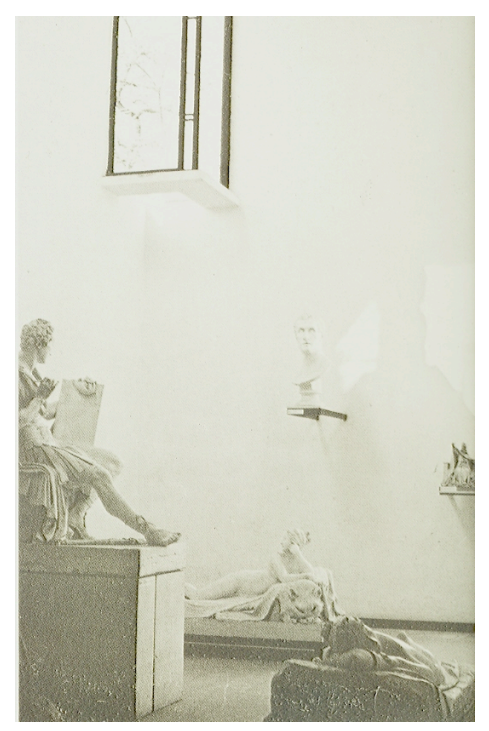

Figure 5.11: Carlo Scarpa, "The High Gallery", Museo Canovian, Possagno, 1957

The quality of light offers a consistency between what is expected and what is found. Should I walk into the space from the day outside, the quality of light echoes the larger environment. The consideration given to this element of the space, is supported with Scarpa's telling assertion, "I real love daylight" ${ }^{59}$ Engaging with the sculptors in the high gallery is an experience mediated by day light. My experience of the low light of a winter's day is not disturbed by a contrived and artificially lit gallery. Likewise, my experience of the sculptures and my body's engagement with the spatial situation may focus on the art works rather that being distracted by a noncausally connected quality of light at odds with the external world.

\footnotetext{
${ }^{58}$ [Hawkes, 2008, 113]

${ }^{59}$ Scarpa, quoted in [Hawkes, 2008, 113]. Originally from a recording of a lecture given on 13 January 1976, published in [Scarpa, 1981, -].
} 


\section{veritable causal connections}

The translation of the quality of light from the larger world to the interior space of the high gallery provides a veritable causal connection for the body that enters the space. The design solution suggests it is possible to create a consistency when accounting for various embodied engagements with a material or space. Both the light of Scarpa's high gallery at the Museo di Canoviano, and the materiality of the entrance bridge of the Querini Stampalia Foundation (as I shall next explain) demonstrate the traits of veritable causal connections. I have chosen to label this contextual design solution to identify a distinct phenomenon. Due to the disputed quality of the terms to adequately explain the notion of veritable causal connection I provide a brief survey of three philosophers' definitions of the notion of causal connection.

An influential definition of causal connection is composed by the Modern philosopher Immanuel Kant. ${ }^{60}$ To establish a causal connection, there must be at least two distinct aspects (aspect reading as, a thing, event or idea) and a directional effect from at least one aspect to the other. ${ }^{61}$ I use the term 'thing' to indicate an event, object, mental state, bodily state or individual human. In line with Kant's "Verknüpfung" or the causal connections within art, I define causal connection as the link between two things, in which at least one thing effects the other's existence. ${ }^{63}$ For example, the water-saturated sash-window effects the stance in which I position myself in order to heave its expanded girth as I open the window.

Furthermore, I employ the term veritable to mean that the experiences of a thing correspond consistently throughout different interaction with that thing. In other words, a thing is veritable if, and only if, all the different perspectives of the thing match up. I find veritable to be a more useful

${ }^{60}$ [Nell et al., 2004, 264] and [Watkins, 2005, 101] for the influence of Kant's definition of causality. Additionally for the general influences of Kant's theory see [Edwards, 2000, xii], [Wood, 2005, 1], [Ross and McWalter, 2005, x]

A causal connection, as our mere understanding thinks it, is one that always constitutes a descending series (of causes and effects): the things that are the effects, and that hence presuppose others as their causes, cannot themselves in turn be causes of these others. This kind of causal connection is called that of efficient causes (nexus effectivus). But we can also conceive of a causal connection [Verbindung] in terms of a concept of reason (the concept of purposes). Such a connection, considered as a series, would carry with it dependence both as it ascends and as it descends: here we could call a thing the effect of something and still be entitled to call it, as the series ascends, the cause of that something as well. This causal connection [Verknüpfung] is easily found in the practical sphere, namely, in art. ${ }^{62}$

[Kant, 1987, 251], [Chalmers, 1997, 86, 193] and [Magee, 1997, 29]

${ }^{63}$ [Kant, 1987, 251] 
term than authentic or genuine, because the truth quality is relevant to the thing or the experience of the thing, rather than to an objective reality. ${ }^{64} \mathrm{~A}$ dictionary notes the particularity of the term as, "veritable implies correspondence with the truth but not necessarily a literal or strict correspondence with reality" ${ }^{65}$ Thus I define veritable causal connections as causal connections, that correspond through varying encounters. In other words, the affordance and materiality of a given spatial situation is dependably effected by the human engagement with the situation.

Asserting that the designed space must have veritable causal connections postulates a working bodily synthesis of the different aspects of a material object and assumes a temporal stretch. It also accounts for the bodily synthesised objects that reach and populate the mind. Though these measures, this idea differs from Pallasmaa's design principle of working with all the senses. ${ }^{66}$ Here, the aim is for a cohesive reliability of a material object that affords a correlated experience of the object from different engagements with the object. I.e., if a user approaches what looks like an oak door, the process of opening the door and moving through the door, and all other uses associated with the door and how the door relates to the rest of the door, should correspond to the materiality of the door.

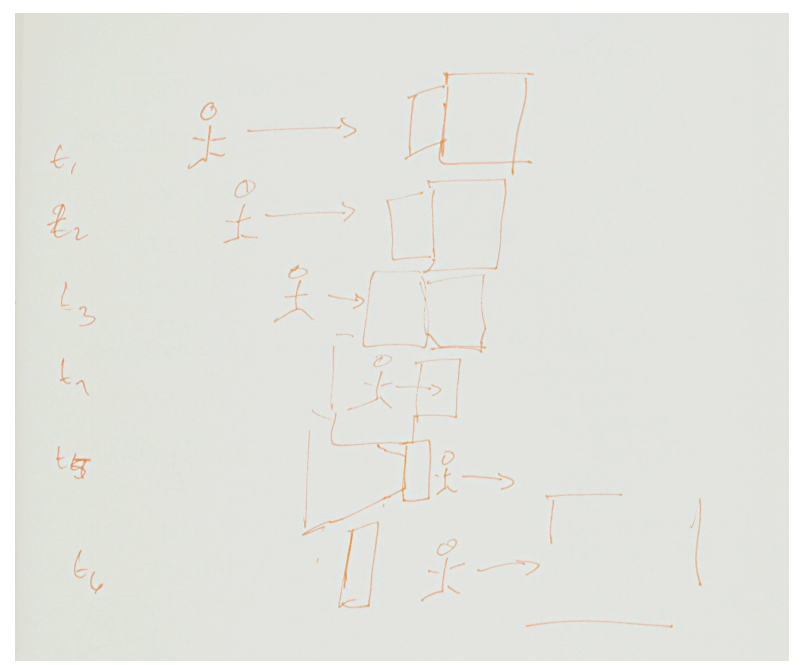

Figure 5.12: Working hand drawing.

\footnotetext{
${ }^{64}$ Objective reality, as a system of order unaffected by perception. "B. n. 1. A thing or class of things external to or independent of the mind; an object of conscious thought; that which is objective (sense A. 3b)" [OED, 2008, objective, 2b1]

${ }^{65}$ [Apple, 2007, -] Also note, " 3 . In extended use, denoting possession of all the distinctive qualities of the person or thing specified". [OED, 2008, veritable,3]

${ }^{66}$ As discussed in the previous chapter.
} 
The light of Scarpa's high gallery welcomes the user into the room as it resonates with the user's previous experience of the day outside. Responding to the space of the gallery does not necessarily involve an observation of the reflective intellect. The body can engage with the space uninterrupted as the verifiability of the causal connection is satisfied. For the thinking body to have veritable causal connections, the first thing needed is a relationship between the embodied intentional flow and a spatial situation. The spatial situation is composed of affordances and materiality. As the embodied intentional flow causes changes to the spatial situation, those changes are consistent throughout the period of engagement. This understanding of the arrangement between body and space affords the idea that the thinking body can anticipate the effects of its actions with some accuracy. Architects can provide this accuracy by the veritable quality of the materials used in the built space, of which Scarpa's volume of light illustrates. To further demonstrate the implications of this design solution founded on Merleau-Ponty's implicit understanding of human experience I now turn to a description of the entrance of the Scarpa's Querini Stampalia Foundation. In analysing the qualities of the Scarpa's architectural volume, I discuss a means of designing for veritable causal connections by avoiding object façadism. 


\subsubsection{Entrance}

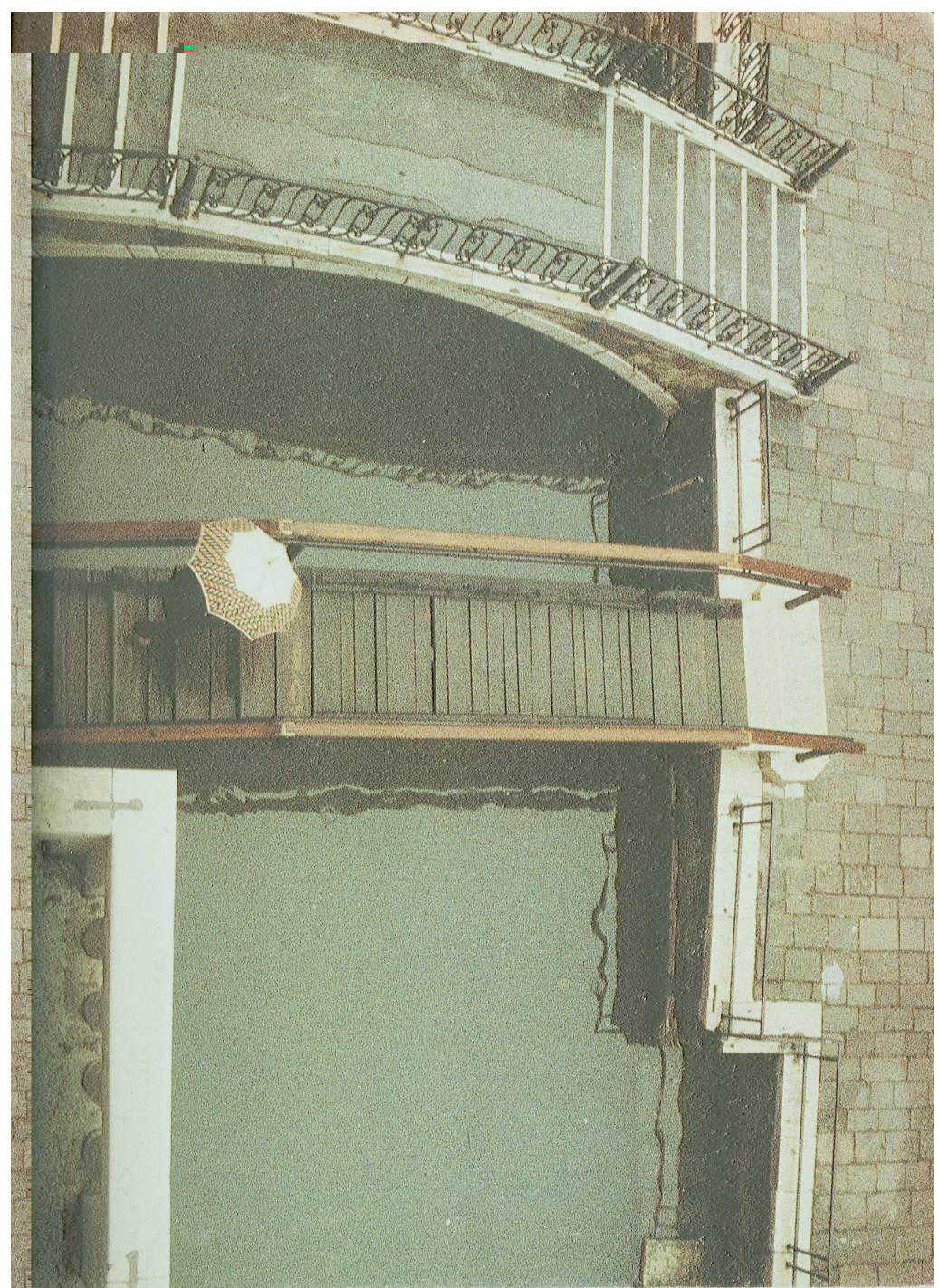

Figure 5.13: Carlo Scarpa, View of entrance bridge seen from above, Fondazione Querini Stampalia, Venice, 1961-1963 


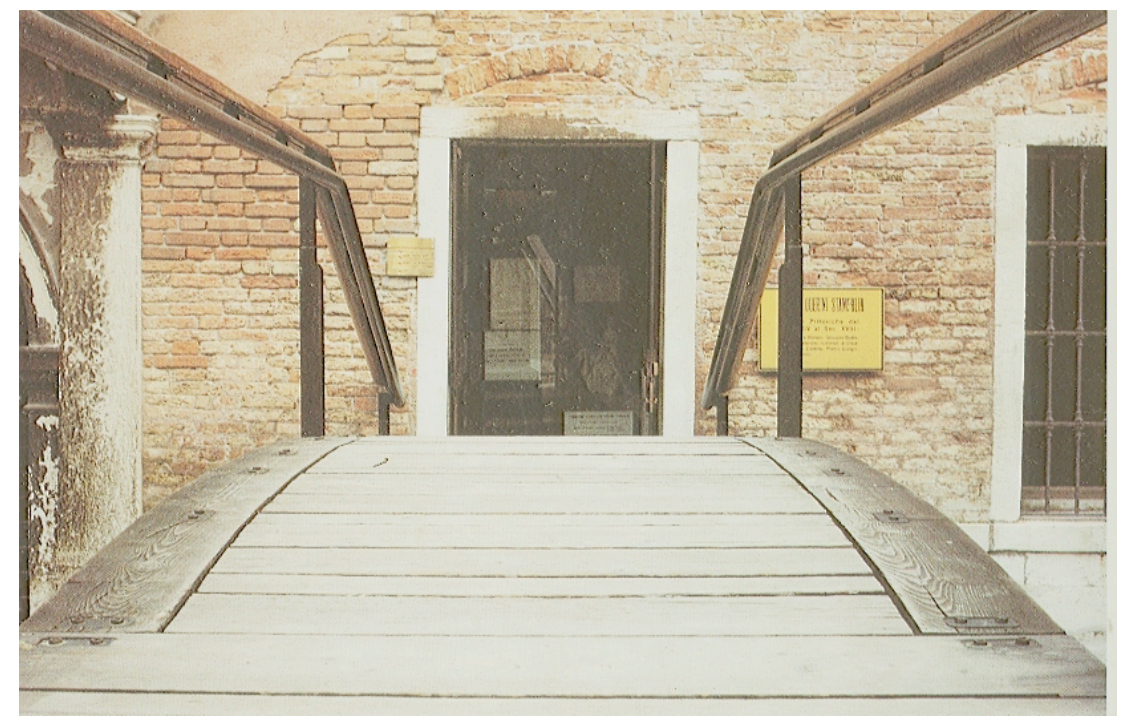

Figure 5.14: Carlo Scarpa, View of entrance bridge seen from calle, Fondazione Querini Stampalia, Venice, 1961-1963

In 1959 Carlo Scarpa began to rework the ground floor of a "shell" of a 16thcentury Venetian villa with the director of the Querini Stampalia Foundation, Giuseppe Mazzariol. ${ }^{67}$ The ground floor of the villa is used as an art exhibition space for the Foundation. Scarpa's first concern was establishing a new entrance to the villa across the canal. The bridge employs a combination of materials. The materials are carefully fitted with each other, and no material obscures the others.

As a person approaches the bridge, the first two steps of stone work can be taken as lifting out of the ground's pavement. The common pavers of the walkways and piazze, meet the pair of large stone steps which prepare for the wood and steel bridge. The steel of the handrails, positioned in the stone, join the elements of teak and brass. The oak steps are raised apart from the steel vault by steel brackets on either side, the steps are slightly angled from the horizontal in the traditional manner. ${ }^{68}$ This is no balustrade, instead, two steel handrails are provided. ${ }^{69}$ Richard Murphy describes the materiality of the bridge as:

\footnotetext{
${ }^{67}$ [Murphy, 1993, 8,2, 7] Respectively citing dates, shell, and director. Giuseppe Mazzariol was also a lifelong friend of Scarpa, and later collaborated on the design of the Brion sanctuary. [Dodds and Tavernor, 2002, 240]

${ }^{68}$ [Murphy, 1993, 9]

${ }^{69}$ [Murphy, 1993, 9]
} 
The connection to a single bar which supports a tubular steel rail is a characteristic Scarpa intensification of both the process of jointing and an acknowledgement of the change of scale from the structure of handrail upright to the more delicate tactile scale of the rail itself. ${ }^{70}$

Elements such as Scarpa's "intensification" of the junction of materials and change of scale compose an overall space that invites the thinking body to confidently approach. ${ }^{71}$ The body's initial assumptions of the material's response to the body's engagement are confirmed as the body further scrutiny the bridge through use.

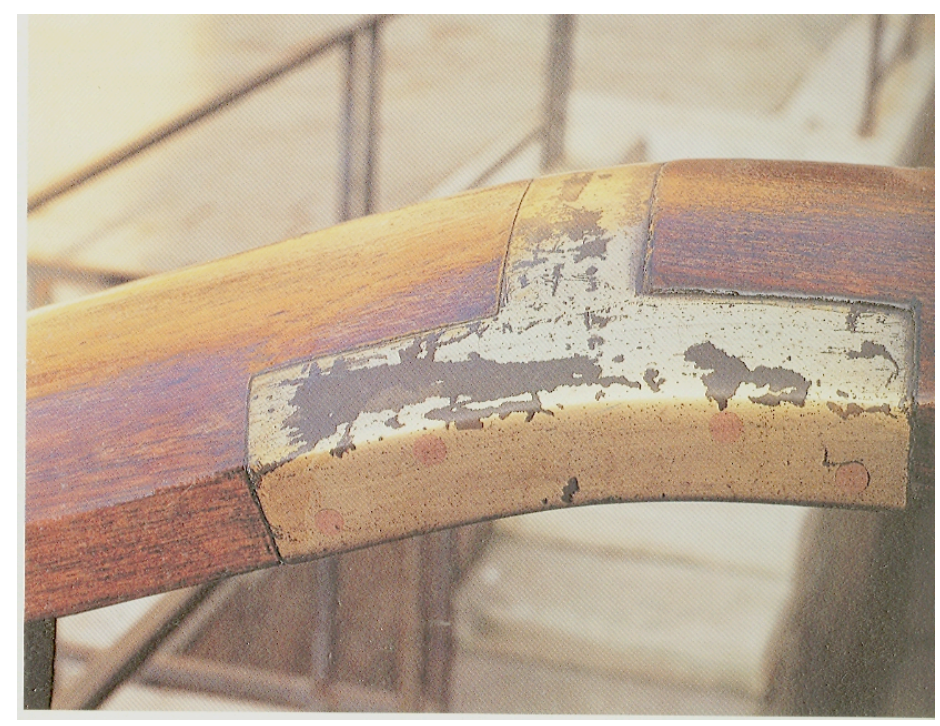

Figure 5.15: Carlo Scarpa, Bridge handrail details, Fondazione Querini Stampalia, Venice, 1961-1963

\section{object façadism}

Architects can creates spaces that aim to avoid interrupting the flow of nonreflective engagement with a spatial situation by avoiding object façadism. I created the term, object façadism, to examine the implications for materiality implicated by the concept of veritable causal connections. I define

\footnotetext{
${ }^{70}$ [Murphy, 1993, 9]

${ }^{71}$ [Murphy, 1993, 9]
} 
object façadism as the design and creation of objects that present a false veil to the user, such that the user is unprepared to engage with the underlying object. In other words, materials that pretend to be something other than what they are. Along these lines, Carlo Scarpa says that architects should acknowledge the "true nature" of the material. ${ }^{72}$ To avoid object façadism means avoiding veneer, paint, "gib-board" or "sheet-rock", clear glass looking windows, and artificial light when it could be provided by sun or moon. Likewise, it advocates the use of whole materials, such as concrete, metal, wood, cloth, stone, etc.

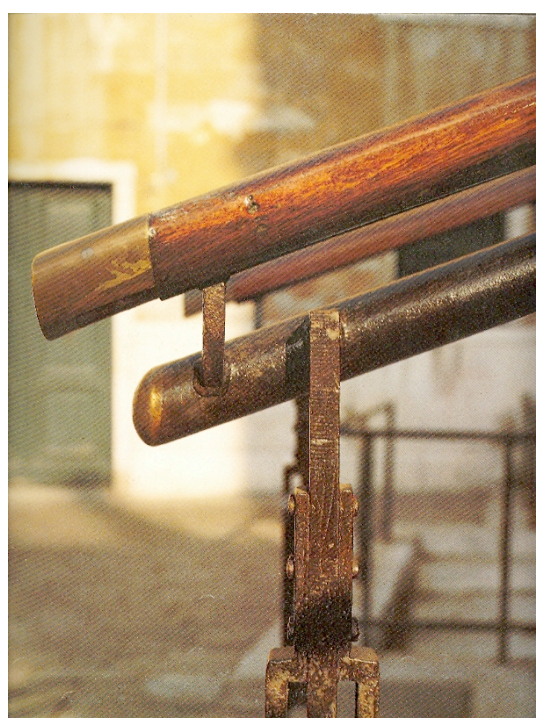

Figure 5.16: Carlo Scarpa, Bridge handrail details, Fondazione Querini Stampalia, Venice, 1961-1963

The following thought experiment is designed to explain why object façadism disrupts the intentional flow of bodily engagement with a spatial situation. For instance, consider the experience of entering a new museum, across a bridge. Let us imagine two situation in which you have to cross a footbridge. In the first case you come to Scarpa's bridge for the Palazzo Querini Stampalia. You identify the bridge from the opposite side of the piazze, and weave through the tourist feeding pigeon. ${ }^{73}$ As you walk, you

\footnotetext{
72 [Murphy, 1993,9] "in every project Scarpa was anxious that the true nature of a material — tectonic or molithic, planar or solid — should always be acknowledged". [Murphy, 1993, 9]

${ }^{73}$ This is a thought experiment, so forgive that while it is common for tourist to feed the pigeon at Piazza S. Marco, it is not likely that this happens at the Palazzo Querini Stam-
} 
keep hold of your bags and keep track of your wallet, easing your way through the extravagant hand gestures. Approaching the bridge you step up onto the first two stone steps, admire the defiant blueness of the water, questioning - 'Don't people always say the water is terribly polluted?' and find yourself entering an impressive collection of art. In the second scenario, you are entering a museum, but rather than Scarpa's bridge, there is bridge designed by an enthusiastic contemporary designer. The bridge is composed of glass railings and a vinyl sheet fastened to a thin plate of steel. Again, you identify the bridge from across the piazze. As you make you way to the bridge, again easing through the other tourist, you start to eye up the bridge. ' How big are those steps?', 'How sturdy, high, slippery is it?' Maybe you glance about the piazze to see if anyone else is about to cross the bridge, for comparison and to get some idea of what you are about to walk on to. When you get to the bridge, you rearrange your shopping bags, to have your hands free, and then step up onto the first step, feeling for its weight and then cautiously guide yourself across the bridge, ready for the unexpected, because the body does not know how the bridge will be. The veneer of the steel and the clearness of the glass disturbed the nonreflective intentional flow of engagement with the spatial situation. The thinking body needs to syntheses the possibilities of the underlying steel as it is hidden underneath the possibilities of the vinyl. Metaphysically, the body must engage with both the thin layer of a cloud of possibilities and the concealed cloud of possibilities.

Avoiding object façadism is about how spatial situations are experienced and accessed, as opposed to how spatial situations mechanically work. Architectural honesty with regard to engineered aspects of a building is an analytically reflective experience; i.e. revealing the plumbing of the building engages analytical intentionality rather than bodily intentionality. Rekecting object façadism is about making the materiality of the building more grasp-able, rather than exposing the bones of a building; such as the wires, ducts or supporting structures. This is akin to notion that for the thinking body, a richer means of engaging with another human being is not about experiencing the other person's arteries and veins.

\subsection{Conclusion}

Architectural theorist Neil Leach states: "not only do we grow into and become part of our environment, but our environment becomes part of us". ${ }^{74}$

\footnotetext{
palia's piazze.

${ }^{74}$ [Leach, 2006, 7]
} 
The environments created by Carlo Scarpa afford smooth transitions from one engagement with a space to another. The stairwell, the light, and the bridge each provide volumes affording the body an uninterrupted metamorphosis into the space. This is not a universally desirable design, however the volumes do cater to the thinking body. The contextual design solutions relate to the implicit structure of human existence abstracted from Merleau-Ponty's work. The non-reflective synthesis of the independent qualities is prioritised by the design solutions. The difference between a collection of senses (as Pallasmaa puts forth) and the synthesis of aspects is the need for reflection. The theory aligned with Merleau-Ponty's proposes that the act of synthesis is independent of reflection. 


\section{Chapter 6}

\section{Conclusion}

My intent in writing this thesis was to share my enthusiasm for MerleauPonty's understanding of how the human body engages with its surroundings. ${ }^{1}$ As I explored architectural theory I found a flaw as I read Juhani Pallasmaa's Eye of the Skin. In turn, as I discussed phenomenology with architectural students, I observed that the unconventionality of MerleauPonty's theory was lost in translation. ${ }^{2}$ There is a richness offered in the layers of description, the paragraphs that span pages, and the originality of Merleau-Ponty's conclusions. This work caught my attention and has lived with me for the past decade. My aim here has been to translate the flowery, poetical and often rambling ideas of Merleau-Ponty's perspective in as clear and logical fashion as possible.

In essence, I first outlined an argument for Merleau-Ponty's phenomenological understanding of the human body's experience of being in space, and in the following chapter used my rendering of the thinking body to critique the architectural theory of Juhani Pallasmaa. I then concluded by responding to the question, what architectural practices cater to the thinking body? In reply I analysed two theoretical accounts of experiencing space, distinguish their structures and then integrated the theoretical account with practical ideas for design practices.

In more detail, I launched into Merleau-Ponty's account of the human

\footnotetext{
${ }^{1}$ As a child, I played the role of 'amateur architect': drawing house plans, sections, visiting my older bother on construction job sites, and destroying my other brother's architectural models as he brought them home from university. Serendipity brought me to study philosophy, but I have invariably gravitated towards architectural texts.

${ }^{2}$ I.e., lost in the various attempts to apply the theory into the world of architecture.
} 
body's capacity for thought, after a brief survey of architectural theorists who critique contemporary architecture for lacking enough consideration of the human body. My examination of the body's capacity for thought leads to understanding the thinking body as experiencing space via an intentional flow of bodily movements. In other words, the body exists in a spatial situation through a directed, knowing, purposeful, flow of actions. This means that bodily actions both understand causal connections and respond to spatial affordances. In chapter two the emphasis for design centres on an individual's perspective of the bodily manner of engaging with space, hence further study of styles of embodied cultural skill could advance design catering to the thinking body. In brief summary, the chapter describes how the readiness to respond to a situation and architectural elements is housed in the body, and thereby a further study of how various styles of embodiment perceive the elements as affording certain actions could increase the consideration given to the body in designed spaces.

I examined five phases of learning new skills to demonstrate the human body's capacity for thought. In the final expert phase, as aspects of space become present, the thinking body syntheses elements and responds to them independently of the reflective capacities of the mind. This process creates the uninterrupted flow of intentionality that is observable in people highly developed of particular skills. The examination revealed various stages by which the body interacts with space, which can translate to a number of ways an individual engages with space and demonstrates elements enabling the body to learn.

In chapter three, theorising the metaphysical function of the thinking body produced an acknowledgement that it is possible to shift the perspective, or mind-set, of an architect to state more compatible with the phenomena of human spatial experience. The shift in perspective takes the architect from the dominant reductive notion of the human body, to one that grants a bodily synthesis. ${ }^{3}$ In particular, the new perspective recognises the body's flow of intentionally engaging with independent things. This is a flow in which the body synthesises possibilities of what-could-be into what-is; i.e., a process that makes objects determinate for the span of time that the body engages with the situation. Additionally, the new approach accounts for the metaphysical limits of materials, as both open to numerous interpretations and limited independently of human beings. Chapter three, therefore, leads to a perspective change rather than directly to a design change. This change in perspective enables a designer to understand the intentional bodily flow, and thus that there is the potential to design for that flow. The analysis leads to understanding the thinking body as one

\footnotetext{
${ }^{3}$ [Imrie, 2003, 58]
} 
which experiences space through a directed, knowing, purposeful, flow of actions.

Although architectural theorists such as Juhani Pallasmaa and Steven Holl, are aware that designing for vision alone is not enough, they miss the innovation of Merleau-Ponty's philosophy. Herbert Spiegelberg, a scholar of Merleau-Ponty, discusses the general misuse of the word phenomenology; "even now, the only protection for the at times all too fashionable term [phenomenology] is its ponderousness and tongue-twisting ugliness. But even this repellant has not been sufficient to make it foolproof against misuse." ${ }^{4}$ Pallasmaa's and Merleau-Ponty's accounts of the human experience of space are incompatible because of 'where' the synthesises of space occurs. 'Where' is an awkward term to use here, but the distinction lies between the understanding of pre-reflective synthesis (bodily intentionality of the thinking body) and a post-reflective synthesis (analytical intentionality of the mind). This contrast entails the degree to which an individual person orchestrates her experience of space. In Merleau-Ponty's account, the individual has greater control over how materials, objects, and spatial situations manifest themselves. He writes:

Hardness and softness, roughness and smoothness, moonlight and sunlight, present themselves in our recollection, not pre-eminently as sensory contents, but as certain kinds of symbiosis, certain ways the outside has of invading us and certain ways we have of meeting this invasion, and memory here merely frees the framework of the perception from the place where it originates. ${ }^{5}$

By contrast the architectural focus of Pallasmaa's human experience of space is based on a collection of sensory experiences that the mind synthesises. The importance of the difference between the accounts surfaces when examining the implications for design.

The architectural focus of Merleau-Ponty's understanding is on clouds of possibility that the body synthesis into spatial situations. Throughout this thesis I have employed examples and thought experiments to illustrate that engaging with spatial situations is not merely about multiple senses absorbing material surfaces and then relaying those brute images to the mind. Rather, it is my body's act of, say, moving through a gallery hall, pausing in front of a painting, adjusting my stance to get the best distance to the painting, so that only then, do I 'find myself' admiring the painting's,

\footnotetext{
${ }^{4}$ [Spiegelberg and Schuhmann, 1981, 2]

${ }^{5}$ [Merleau-Ponty, 1962, 317]
} 
i.e. reflecting on the painting's beauty, symbolism, etc. That is, the theory of the thinking body, presumes three things; that there is something independent of human beings which influences but does not determine the objects and spatial situations an individual engages with, that it is fundamentally the body and not the mind that synthesise these independent things into the determinate spatial situations we engage with, and that the readiness to respond and interact with situations is housed in the body itself, rather than in the mind.

In chapter five, I tease out a pair of contextual design solutions through a study of the architectural practices of Carlo Scarpa. Elements of Scarpa's work are sympathetic to an individual's flow of intentional bodily engagement. Primarily, his use of materials and spatial composition afford veritable causal connections between an individual and the architectural volumes inhabited. Secondly, spaces are designed to attract people to use the space in a particular manner, i.e. designing for spatial affordances based on a richer understanding of styles of cultural embodiment. Merleau-Ponty's position suggests that the architect should work towards architectural spaces and elements that are sympathetic to the thinking body. In particular, the architect should be wary of inadvertently 'tricking' the body. That is, if an architect is designing for the thinking body, then tricking the body is counterproductive because it disturbs its intentional flow. Scarpa's architectural practices provide for the thinking body by creating spaces that offer the body the same information through a number of positions and engagements with the materiality and affordance. This is a conditional claim; I am not arguing that all architecture should blindly cater to the thinking body. I acknowledge that there are cases for architecture that attempts to challenge the inhabitant of the built space, but this is critical.

I believe that the element often lacking from the spaces contemporary architecture are the non-reflective aspects of human movement and engagement with space. The manner in which the body engages with its surroundings by "opening a world" offers challenges and possibilities for the artists of architecture. ${ }^{6}$

${ }^{6}$ [Merleau-Ponty, 1962, 297] 


\section{Bibliography}

Stanford Encyclopaedia of Philosophy, http:// plato.stanford.edu/.

(2003). The Columbia Electronic Encyclopaedia, sixth edition. Columbia University Press.

(2008). Castelvecchio Museum website, http://en.myverona.it/castelvecchio ${ }_{m} u_{\text {seum }} c_{6} 6 . h t m$.

(2008). Technology for Exhibits, http://www.technology-for-exhibits . com/index.htm.

(2008). Oxford English Dictionary. Oxford University Press.

(2009). Architecture and Phenomenology. Second International Conference, Kyoto Seika University.

Albertini, B. (1988). Carlo Scarpa: Architecture in details. MIT Press.

Apple (2007). Dictionary. Apple Inc.

Bachelard, G. (1958). The Poetics of Space. Beacon Press.

Ballantyne, A. (2005). Architecture Theory; A Reader in Philosophy and Culture. Continuum,

Bowness, A. (1972). Mordern European Art. Thames and Hudson.

Brentano, F. (1995). Psychology from an Empirical Standpoint. Routledge.

Buck, D. (2000). Responding to Chaos. Taylor and Francis. 
Carman, T. and Hansen, M., editors (2005). The Cambridge Companion to MerleauPonty. Cambridge University Press.

Chalmers, D. (1997). The Conscious Mind: In Search of a Fundamental Theory. Oxford University Press.

Classen, C. (2005). The Book of Touch. Berg.

Crippa, M. A. (1986). Carlo Scarpa: theory, design, projects. MIT Press.

Danto, A. C. (2008). "House in use". Artforum, 46(8):123-126.

Depaulis, J. (2003). Paul Cézanne. Grange Books.

Dick, P. K. (2002). Minority Report. Steven Spielberg.

Dodds, G. and Tavernor, R., editors (2002). Body and Building. MIT Press.

Dreyfus, H. A Phenomenology of Skill Acquisition as the basis for a Merleau-Pontian Non-representationalist Cognitive Science. Unpublished.

Dreyfus, H. (1989). “Alternative Philosophical Conceptualizations of Psychopathology" In Phenomenology and Beyond: The Self and Its Language,. Dordrecht: Kluwer Academic Publishers.

Dreyfus, H. (2005a). APA Pacific Division Presidential Address 2005. In Overcoming the Myth of the Mental: How Philosophers Can Profit from the Phenomenology of Everyday Expertise.

Dreyfus, H. (2005b). "Conversations with History: Meaning, relevance, and the limits of technology". Insitiute of International Studies, UC Berkeley.

Dreyfus, H. (2008). Personal interview. Interview with Professor Hubert Dreyfus.

Dreyfus, H. (Spring 1996). “The Current Relevance of Merleau-Ponty's Phenomenology of Embodiment". The Electronic Journal of Analytic Philosophy, $(4)$.

Dreyfus, H. and Wrathall, M., editors (2006). A Companion to Phenomenology and Existentialism. Blackwell Publishing Ltd.

Edwards, J. (2000). Substance, Force, and the Possibility of Knowledge. University of California Press.

Eggener, K. (2004). American Architectural History: a contemporary reader. Routledge.

Freeman, W. (1991). "The physiology of perception". Scientific American, 264(2):78-85. 
Fürst, A. C. and Taschen, A. (2007). Hundertwasser: Achitecture: For a more human architecture in harmony with nature. Taschen.

Gannon, T. (2004). Steven Holl; Simmons Hall. Princeton Architectural Press.

Garris, L. B. (2006). “Elevators". Buildings, 100(2).

Gins, M. and Arakawa (2002). Archictural Body. The University of Alabama Press.

Goguen, J. A. Consciousness and the Decline of Cognitivism. Unpublished.

Greene, V. (2007). Divisionism, Neo-Impressionism: Arcadia and Anarchy. The Solomon R. Guggenheim Foundation.

Gregotti, V. (1996). Inside Architecture. MIT Press, translated by Peter Wong and Francesca Zaccheo edition.

Grosz, E. (2001). Architecture from the Outside. MIT Press.

Hatano, R. (2008). Ten plus one.

Hawkes, D. (2008). The Environmental Imagination. Routledge, Taylor and Francis Group.

Heidegger, M. (1982). The Basic Problems of Phenomonology. Indiana University Press.

Holl, S. (1989). Anchoring: Selected Porjects 1975-1988. Princeton Architectural Press.

Holl, S. (1996). Stretto House. The Monacelli Press.

Holl, S. and Futagawa, Y. (1996). In Steven Holl, volume Document Extra. Gobal Architecture.

Holl, S., Tianen, J., and of New York, S. H. A. A. L. (1997). Museum of Contemporary Art Helsinki: Kiasma. Museum of Contemporary Art and the Finnishing Buiding Center Ltd.

Hundertwasser (1973). Hundertwasser, "Hundertwasser exhibition in New Zealand and Australia". Auckland City Art Gallery.

Husserl, E. (1999). The Idea of Phenomenology. Springer.

Imrie, R. (2003). "Architects' conceptions of the human body". Environment and Planning D: Society and Space, 21:47-65.

Johnson, P.-A. (1994). The Theory of Architecture. John Wiley and Sons, Inc. 
Judith Carmel-Arthur, S. B. (2002). Carlo Scarpa: Museo Canoviano, Possagno. Edition Axel Menges.

Kant, I. (1987). The Critique of Judgment (1790). Hackett Publishing.

Kipnis (2007). Stone and Feather: Steven Holl Architects: The Nelson-Atkins Museum Expansion. The Nelson-Atkins Museum of Art.

Krell, D. F. (1997). Archeticture: Ecstasies of space, time, and the human body. State University of New York Press.

Lacan, J. (1991). "Le seminaire livre xvii l'envers de la psychanalyse". Editions de Seuil.

Lagrange, J. (1967). Play Time. Jacques Tati, film.

Leach, N., editor (1997). Rethinking Architecture: A Reader in Cultural Theory. Routledge.

Leach, N. (2006). Camouflage. MIT Press.

Lefebvre, H. (1991). The Production of Space. Blackwell Publishing.

MacKeith, P., editor (2006). Archipelago; Essays on Architecture. Rakennustieto Oy (Building Information Ltd.).

Magee, B. (1997). The Philosophy of Schopenhauer. Oxford University Press.

Merleau-Ponty, M. (1962). Phenomenology of Perception. Routledge, Taylor and Francis Group, New York, NY.

Merleau-Ponty, M. (1964). The Primacy of Perception. Northwestern University Press.

Murphy, R. (1993). Querini Stampalia Foundation; Carlo Scarpa. Phaidon.

Nell, E., Argyrous, G., Forstater, M., and Mongiovi, G. (2004). Growth, Distribution, and Effective Demand. M.E. Sharpe.

Noland, C. (2007). Motor intentionality: Gestural meaning in bill viola and merleau-ponty. Master's thesis, University of Califoria, Irvine.

Norberg-Schulz, C. (1971). Existence, Space and Architecture. Studio Vista Limited.

Olkowski, D. and Morley, J., editors (1999). Merleau-Ponty, Interiority and Exteriority, Psychic life and the world Merleau-Ponty, Interiority and Exteriority, Psychic life nad the world Merleau-Ponty, Interiority and Exteriority, Psychic life and the Wold. Suny Press. 
Pallasmaa, Pérez-Gómez, and Holl (2006). Questions of Perception: Phenomenology of Architecture. William Stout Publishers, second edition.

Pallasmaa, J. (1991). Architecture in Miniature. Paccolta Alvar Aalto alla Biennale di Venezia.

Pallasmaa, J. (1994). "Identity, intimacy and domicile: Notes on the phenomenology of home". Finnish Architectural Review, 1.

Pallasmaa, J. (1996). The Eyes of the Skin. Academy Editions.

Pallasmaa, J. (2000). "Hapticity and time: Notes on fragile architecture". The Architectuaral Review, 207(Iss. 1239):78-85.

Pallasmaa, J. (2005a). Encounters. Rakennustieto.

Pallasmaa, J. (2005b). "Touching the world: Architecture, hapticity and the emancipation of the eye". EAAE News Sheet, (73).

Pallasmaa, J. (2006). "Eyes of the skin: Architecture and the senses". Architecture, 95(issue 3):28.

Pallasmaa, J. (2007). Reconciling poetics and ethics in architecture. In The History and Theropy of Architecture. McGill University School of Architecture.

Payne, L. (2000). Klimt. Parragon Publishing Book.

Pérez-Gómez, A. (2006). Built Upon Love. MIT Press.

Pérez-Gómez, A. and Parcell, S., editors (2004). Chora: Intervals in the Philosophy of Architecture. McGill-Queen's Press.

Piotrowski, A. and Robinson, J. W., editors (2001). The Discipline of Architecture. University of Minnesota Press.

Pojman, L. (2004). Introduction to Philosohpy. Oxford University Press.

Rasmussen, S. E. (1959). Experiencing Architecture. MIT Press.

Rattenbury, K. (2002). This is Not Architeture:Media Constructions. Routledge.

Robert C. Solomon, D. L. S., editor (2003). The Blackwell Guide to Contenental Philosophy. Blackwell Publishing.

Ross, G. M. and McWalter, T., editors (2005). Kant and His Influence. Continuum International Publishing Group.

Salingaros, N. A. and Alexander, C. (2004). Anti-Architecture and Deconstruction. Umbau-Verlag Harald Püschel. 
Scarpa, C. (1981). “Carlo Scarpa, Frammenti, 1926/1978”. Rassengna.

Schultz, A.-C. (2007). Carlo Scarpa: Layers. Edition Axel Menges.

Seamon, D. (2000). A Way of Seeing People and Place:Phenomenology in Environment-Behavior Research. Plenum.

Smith, B. and Smith, D., editors (1995). The Cambridge Companion to Husserl. Cambridge University Press.

Smith, D. W. and Thomasson, A. L. (2005). Phenomenology and Philosophy of Mind. Oxford University Press.

Sokolowski, R. (2000). Introduction to Phenomenology. Cambridge University Press.

Soroka, E. C. (1979). Connections in design: A generic attitude. Master's thesis, Massachusetts Institute of Technology.

Spiegelberg, H. and Schuhmann, K. (1981). The Phenomenological Movement. Springer.

Spiegelberg, H. and Strasser, S. (1975). Phenomenological Perspectives. Springer.

Tadao Ando, Francesco Dal Co, V. G. (2008). Tadao Ando. University of Michigan.

Tafuri, M. (1975). “The architecture of today". L'architecture d'aujourd'hui or The architecture of today, 181.

Taub, E. A. (1998). "Elevator technology: Inspiring many everyday leaps of faith". New York Times.

Tournier, M. (1998). The Mirror of Ideas = Le Miroir Des Idees. University of Nebraska Press.

Wark, M. (2008). 50 Years of Recuperation of the Sutuationist International. Princeton Architectural Press and Buell Center/ FORuM Project.

Watkins, E. (2005). Kant and the Metaphysics of Causality. Cambridge University Press.

William Lidwell, Kritina Holden, J. B. (2003). Universal Principles of Design: 100 Ways to Enhance Usability, Influence Perception, Increase Appeal, Make Better Design Decisions, and Teach Through Design. Rockport Publishers, Inc.

Williams, J. M. (2000). Style: Ten Lessons in Clarity and Grace. Sixth Edition. Addison-Wesley Educational Publishers, Inc.

Wood, A. (2005). Kant. Blackwell Publishing. 
Wrathall, M. and Malpas, J. E., editors (2000a). Heidegger, Authenticity, and Modernity, volume 1 of Essays in Honor of Hubert L. Dreyfus. MIT Press.

Wrathall, M. and Malpas, J. E., editors (2000b). Heidegger, Authenticity, and Modernity, volume 2 of Essays in Honor of Hubert L. Dreyfus. MIT Press.

Zambonini, G. (1983). Process and theme in the work of carlo scarpa. Perspecta, 20:21-42.

Zhou, R. (2008). "Elevator ladies, checkout clerks and the human touch". China Daily, page 4 .

Zumthor, P. (2006). Thinking Architecture. Birkhäuser-Pubishers for Architecture. 